\title{
EXAMINATION OF MUNICIPAL ELECTED OFFICIALS' CONSIDERATION OF THE SPATIAL ASPECT OF OTTAWA'S PROPOSED LIGHT RAIL EXPANSION PROGRAM,
}

\author{
By
}

Kenneth Morrison, B.A. (Hons)

A thesis submitted to the Faculty of Graduate Studies and Research in partial fulfillment of the requirements for the degree of

\section{MASTER OF ARTS}

\author{
Department of Geography and Environmental Studies \\ Carleton University \\ Ottawa, Ontario
}

APRIL 2005

(C) copyright

2005, Kenneth Morrison 
Library and

Archives Canada

Published Heritage

Branch

395 Wellington Street Ottawa ONK1A ON4

Canada
Bibliothèque et

Archives Canada

Direction du

Patrimoine de l'édition

395 , rue Wellington

Ottawa ON K1A ON4

Canada

\section{0-494-06771-3}

Your file Votre référence

ISBN:

Our file Notre reterence ISBN:
NOTICE:

The author has granted a nonexclusive license allowing Library and Archives Canada to reproduce, publish, archive, preserve, conserve, communicate to the public by telecommunication or on the Internet, loan, distribute and sell theses worldwide, for commercial or noncommercial purposes, in microform, paper, electronic and/or any other formats.

The author retains copyright ownership and moral rights in this thesis. Neither the thesis nor substantial extracts from it may be printed or otherwise reproduced without the author's permission.
AVIS:

L'auteur a accordé une licence non exclusive permettant à la Bibliothèque et Archives Canada de reproduire, publier, archiver, sauvegarder, conserver, transmettre au public par télécommunication ou par l'Internet, prêter, distribuer et vendre des thèses partout dans le monde, à des fins commerciales ou autres, sur support microforme, papier, électronique et/ou autres formats.

L'auteur conserve la propriété du droit d'auteur et des droits moraux qui protège cette thèse. $\mathrm{Ni}$ la thèse ni des extraits substantiels de celle-ci ne doivent être imprimés ou autrement reproduits sans son autorisation.
In compliance with the Canadian

Privacy Act some supporting forms may have been removed from this thesis.

While these forms may be included in the document page count, their removal does not represent any loss of content from the thesis.

\section{Canada}

Conformément à la loi canadienne sur la protection de la vie privée, quelques formulaires secondaires ont été enlevés de cette thèse.

Bien que ces formulaires aient inclus dans la pagination, il n'y aura aucun contenu manquant. 


\begin{abstract}
This study explores the extent to which municipal elected officials explicitly consider the spatial aspect of the link between land use planning and transportation planning for the proposed light rail expansion in Ottawa, Ontario. Specific research objectives included reviewing the current plans of the proposed light rail expansion, identifying the factors used to specify the proposed light rail corridors and eliciting the opinions of municipal elected officials on this link when formulating light rail expansion policies and plans. An established research methodology consisting of a design-evaluation process was adopted to collect and analyze interview responses from municipal elected officials. The responses were compared with a list of key terms/phrases, light rail expansion policies and plans, and a series of maps. Results from this analysis indicated that the municipal elected officials have a limited consideration for the spatial aspect associated with the proposed light rail expansion in Ottawa.
\end{abstract}




\section{ACKNOWLEDGEMENTS}

There are several people whose time, energy, and support contributed to this thesis, and are appropriately acknowledged. I wish to begin by thanking my parents for their understanding, encouragement, and support throughout the thesis process.

The guidance and support of my supervisors, Dr. Barry Wellar of the University of Ottawa, and Mike Fox of Carleton University contributed significantly to this thesis. I thank each of them very much for their advice, encouragement, criticisms, patience, and time. Their willingness to direct the research is greatly appreciated.

Contributions are also acknowledged for the individuals at the City of Ottawa who provided their expertise during the fieldwork phase, notably Peter Steacy, who was always available to answer questions pertaining to the proposed light rail expansion. Helen Gault is also thanked for her assistance in discussing light rail related matters. Further acknowledgement is given to Ian McCord and the crew of Ottawa Central Railway Train 529 for giving me the opportunity to view firsthand a substantial part of the proposed east-west corridor. Words of appreciation are extended to the representatives of the various organizations who participated in the pilot study phase of this thesis. In addition, I would also like to thank the members of the Ottawa City Council who took time away from their hectic schedules to participate in the interview process.

Finally, Hazel Anderson and Ravinder Virk are thanked for providing assistance with the formatting of this thesis. 


\section{TABLE OF CONTENTS}

Page

\section{Chapter 1 Introduction}

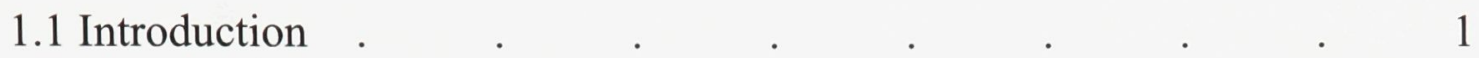

1.2 Research Question . . . . . . . . . . $\quad$. 2

1.3 Research Objectives . . . . . . . . . . 3

1.4 Methodological Approach . . . . . . 3

1.5 Context of Research Study . . . . . . . . . 44

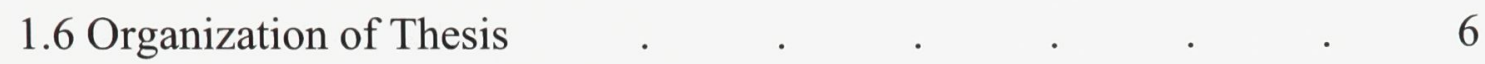

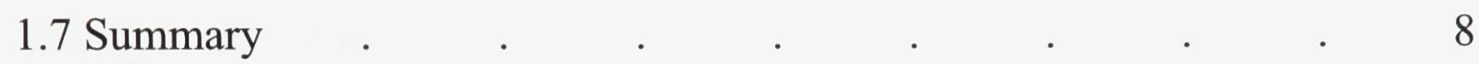

\section{Chapter 2 Research Background}

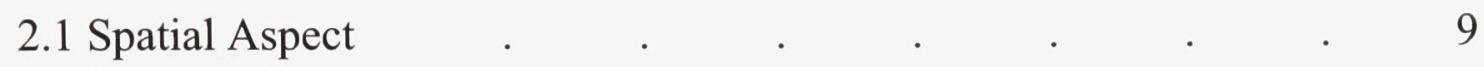

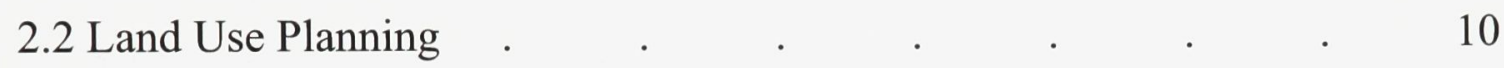

2.3 Transportation Planning . . . . . . . . . $\quad$. 14

2.4 Relationship Between Land Use Planning and Transportation Planning 17

2.5 A Note on Sustainable Development . . . . 21

2.6 Land Use Planning and Transportation Planning in Popular Literature 23

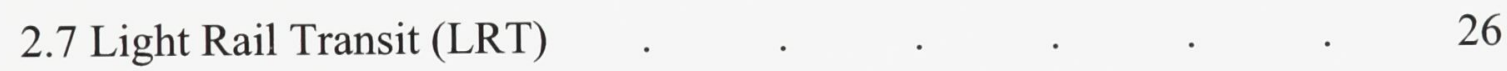

2.7.1 Definition of Light Rail Transit _ . . . . . $\quad$. 26

2.7.2 A Brief History of Light Rail . . . . . . 27

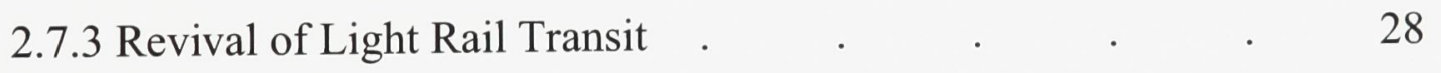

2.7.4 Current Light Rail Situation in Ottawa $\quad$. . . $\quad 29$

2.8 Summary . . . . . . . . . . . . . 32

\section{Chapter 3 Light Rail Transit Case Study}

3.1 Brief History of Light Rail Transit (LRT) in Ottawa . . 34

3.2 Planning of Proposed Light Rail Transit in Ottawa · · 35

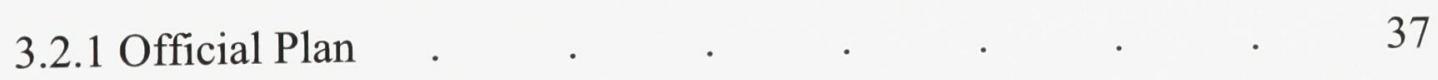

3.2.2 Public Transportation Plans for Ottawa $\quad$. . . $\quad 39$

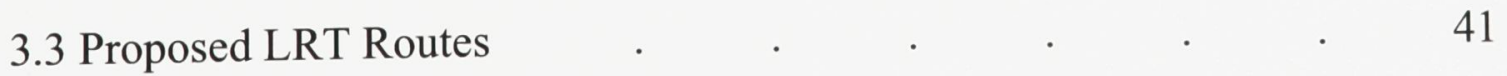


3.3.1 North-South LRT Corridor . . . . . . 42

3.3.2 East-West LRT Corridor . . . . . . . 44

3.3.3 Summary of N-S and E-W LRT Corridors in Ottawa . . 46

3.4 The Land Use and Transportation Planning Link for LRT in Ottawa 46

3.5 Light Rail Decision-Making Process in the City of Ottawa . . 52

3.6 Summary . . . . . . . . . . . . 56

\section{Chapter 4 Research Methodology}

4.1 Methodology . . . . . . . . . 57

4.2 Research Methodology . $\quad$. $\quad$. $\quad . \quad . \quad 58$

4.2.1 Pilot Study . . . . . . . . . . . 63

4.2.2 Prestest . . . . . . . . . . 66

4.2.3 Trial Run _ . . . . . . . . . . . 66

4.2.4 Interviews . . . . . . . . . . . 67

4.2.5 Assessment of Interview Responses . . . . . 68

4.3 Summary . . . . . . . . . . . . . 71

\section{Chapter 5 Design-Evaluation Process Results}

5.1 Pilot Study Feedback $\quad$. $\quad$. $\quad$. $\quad$. $\quad$. 72

5.1.1 Evaluation of Interview Questions . . . 72

5.1.2 Evaluation of Key Terms/Phrases . . . . . . 76

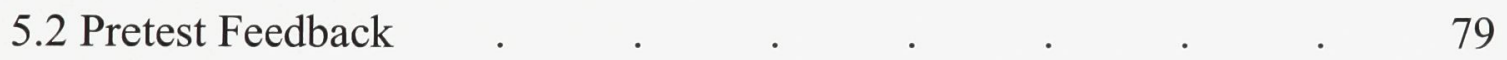

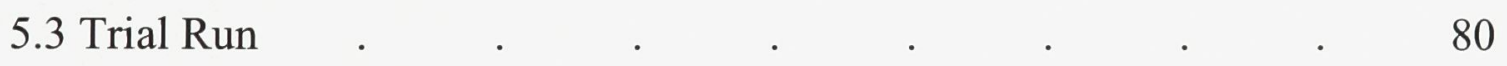

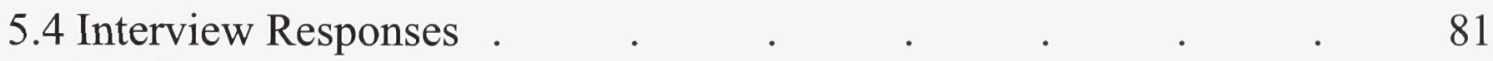

5.5 Comparison of Interview Responses with Key Terms/Phrases $\quad 89$

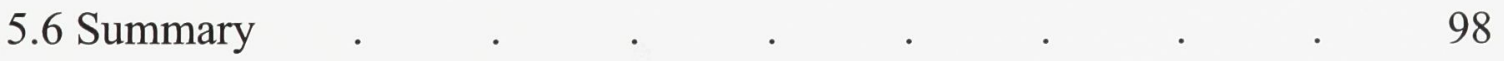

Chapter 6 Comparison of Participants' Responses with Published Literature

6.1 Spatial Factor Connection with Planned Growth . . . . 99

6.2 Comparison with Published Literature ․ . . . . 103

6.2.1 Official Plan Land Use Planning Proposals . . . . 103 
6.2.2 Rapid Transit Evaluation Study (RTES)

Land Use Planning Proposals . $\quad$. $\quad$. $\quad$. $\quad$. 105

6.3 Mapping Proposed Residential and Employment Areas . . . 106

6.4 Evaluation of Interview Responses with Land Use

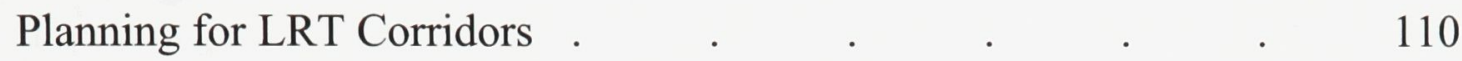

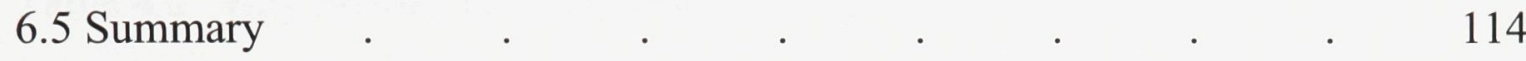

Chapter 7 Assessment and Implications of Spatial Factors in O-Train Deliberations

7.1 Concluding Assessment of Interview Responses . $\quad$. $\quad$. 115

7.2 Implications of Interview Responses on O-Train Deliberations 117

7.3 Summary . . . . . . . . . . . . . 121

Chapter 8 Conclusion and Implications for Future Research

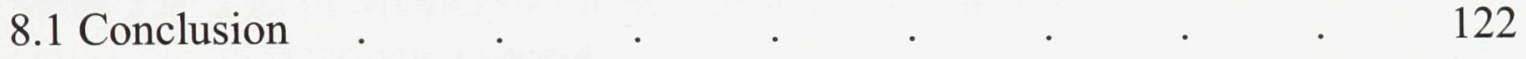

8.2 Limitations . . . . . . . . . . . . 126

8.3 Potential Future Work within Study Area $\quad . \quad$. $\quad$. $\quad$. 127

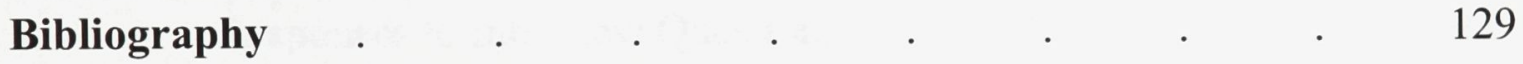

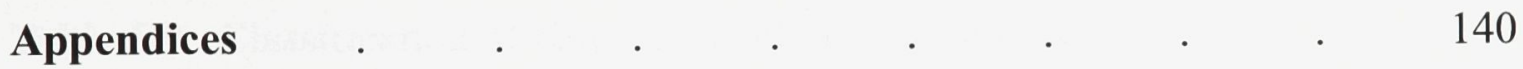




\section{LIST OF FIGURES}

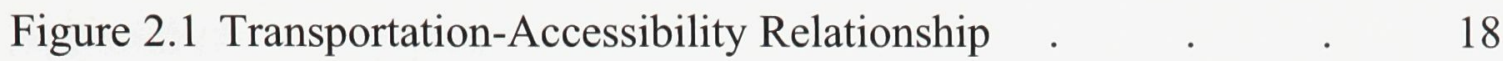

Figure 2.2 Proposed Light Rail Transit Corridors _ . . . 31

Figure 3.1 Ottawa Light Rail Pilot Project a $\quad$. $\quad$. $\quad 36$

Figure 3.2 Proposed North-South Light Rail Transit Corridor . . 43

Figure 3.3 Proposed East-West Light Rail Transit Corridor . $\quad$. 45

Figure 3.4 Proposed North-South Light Rail Transit and East-West Light Rail Transit Corridors . . . . 47

Figure 3.5 Planned Residential and Employment Areas in Ottawa . $\quad 51$

Figure 3.6 Light Rail Decision-Making Processes for Proposed NorthSouth Corridor . . . . . . . . $\quad$. 53

Figure 4.1 Phases of the Design-Evaluation Process for Interviewing Municipal Elected Officials . $\quad$. $\quad$. $\quad$. $\quad$. 61

Figure 4.2 Screening Process Used for Identifying Key Terms/Phrases In Design-Evaluation Process

Figure 4.3 Phases for Assessment of Municipal Elected Officials Interview Results . . . . . . . . 70

Figure 6.1 Land Use Composition of Ottawa 107

Figure 6.2 Land Use Composition of Ottawa (Downtown) . . 109 


\section{LIST OF APPENDICES}

Page

Appendix I $\quad$ Glossary of Terms $\quad$. $\quad$. $\quad$. $\quad$. $\quad$. $\quad 141$

Appendix II Pilot Study Screening of Questions . . . 145

Appendix III Ranking of Key Terms/Phrases _ . . . $\quad 151$

Appendix IV Revised List of Questions from Pretest Phase 157

Appendix V Municipal Elected Officials Responses

to Interview Questions $\quad$. $\quad$. $\quad$. $\quad$. 158

Appendix VI Contact Letter Sent to Pilot Study Participants . 179

Appendix VII Contact Letter Sent to Municipal Elected Officials . 180

Appendix VIII Newspaper Exhibit Articles . $\quad$. $\quad$. $\quad$. 181

Appendix IX Overview of Map Design $\quad$. $\quad . \quad$. $\quad . \quad 185$ 


\section{LIST OF ACRONYMS}

BRT

Bus Rapid Transit

E-W LRT

East-West Light Rail Transit Corridor

LRPP

Light Rail Pilot Project

LRT

Light Rail Transit

MEO

Municipal Elected Official

N-S LRT

North-South Light Rail Transit Corridor

OP

Ottawa Official Plan

ORTEP

Ottawa Rapid Transit Expansion Program

RMOC

Regional Municipality of Ottawa-Carleton

ROW

Rights of Way

RTES

Rapid Transit Expansion Study

SUT

Sustainable Urban Transportation

$\mathrm{T} \& \mathrm{TC}$

Transportation and Transit Committee

TMP

Transportation Master Plan

TOD

Transit-Oriented Development

ToR

Terms of Reference 


\section{CHAPTER 1 INTRODUCTION}

\subsection{Introduction}

The urban form of Canadian cities has changed quite substantially since the early 1970s. There has been a marked decline in population densities within cities and substantial changes in the spatial arrangement of land uses (NRTEE: 2003, p.12). A major catalyst in such urban change has been an increasing dependence on the private automobile for urban travel (Raad: 1998, p. 33). This dependence has resulted in several urban transportation-related problems, including road congestion, environmental and health problems, urban sprawl, and a lack of public transportation options (CCC: 2002, Duncan: 1996). In fact, these problems are exacerbated since the land uses in many urban areas have been designed to accommodate automobiles and not maximize public transportation use (Raad: 1998, p. 153).

While recent studies indicate that since 1990 public transit ridership has declined and travel by automobile has significantly increased in Canadian cities, public concern and public policy have resulted in substantial changes to urban transportation planning (Garrison: 1979, NTREE: 2003, Raad: 1998, p. 20). These changes are aimed at addressing mobility issues and at shaping the spatial configuration of Canadian cities through an expansion of public transit infrastructure, the implementation of urban sustainability policies, and a recognition that land use planning and transportation planning should be integrated in urban development plans (Duncan: 1996; Rodrigue: 2005; Wellar: 1982). Although the most substantial urban public transportation developments so far have occurred in Canada's largest cities of Toronto, Montreal, and Vancouver, mid-sized cities such as Ottawa are also attempting to improve the 
relationship between urban growth and public transportation development (Wellar: 1994), one aspect of which is to be explored in this thesis.

On May $13^{\text {th }} 2003$, the municipal council of the City of Ottawa adopted a new Official Plan that is intended to provide a strategic direction for the growth of the city until 2021, with a stated overall goal of achieving sustainable development (City of Ottawa: 2003f, 1.1). The 2003 Official Plan proposes to manage the growth of the city in a variety of ways, including improvement and expansion of its existing transportation infrastructure. One element of the Plan is a proposal to expand light rail as a means to increase the use of public transit and reduce the dependency on automobile use (City of Ottawa: 2003f, 1.1). Within the context of the light rail expansion program, numerous issues are addressed, including location of residential and employment areas, commuter trip patterns, and land use designations. The purpose of this study is to examine the extent to which the spatial aspect has been considered and incorporated in the light rail policies and expansion plans.

\subsection{Research Question}

This investigation into the relationship between Ottawa's land use plans and light rail transit plans is based on the following research question:

To what extent do municipal elected officials explicitly take into consideration the spatial aspect of the link between current and future land use planning and current and future transportation planning for the proposed light rail expansion in the city of Ottawa, Ontario? 


\subsection{Research Objectives}

The thesis has four principal research objectives:

- Review and summarize the current plans of the proposed light rail expansion in Ottawa through analysis and synthesis of existing literature.

- Identify the factors used to specify the corridors for light rail expansion.

- Elicit the opinions of municipal elected officials on the spatial aspects of the link between land use planning and transportation planning when formulating light rail expansion policies and plans.

- Assess whether the municipal elected officials consider this link a significant issue when selecting the location of the proposed light rail corridors.

\subsection{Methodological Approach}

The research methodology for this study adopts procedures that follow the design model developed by Ackoff (1953). As well, the operational and empirical research activities adhere to the research approaches successfully developed by Wellar in the Walking Security Index $(1996,1998,2000 a, 2002)$ and the City of Ottawa in the Rapid Transit Expansion Study (2003).

The methodology is summarized as follows:

- Implement a design-evaluation process that screens potential questions for the interview.

- Compile a list of key terms and phrases cited in the literature on the spatial aspects of land use planning and light rail expansion. 
- Determine how this list will be verified against error to ensure terms and phrases are related to the interview process.

- Interview municipal elected officials.

- Compare analysis of results from interviews with list of key terms/phrases and light rail expansion policies and plans.

- Design a series of maps to visually represent the spatial configuration of the proposed light rail expansion.

This methodological approach is designed to meet the research objectives and answer the research question.

\subsection{Context of Research Study}

The metropolitan area of Ottawa-Gatineau is currently the fourth most populated urban region in Canada with a population of approximately 800,000 people, and is projected to increase to 1.2 million within twenty years (City of Ottawa: 2003d, p. 1). Ottawa's public transportation options include paths for walking and cycling, and an extensive bus system known as the Transitway, which is a network of bus-only roads (City of Ottawa: 2003f, Section 2.3.1). The City of Ottawa has also re-introduced the use of railways as part of its public transit system, and has proposed that its two-year pilot light rail project, referred to as the "O-Train", be upgraded into a permanent element of its public transit system. ${ }^{1}$

\footnotetext{
1"City" and "City of Ottawa" refer to the legal title that designates all aspects of the municipal government in Ottawa, Ontario.

The term "city of Ottawa" is used to designate the actual geographical area of Ottawa
} 
The City has produced three major documents in conjunction with the Official Plan (OP) that provide a guideline for the city's planned transportation expansion. ${ }^{2}$

- $\quad$ Transportation Master Plan (TMP);

- $\quad$ Rapid Transit Expansion Study (RTES);

- Ottawa Rapid Transit Expansion Program Implementation Strategy (ORTEP)

These documents address the necessity for a major expansion of the light rail system to assist in increasing the number of public transit users in the city. The expansion of the light rail system would be one of the means used to achieve the City's goal of almost doubling public transit's share of all motorized trips from $17 \%$ in 2001 to $30 \%$ in 2021 (City of Ottawa: 2003f, 2.3.1).

The OP, TMP, RTES, and ORTEP documents on the planned growth of Ottawa cited above have all been produced by City of Ottawa staff and consultants, with the endorsement of the municipal elected officials who held office when these documents were made public. These planning documents show that the City of Ottawa is proposing to expand Ottawa's transportation infrastructure in order to integrate the expanding transportation system with the overall development of the city (City of Ottawa: 2003b; City of Ottawa: 2003c; City of Ottawa: 2003e; City of Ottawa: 2003f). What is not necessarily reflected in the documents, however, is the knowledge of municipal elected officials regarding the extent to which the spatial factor has been considered in light rail expansion policies and plans. Nor, more importantly, is there anything reporting on their knowledge about the spatial connections and relationships between current and future land uses and the possible routes of the O-Train.

\footnotetext{
${ }^{2}$ The Official Plan is a supporting plan of the Ottawa 2020 initiative which documents the growth plans of city until 2021 (City of Ottawa: 2003f, 1.3).
} 
The absence of published documentation on Ottawa's municipal politicians' consideration for the spatial factor in the proposed light rail expansion plans and policies suggests that the research question has not yet been investigated in a formal manner with respect to the city of Ottawa. In fact, and as the thesis literature revealed, there does not appear to be any such published documentation for any urban area within Canada.

The fact remains, however, that municipal elected officials make the final decision about the timing and location of light rail expansion(s), and thereby directly affect the spatial aspects of Ottawa's land use-transportation relationship. It therefore follows that in order to better understand their reasoning process, and how the spatial aspect is factored into land use and transportation plans, it is necessary to conduct research which is designed to investigate those matters.

The research project is part of the larger urban transportation discussion, and addresses one particular theme which to date has received little formal examination. That is, and using the City of Ottawa as a case study, the research examines the extent to which municipal elected officials explicitly take into consideration the spatial aspect of the link between current and future land use planning and current and future transportation planning for the proposed light rail expansion.

\subsection{Organization of Thesis}

Chapter 1 introduces the research topic for this study. The research question and research objectives are presented along with a brief overview of the methodological approach. In addition, insight into the context of the research study is provided. 
Chapter 2 provides the rationale behind the study and discusses the issues involved in Ottawa's proposed light rail expansion. A review of the literature in the fields of land use planning, transportation planning, and (briefly) sustainable development is provided, along with a discussion of light rail transit in the Canadian public transportation sector.

Chapter 3 discusses the proposed light rail expansion in Ottawa. This chapter reviews documentation on the proposed corridors, the proposed location of these corridors, and the integration of the corridors with the planned growth of Ottawa. In addition, it discusses the relationship between land use planning and the light rail expansion based on existing documentation.

Chapter 4 describes the research methodologies used to construct the study, and outlines how the research-design evaluation process designed by Ackoff (1953) was used to structure the design process.

Chapter 5 presents the results from the interviews with municipal elected officials who were asked to comment on the consideration for the spatial aspect of the proposed light rail expansion policies and plans.

Chapter 6 highlights the key findings of the research by comparing the link between land use planning and the proposed light rail expansion as stated in official documents, with the research findings produced through the interviews with municipal elected officials.

Chapter 7 discusses the implications of the municipal elected officials' perceptions of the spatial factor in the proposed light rail expansion deliberations.

Chapter 8 summarizes the study, makes the limitations explicit, and provides suggestions for future research. 


\subsection{Summary}

This chapter introduces the research topic that will be examined in this study. The research question and research objectives are identified, in addition to presenting a brief description of the methodological approach that is adopted for this study. An introductory description of how the research topic was selected is given, along with presenting an overview of how the paper is structured. 


\section{CHAPTER 2 BACKGROUND}

This research examines Ottawa's municipal elected officials' understanding of the spatial connections and relationships between land use planning and transportation planning, in the context of the proposed light rail corridors. The issues that are involved in these connections and relationships are the essential components of the spatial factor to be identified and examined in this research. This chapter provides the context for the research by discussing how the two fields of planning are connected with the planned light rail expansion, and how the extent of the integration of these two types of planning affects light rail expansion.

\subsection{Spatial Aspect}

The spatial aspect is the key component being evaluated in the research; specifically, the study seeks to ascertain and assess the extent to which municipal elected officials in Ottawa have considered the link between land use planning and transportation planning when making decisions about the location of the proposed light rail corridors. The concept of "spatial", has to "do with geographic space", in terms of the "distribution or location across a landscape or surface" (Mayhew: 1997, p. 392).

A spatial aspect can be defined as the geography of a matter, situation, or process. Within this spatial context, one other term used in this study is "spatial factor". This refers to the "elements of the natural and built environment, as well as statements in public policies, plans, and programs that affect where things are located and where populations travel" (Wellar: Personal Communication, 2004). In relation to this study, the spatial factor is involved in determining the various types of land use development that 
will be in proximity to the proposed light rail corridors. For example, decisions on land use designations along these light rail corridors will shape the layout of nearby residential communities and employment areas.

\subsection{Land Use Planning}

In advance of providing an explanation of land use planning, it is imperative to grasp the concept of land use, which is defined in a Canadian context as "All arrangements, activities and inputs (sets of human actions) undertaken in a certain land cover type" (Federal House in Order: 2004). Although "urban land use" can be subsumed under the general term "land use", these terms appear to be used interchangeably in the literature. Urban land use describes the residential, industrial, commercial, retail business, governmental, and institutional composition of the land (Blunden: 1984, p. 4). The terms land use planning and urban land use planning are also used interchangeably in the literature, and so to avoid any confusion, the term land use planning is used in this study.

Land use planning is a diverse field of study that encompasses a range of academic disciplines such as urban planning, architecture, civil engineering and geography, and integrates the physical, social, and environmental aspects of the human landscape. A review of the literature indicates that rather than a specific accepted definition for this field of study, there are a variety of similar definitions.

One definition that addresses the essential components involved in land use planning is given by Leung: "The process of protecting and improving the living, production and recreation environments in a city through the proper use and development of land" (Leung: 2003, p. 1). From a local perspective, the Transportation Master Plan (TMP) 
defines land use planning as "Shaping development patterns to support transportation goals" (City of Ottawa: 2003d, p. 29). Land use planning involves, for example, the distribution and intensity of industrial and retail development, residential areas relative to open space, as well as transportation systems (Chapin: 1979, p. 63). In a general sense, land use planners concern themselves with questions related to the type, amount, and the location of the uses of land (Leung: 2003, p. 1).

The task of translating land use plans into actual physical development falls in Canada to the legislative body responsible for the major policies regarding future physical development (Kent: 1964, p. 18). In this country, planning legislative powers are exercised exclusively (not including federal lands) by provincial and local governments (Leung: 2003, p. 14). Usually, however, it is local governments that are given the powers for plan making and development control, while the provincial governments and sometimes even the federal government take on the role of supervisors for these powers in the event of planning disputes (Leung: 2003, p. 14).

Within the framework of the local governments, land use planning is undertaken by a municipal planning department, with departments responsible for public works, parks and recreation, education, public transit, and roads all participating in the planning process. In addition, interested residents, such as local groups, community associations, industries and businesses, organized public interest groups, specifically ratepayer's groups, real estate boards, and chambers of commerce also participate in land use planning (Leung: 2003, p. 14).

Land use planning involves both physical and human components. The physical aspects include, for example, consideration of soil composition, geologic formations, and 
environmental conditions such as slope, drainage, and flora and fauna. While the physical aspects are vital to any land use development, the focus of this study is on the human component.

The human component of land use planning involves a number of participants including individuals, groups and corporations with an interest in planning. Some participants have more influence in the decisions made than others, although all of the parties involved are vying to get their ideas incorporated in the actual development (or not) of the land. These participants comprise various government departments, municipal planners, land developers, home and commercial builders, community associations, education boards, lobby groups, and ordinary citizens.

The following are among the number of public interest elements to which the parties to land use planning actions may refer when discussing or examining a planning document or proposal:

- Health and Safety: one of the basic principles in modern planning is the prevention of conditions that are hazardous or can cause injuries to the physical well-being of people and property

- Convenience: (i) adequacy and suitability of a space for activities to be carried out in (ii) accessibility and choice of services and facilities at a location, including the reduction in time and distance between the following points: home, work, school, recreation, shopping, and for movement of goods (iii) affected by density and compactness of the land development

- Efficiency: thought of in terms of public cost (especially municipal government expenditure), growing consensus about efficient use of serviced land, meaning more compact and higher density development

Example: haphazard and low density land use pattern would involve more roads, greater length of utility lines, cost more money to build, operate, and maintain

- The Environment: traditionally, environmental hazards such as flooding, landslides, soil erosion have been well recognized in land use planning, must now take into consideration the environmental protection guidelines concerning air quality when deciding on the location of transportation facilities, and the distribution of different land uses 
- $\quad$ Protection of Agricultural Land: land use planning and regulations need to manage urban growth at fringe areas of a city in order to halt encroachment on agricultural land and protect rural ambiance

- $\quad$ Energy: modern land development and building technology based on plentiful supply of cheap energy have ignored many of the simple, commonsense lessons of energy conservation

- Transportation: traffic problems in the past were solved by road widening, road construction, realignment, such improvements attracted more cars and caused more congestion

- past 30 years have provided evidence for problems associated with allowing for unrestricted automobile use, new demand for public transit

- Amenity: referring to the pleasantness of the urban environment as a place in which to live, work, and participate in recreation activities (Leung: 2003)

In addition, general land use planning principles are customarily related to five major functional areas within the urban setting: work areas, living areas, shopping and leisuretime areas, community facility systems (schools, medical facilities) and environmentally sensitive areas (land and water). Literature on the location of these land use areas has stressed the need for interconnecting transit and thoroughfare routes for accessibility between the different areas, with an emphasis on access to the living areas (Chapin: 1979, p. 366).

There is a consensus in the land use planning literature that the transportation/land use association is of utmost importance, because ultimately transportation will influence how land is planned for future development. This link between land use planning and transportation planning is not a new concept. In Transportation and Urban Land, written over forty years ago, Wingo (1961) states that land use patterns are based on the concept of accessibility, in which residential location discussions stem from a trade-off between transportation costs and space costs. He hypothesises that smaller areas are occupied by households in the most accessible locations within a city, leading to higher population 
densities. This link between accessibility and densification is addressed later in this chapter.

\subsection{Transportation Planning}

Transportation planning is a very specialized discipline, and is often considered to be its own field of study, although it is sometimes thought of as a sub-discipline within the fields of land use planning and urban planning (Leung: 2003, p. 70). It is defined as the "interaction between transportation services and land use patterns, and their combined effect on the quality of life in a community" (PCUTP: 1977, p. 3). This form of planning is based on the proposition that decisions affecting changes to transportation services must reflect the values and goals of the communities they serve.

This field of planning is based on several premises, steps and goals prior to the building of transportation routes. One premise of transportation planning is that transportation systems influence the development of urban areas, in addition to serving these areas. In addition, the study of transportation systems is an integral aspect of an overall planning process, and should not be considered in isolation from other factors (Bruton: 1970, p. 22). Regarding the steps applied to the planning of transportation routes as identified in transportation planning literature, they encompass a variety of factors, including population, economic, and travel demand patterns.

The steps are summarized below:

- Collection of land use, population, economic, and travel demand pattern for the present-day situation

- Establishment of quantifiable relationships between land use and current transportation patterns

- Prediction of future land use, population, and economic factors to the target date of the study 
- Predictions of the origins, destinations, and distribution of the future movement demands using the relationships established for the present-day situation and the predicted land use, population, and economic factors (Bruton: 1970, p. 22)

In addition to these steps, various transportation planning simulation models (originating in the late 1960s) have been developed to provide information on travel patterns, especially in urban areas. The models were derived from the co-ordination of land use development and urban transportation networks. These models assist transportation planners in predicting such critical factors as ridership on planned rapid transit routes (PCUTP: 1977, p. 82). While transportation models are not thought to be the only solution to urban transportation problems, they are nonetheless considered a critical phase in transportation planning. An overview of the techniques applied to transportation models is as follows:

1. Trip generation: use of category analysis in which trip-generation relationships are studied by analyzing the amount of travel undertaken by various types of households

2. Trip distribution: a measure of the number of trips made from one zone in an urban area to all other zones

3. Modal split: determines the proportion of person trips made by automobile versus public transit

(PCUTP: 1977, pp. 82-93)

For transportation planning to be successful, transportation plans pertaining exclusively to transportation issues must ensure that the following goals can be met:

1. Access to employment (regardless of whether individuals have access to an automobile)

2. Access to the facilities and services of an entire city (regardless of whether individuals have access to an automobile)

3. Transportation system that is comprehensible (whereby the system is capable of being understood, and conceivable)

(PCUTP: 1977, p. 17) 
These goals can only be achieved, however, if there is accessibility to employment for all income groups (low, medium, high), and if there are increasing rates of improvement to urban transportation systems (PCUTP: 1977, p. 17).

The above list of goals highlights one of the most important elements associated with transportation planning: the concept of accessibility. This concept is prevalent throughout the literature on this topic. Accessibility is defined as “...a combination of two elements: location on a surface relative to suitable destinations, and the characteristics of the transportation network or networks linking points on that surface" (Vickerman: 1974, p. 676). From a local perspective, Ottawa's public transit provider, OC Transpo, defines accessibility via public transit as "the minimization of waiting time, waiting time between transfers, walking time between home and (transit) stop and the walking time between the final (transit) stop and the opportunity" (Cameron: 1995, p. 130).

In terms of transportation network(s), the availability and in particular the type of transport mode is important as it is able to influence the level of accessibility (Cameron: 1995, p. 50). This ability to influence levels of accessibility is especially true with private automobile use, as higher levels of accessibility are associated with lower levels of automobile use (Cameron: 1995, p 51). In Canada, the ability to make decisions on matters pertaining to accessibility, such as the location of travel routes and the spatial characteristics of transportation networks, is for the most part controlled by the public sector (Transport 2021: 1993, p. 22).

Accessibility also plays a part in the relationship between land use planning and transportation planning, in which it is acknowledged that "...transportation affects land use by making different parcels of land more or less accessible by different modes. In 
turn, the mix and density of land use will affect travel in terms of the number and length of trips made, and the modes employed" (Regional Municipality of Ottawa-Carleton: 1993, p. 3). This relationship between accessibility and transportation planning is illustrated in Figure 2.1. While it is not within the purview of this thesis to discuss at length accessibility as it relates to transportation planning, Cameron's figure details the various factors associated with this relationship.

\subsection{Relationship Between Land Use Planning and Transportation Planning}

One issue that is repeatedly emphasized when discussing transportation planning is the need for the practice of this type of planning to become more integrated with the practice of land use planning (Wellar: 1994). There is a consensus that transportation planning should not be absorbed into land use planning or vice versa, but rather these forms of development should work in conjunction with one another. This is evident from both land use planning literature (Cervero: 1989; Chapin: 1979; Gordon: 1982; Loo: 2002), and transportation planning literature (Black: 1995; Dimitriou: 1992; Miller: 2001; Newman: 1999; Orford: 1982).

Although the urban development community has recently demonstrated the need for a connection between these two forms of planning, as mentioned earlier, this is hardly a new idea. Similar encouragement can be found in literature dating back to the late 1960s. For example, Steger and Lakshmanan (1968, p. 38) noted that public policy-makers were becoming fully aware that transportation systems serve as "key controllable variables" that guide future economic and social arrangement in an urban area. Further, they addressed the notion that housing and recreational issues were increasingly being 
Figure 2.1

Transportation - Accessibility Relationship (adopted from Cameron: 1995)

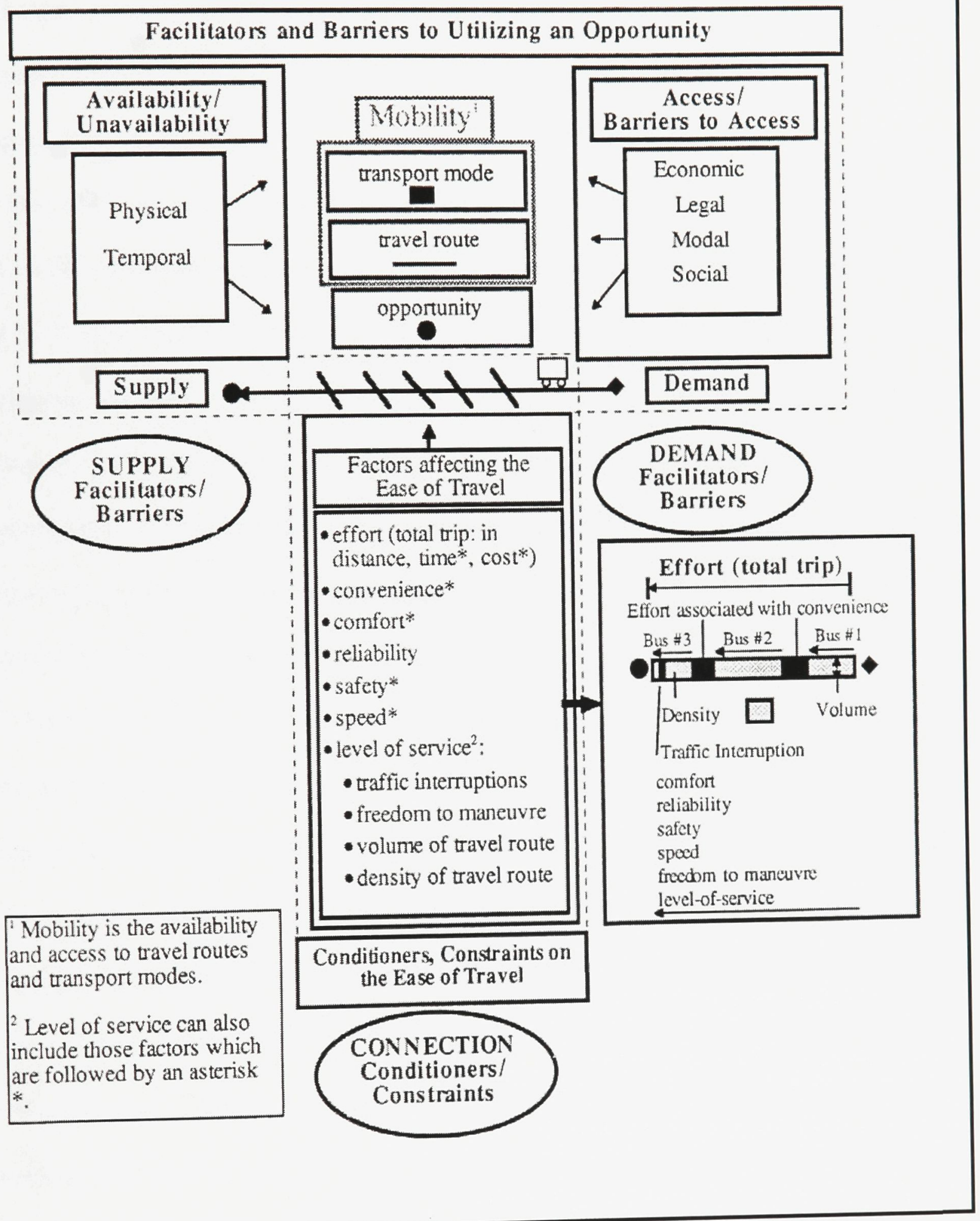


considered in urban planning studies in conjunction with transportation and land use planning (Steger and Lakshmanan: 1968, p. 51.). While most of the following discussion cites more recent literature, it is clear that this relationship in current municipal planning documents is not a newfound planning initiative, but rather a process that has been adapted from various sources over the past several decades (Wellar: 1982).

One of the strongest forces recently driving the connection between land use planning and transportation planning is related to meeting stricter environmental standards. Canada and the United States are having to implement new planning strategies in order to meet environmental laws. These existing/tabled acts and regulations include the Energy Efficiency Act established in Canada in 1992, the U.S. Clean Air Act and its amendments, and the proposed legislation in Canada that stresses the need to mitigate congestion-related emission problems, as urban traffic congestion is a key contributor to atmospheric pollution (Syzmanis: 1999, p. 23).

From the land use perspective, the environmental connections were evident as far back as the late 1970s, as Chapin for example, emphasizes the need for a broadening perspective on the combined impacts of land use and transportation decisions (Chapin: 1979, p. 619). He further notes that land use is seen as an important determinant of demand for travel, and therefore partially determines the performance of a transportation system (Chapin: 1979, p. 621). This observation is supported by the fact that traffic considerations are quite significant in land use planning, including factors such as reducing air pollution, decreasing the number of transportation-related accidents, and increasing transit ridership levels (Leung: 2003, p. 10). 
The literature in the field of transportation planning also strongly supports a link between land use planning and transportation planning (Black: 1995; Bruton: 1970; Dimitriou: 1992; Giuliano: 1995; Miller: 2001; Newman: 1999; Vuchic: 1999). This is further emphasized by Miller, who states that "transportation planning must be seen as part of land use planning and development process" (Miller: 2001, p. 3), based on the fact that long-term transportation planning influences patterns of growth and economic activity through the accessibility it provides to land. Some authors/researchers are so confident about this linkage as to proclaim that the promotion of public transit through coordinated land use and transportation planning is a necessary prerequisite to permanently avoid future aggravated urban transportation problems (Vuchic: 1999). To have this link incorporated into actual development, it is suggested that a transportation system be planned to promote the growth of land use that is proposed by urban planners and approved by local elected officials, which in turn requires the participation of city planners, politicians and transportation engineers (Schofer: 1967; Wellar: 1994).

From a Canadian perspective, there have been several reports published by urban planners that encourage the relationship between land use planning and transportation planning within Canadian cities (Wellar: 1982). Using the Scarborough Light Rail Transit (LRT) line as a case study, Gordon demonstrates that the approval of this line several years prior to when its first train ran in 1985 was justified in the line's ability to "serve future growth... and shape future land use in a more desirable urban form" (Gordon: 1982, p. 170). In fact, the Scarborough LRT was the first rapid transit line in the country to be approved primarily to assist in achieving land use objectives prior to the 
construction of the line, including the construction of major and intermediate suburban employment centres (Gordon: 1982, p. 173).

Another report highlights the relationship between land use planning and transportation planning as it applied to the construction of the light rail system in Calgary, Alberta (Orford: 1982, p.184). The Calgary City Council adopted strategies to channel and structure land use patterns in order to provide efficient spatial and energy requirements within the city, and an LRT system was recognized as a critical element in achieving the council's desired goals (Orford: 1982, p. 184). Further, the report states that in terms of the role of public transportation within Calgary, one of the key principles is the recognition of the relationship between the use of land and transportation facilities (light rail transit) needed to serve the various land uses. As evident in the above examples then, not only are there Canadian planners who support the link between land use planning and transportation planning, but in addition, as evidenced by reports published in 1982, the recognition for encouraging this link within Canadian urban areas has been around for more than twenty-five years (Wellar: 1994; Wellar 2000a).

\subsection{A Note on Sustainable Development}

The importance of the spatial relationships between land use planning and transportation planning has been further emphasized by the sustainable development movement. Sustainable development can be defined as: "Development meeting the needs of the present without compromising the ability of future generations to meet their own needs" (WCED: 1987). While the concept of sustainable development is introduced, it is 
only brought to the attention of the reader to emphasize the importance of the relationship between land use planning and transportation planning.

The link between land use planning and transportation planning has in fact acknowledged the importance of sustainability during the past two decades as it has been featured in urban development plans within Canadian urban regions. For example, recent urban development plans concerning public transit projects include higher densification of land uses in proximity to transit stations, as well as the implementation of mixed land uses along the routes (City of Calgary: 2004). The literature on sustainable development includes discussion of public transportation, in which it stresses the need for the integration of land use planning and transportation planning. Loo in particular emphasizes "urban planners have to develop a better understanding of how transportation interrelates to important aspects, such as industrial and residential locations" (2003, p. 215).

One other topic that is of particular relevance to the present work is that of Sustainable Urban Transportation (SUT), which is regarded as "satisfying the current transport and mobility needs without compromising the ability of future generations of urban citizens to meet these needs" (Whitlegg: 1993, p. 7). The overwhelming belief amongst SUT researchers is that in order to effectively create a SUT infrastructure, the expansion of public transit must be emphasized (Chapin: 1979; Miller: 2001; PCUTP: 1977). Literature on SUT portrays the benefits of providing and promoting an increase in public transit in the following manner: urban public transit facilitates a high density of residential and employment areas, which are often achieved in urban centres and major suburban centres (Patterson: 1995, p. 38). The above examples demonstrate that within 
an SUT context there is a connection between the planning of public transportation infrastructure and land use planning.

\subsection{Land Use Planning and Transportation Planning in Popular Literature}

The relationship between land use planning and transportation planning is discussed in the preceding sections to demonstrate how the link between these types of planning is perceived as a critical factor in improving both land use development and transportation systems in urban areas. As this study seeks to ascertain the extent to which municipal elected officials have considered this link in relation to the spatial aspect associated with the proposed light rail expansion in Ottawa, it is relevant to show how long this link has been involved in local public records. The term "popular literature" is used to describe the local public records comprising daily newspapers and community newspapers, and this term is adopted from the literature review performed in the Walking Security Index (Wellar: 1996; Wellar: 2000a).

Due to the demanding job requirements of a municipal elected official (MEO), it is highly unlikely for them to have read and/or studied a substantial amount of formal or learned literature on the spatial aspect of the link between land use planning and transportation planning, as well as every report on the proposed light rail expansion (Wellar: 1994; Wellar: 2000a). It is safe to presume, however, that at the very least these MEOs frequently read local newspapers to keep themselves updated on current events, including those articles pertaining to development in the city and the proposed light rail expansion. In fact, it is believed that there is a common link between MEOs and newspapers (Wellar: 2004, Personal Communication), because in addition to community 
group association meetings and letters written by the public to the municipal elected officials, newspapers provide an essential forum in which the public can express their opinions on current events.

Public opinion can be expressed in three common formats in a daily newspaper:

- $\quad$ articles written by newspaper staff or outside press

- $\quad$ editorial comments provided by newspaper or picked up by outside source

- $\quad$ letters to the editor submitted by the public

As it is presumed that MEOs obtain at least some of their knowledge from local newspapers, it is therefore expected that newspapers provide a critical outlet from which MEOs can decipher the opinions of the general public as they pertain to specific current events (Wellar: 2004, Personal Communication). Assuming that local popular literature acts as an important, though hard-to-quantify measure of public opinion, local newspaper sources can assist members of city council in their decision-making. For example, if there is overwhelming feedback from the general public in the local press on the need for the current light rail service to be expanded in the near future, it is anticipated that the feedback provided in local newspapers will influence the MEOs decision-making on whether or not to proceed with the expansion.

In order to investigate the length and nature of the debate on light rail expansion and land use planning, or even public transit and land use planning in Ottawa, a search of local newspaper sources was conducted. Table 2.1 provides a sample of some of the more revealing newspaper headlines/articles found in the search

For the newspaper articles identified in this study, the matter of taking words, numbers, or graphics out of context can result in a bias of the material. As stated in 
Table 2.1

Selection of Local Newspaper Sources Which Refer to Land Use Planning /Transportation Planning Relationship

\begin{tabular}{|c|l|c|c|}
\hline Number & \multicolumn{1}{|c}{ Article Title } & Newspaper & Date Published \\
\hline 1 & $\begin{array}{l}\text { Light-rail plan doesn't go far } \\
\text { enough } \\
\text { (letter to the editor) }\end{array}$ & Ottawa Citizen & $2004 / 05 / 26$ \\
\hline 2 & $\begin{array}{l}\text { Why light-rail is seen } \\
\text { in Ottawa's future }\end{array}$ & Ottawa Citizen & $2003 / 11 / 06$ \\
\hline 3 & City Should Expand O-Train & $\begin{array}{l}\text { The News: } \\
\text { Hunt Club } \\
\text {-Riverside }\end{array}$ & $2003 / 09 / 18$ \\
\hline 4 & Light-rail must serve the masses & Ottawa Citizen & $2002 / 12 / 13$ \\
\hline 5 & Tracking Rapid Transit in Ottawa & Ottawa Sun & $2002 / 12 / 08$ \\
\hline 6 & $\begin{array}{l}\text { Emphasize transit } \\
\text { to avoid gridlock }\end{array}$ & Ottawa Citizen & $2001 / 06 / 12$ \\
\hline 7 & $\begin{array}{l}\text { Ottawa is well suited for } \\
\text { light-rail network }\end{array}$ & Ottawa Citizen & $2001 / 02 / 01$ \\
\hline 8 & Voters seem willing to spend & Ottawa Citizen & $2000 / 11 / 09$ \\
\hline 9 & $\begin{array}{l}\text { Convenience key to } \\
\text { good public transit }\end{array}$ & Ottawa Citizen & $1998 / 02 / 12$ \\
\hline 10 & $\begin{array}{l}\text { Region votes to start } \\
\text { planning for tunnel }\end{array}$ & Ottawa Citizen & $1990 / 11 / 29$ \\
\hline 11 & $\begin{array}{l}\text { Region's land use } \\
\text { dictates automobiles }\end{array}$ & Ottawa Citizen & $1990 / 09 / 23$ \\
\hline 12 & $\begin{array}{l}\text { The urban planning process- } \\
\text { the way to an imaginable future }\end{array}$ & Ottawa Citizen & $1986 / 05 / 24$ \\
\hline 13 & $\begin{array}{l}\text { The Transitway: Has it failed to } \\
\text { 'reshape the urban structure'? }\end{array}$ & Ottawa Citizen & $1985 / 10 / 05$ \\
\hline 14 & $\begin{array}{l}\text { Taking steps towards the } \\
\text { end of the automobile era }\end{array}$ & Ottawa Citizen & $1975 / 12 / 09$ \\
\hline
\end{tabular}


previous literature reviews, it is not possible to "prevent... research materials from being taken out of context... and cannot prevent the contents of materials selected for exhibit from being taken out of context" (Wellar: 2000a, p. 8). That said, this newspaper search was able to identify articles that either pertain specifically to the research topic, or are associated with the research topic, simply by using keywords based on terms and phrases contained in Sections 1.2, 1.3, and 1.4 above. Moreover, to affirm the validity of the approach employed in this search, the articles are simply attesting to the premise of a public policy topic in newspapers and are not being used for advocacy purposes.

\subsection{Light Rail Transit (LRT)}

As the municipal elected officials are being examined on their knowledge of the spatial factors associated with the link between land use planning and transportation planning based on the proposed light rail expansion policies and plans, it is essential to provide a concise description of the mode of public transportation that is known as light rail transit. The following three sections provide an important but abbreviated historical background of light rail transit in Canada, as well as its present and future roles within Ottawa.

\subsubsection{Definition of Light Rail Transit}

Light rail transit (LRT) refers to a particular type of transit system "which provides capacity of a level between that which is possible with surface transit systems and that of conventional rapid transit systems" (Soberman: 1980, p. 95). The term "light rail" was reportedly first used during the 1960 s in the public transit vernacular to disassociate it 
from electric railways, such as streetcar and trolley systems. In reality, though, this form of mass transit is hardly "light" as these systems can reach speeds of up to $100 \mathrm{~km} / \mathrm{h}$, and can carry hundreds of passengers at a time. An inherent advantage that light rail transit systems have over other rapid transit systems is their ability to operate within a variety of rights-of-way (ROW), ranging from operating on surface street ROW with vehicular traffic moving adjacent to the rail lines, to semi-exclusive ROW where the rails are separated from other traffic except at grade crossings, to exclusive ROW where the rails are not intersected by grade crossings (Soberman: 1980, p. 95).

\subsubsection{A Brief History of Light Rail Transit}

The predecessor to the modern light rail vehicles was the electric streetcar, which began its first revenue service in the Berlin, Germany, suburb of Lichterfelde in 1881. By July 1884, this new form of public transit had commenced operations in North America as the first electric railway began regular service in East Cleveland, Ohio. The following year, Toronto became the first Canadian city to obtain an electric streetcar system (Black: 1995, p. 17). During the twenty years after the completion of the Toronto system, electric railways were built in no fewer than forty-three Canadian cities, including two systems in the Ottawa-Gatineau area (Wyatt: 2002). This form of public transit gained tremendous popularity in Canadian cities during the early decades of the Twentieth Century, as electric railways provided a great source of mobility to urban dwellers whose previous options had been limited to walking and horse transportation.

The presence of electric railways in Canadian cities as a dominant form of public transportation was short-lived though, as its popularity rapidly declined following WWII. This was due to the combination of the surging growth in automobile use following the 
war, and the dismantling of the electric railways from the 1930s to the 1950s because of shrinking ridership (Kuby: 2003, p. 1 and Wyatt: 2002). In fact this decline was so prevalent in Canadian cities that with the cessation of operations of the Montreal electric railway system on August $30^{\text {th }}$, 1959 , Toronto remained the only city left in the country with an electric railway system in operation (Wyatt: 2002).

\subsubsection{Revival of Light Rail Transit in Canada}

The renewed interest in LRT systems began in the late 1970s and early 1980s in European and North American cities, stemming from the belief that "auto alone cannot satisfy [the] transportation needs of cities for physical, social, economic, and environmental reasons" (Hobson: 1992, p. 2). In Canada, several cities have opted to build light rail systems as a means of increasing public transit use (Kuby: 2003, p. 1). One additional reason for the demand for light rail transit in Canadian cities is an increasing consensus that some form of electrified rail system can assist in alleviating road traffic congestion and curb the increasing levels of noise and air pollution in cities (Hobson: 1992, p. 3).

Canada began its light rail revival in Edmonton in 1978. Two other Canadian cities, Calgary and Vancouver, followed suit when they built LRT systems in the 1980s. Calgary opened its first LRT line in May 1981 and completed another line in time for the 1988 Winter Olympics. Vancouver commenced operation of a LRT system during the 1980s, when it built its Skytrain system in time for Expo 86 (Black: 1995, p. 102).

The emergence of LRT systems as a major component in urban transportation infrastructure expansion plans does not appear to be merely a temporary fad in the 
Canadian urban transportation scene. This view can be justified based on the fact that presently there are four Canadian cities with LRT systems (Wyatt: 2002). In addition, there are proposals for LRT systems in another three Canadian cities: Halifax, Winnipeg, and Victoria (Garnet: 2000; Light Rail Now: 2003; 2004).

One critical component involved in implementing an LRT system within Canadian cities is the belief that such a form of public transit will reduce private vehicle use, while encouraging land use policies that promote mixed-use centres and higher density commercial and residential development (Wellar: 1994). One identified successful case is with the C-Train in Calgary, Alberta (City of Calgary: 2004).

In Calgary, the city's transit governing body has implemented a long-range TransitOriented Development (TOD) plan that emphasizes mixed-use development around transit stations. Specifically, the TOD around the LRT stations in Calgary focuses on concentrating "higher density" residential and commercial development near the stations in order to make transit convenient and increase ridership (City of Calgary: 2004). This form of integrating a built LRT route with land use planning is already evident around a few C-Train stations. An example of this integrated planning has taken place adjacent to the Lions Park Station, where private developers have built a mixed-use office and residential centre above a shopping centre. The result of this development has increased mixed-use densities in the station area, as well as providing a captive market for the shopping centre (City of Calgary: 2004).

\subsubsection{Current Light Rail Transit in Ottawa}

The City of Ottawa began a light rail pilot project in October 2001 on a lightly-used 8.3 kilometre section of a Canadian Pacific Railway freight line. This light rail service is 
considered unique among light rail systems in operation, as it operates diesel multiple units on existing track that was built for freight service, and is intersected by two frequently used at-grade rail crossings (North American Light Rail Systems: 2004). Referred to as the "O-Train", it is integrated with the city's transportation network, by means of connections to several bus routes at all five of its stations, and with the Transitway at its terminus points. At the conclusion of its two-year pilot project assessment in the spring of 2003, the City decided to include the O-Train as part of its permanent transportation system because it had surpassed predetermined ridership goals (City of Ottawa: 2004f). In addition, due to the recommended expansion of rapid transit in Ottawa set out in the Rapid Transit Expansion Study (RTES) report and the perceived success of the O-Train, the City has proposed to expand the O-Train system (City of Ottawa: 2004f).

The proposed expansion calls for the creation of three new LRT corridors, with two of the corridors using existing rail and hydro ROW, and the third operating on a surface road ROW. Of these three lines, one line is to extend the current O-Train route eastwards to the Rideau Centre in the city's downtown core, and southwards to Riverside South and South Nepean in the city's southern suburbs. Another is aligned east-west, from suburban Kanata in the west to the southeastern-most communities in suburban Orleans, bypassing downtown. The third proposed line is a trolley-type transit service that will operate on surface road ROW using a northern route connecting existing communities in the city's west and east neighbourhoods via the downtown core (City of Ottawa: 2003c, p.17). These corridors are illustrated in Figure 2.2. 
Figure 2.2

Proposed Light Rail Transit Corridors in Ottawa (adapted from City of Ottawa: 2003c)

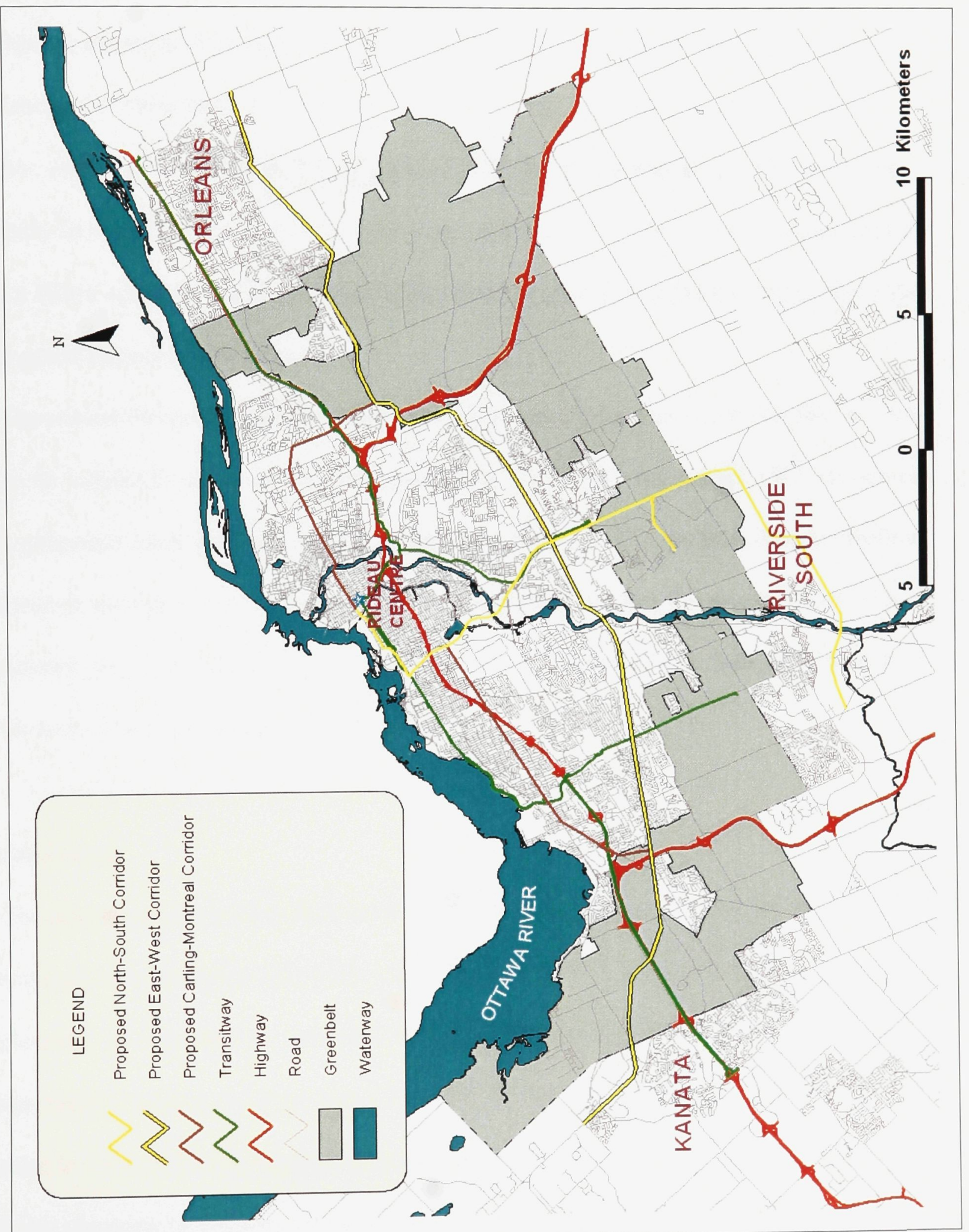


Two of the three proposed LRT corridors, consisting of those that are to operate within existing rail and hydro ROW corridors, will be included in this study. These two corridors were selected as they are in the active planning stage, and are currently undergoing environmental assessment, a critical process in the planning stage. As well, construction of these lines could potentially begin in less than three years (City of Ottawa: 2003c, p. 47). Finally, the decision to limit the research to the corridors that are currently in the planning stages means that the politicians involved in the research might have a better sense of the planning of these selected corridors, and knowledge about the plans could be more substantive.

The reason for excluding the trolley-type transit service is due to the fact that it is not due to be subject to an environmental assessment until 2009, nor to have LRT service on these proposed lines until 2015 (City of Ottawa: 2003c, p. 47). As the proposed trolleytype transit service is not slated to begin its preliminary studies for several years, this is considered too far in the future to explore route scenarios at this time, and to expect MEOs to have much insight into this service.

\subsection{Summary}

This chapter provides the context for the research by introducing the fields of land use planning and transportation planning, and indicating that the link between these two types of planning is regarded as a critical factor in improving land use development and transportation systems in urban areas. A search of local newspaper sources is conducted in order to investigate the length and nature of the debate on public transit planning and land use planning in Ottawa. As well, in order to introduce the reader to the case study 
that is used in this research, an abbreviated historical background of light rail transit in Canada, along with the current and proposed future status of light rail transit in Ottawa is included. 


\section{CHAPTER 3 LIGHT RAIL TRANSIT CASE STUDY}

This chapter discusses the planning background to light rail transit (LRT) and its expansion in Ottawa. It reviews the literature on the LRT policies and plans in Ottawa, particularly official municipal documents, and identifies the decision-making processes of the municipal elected officials regarding the proposed light rail expansion. Before addressing these topics, however, a brief history of the light rail planning situation within the city of Ottawa is presented to provide a background for the discussion of current LRT plans and the decision-making processes related to LRT corridor selection.

\subsection{Brief History of Light Rail Transit Planning in Ottawa}

In July 1997, the Ottawa-Carleton Regional Council adopted an updated Regional Official Plan and Transportation Master Plan (TMP) for the Ottawa region, which declared a goal of achieving a $73 \%$ increase in transit ridership over the next twenty-five years (Gault: 2002, p. 2). To help meet this target, the Official Plan incorporated a longrange transportation plan component that included the use of LRT to complement its busbased rapid transit (BRT) service (Gault: 2002, p. 2). The Official Plan recommended a rail transit pilot project within an existing rail corridor in order to test the feasibility of rail transit service operating in Ottawa (City of Ottawa: 2001b, p. 13). By September 1999, the council of what was then the Regional Municipality of Ottawa-Carleton (RMOC) approved the integration of the Light Rail Pilot Project (LRPP) with the city's public transportation infrastructure (City of Ottawa: 2002a, p.1) . $^{3}$

\footnotetext{
${ }^{3}$ The new City of Ottawa was created on January $1^{\text {st }}, 2001$ by amalgamating eleven urban and rural municipalities and a regional government into one municipal government.
} 
The stated objectives of this pilot project were:

1. Assess the technical feasibility of using an existing freight rail corridor for rapid transit

2. Validate the projections for ridership, cost, and performance

3. Allow proper analysis of larger scale implementation

(Source: City of Ottawa: 2002a, p.3)

The selection process for an appropriate corridor for the LRPP involved consultation with the public transit industry as well as the general public. The optimal rail corridor for the LRPP was selected using key indicators of potential ridership estimates and cost per passenger (Gault: 2002, p. 3). A corridor was selected that was believed to have one of the highest potential riderships and lowest operating cost per passenger. In addition, as shown in Figure 3.1, the line is in close proximity to two major employment centres (Natural Resources Canada and Confederation Heights complex: federal government departmental offices), a university (Carleton), and a box-store style shopping centre (South Keys shopping plaza) (Gault: 2002, p. 2), thereby demonstrating the link between transportation planning and land use development. It should be pointed out that the land in proximity to the selected corridor was already developed prior to the start up of the LRPP, so there was very limited planning of land use in conjunction with the implementation of light rail service within this corridor.

\subsection{Planning of Proposed Light Rail Transit Expansion in Ottawa}

This section discusses the location and timing of the proposed LRT expansion as outlined in the Official Plan, Transportation Master Plan, and subsequent documents regarding transportation in Ottawa. 
Figure 3.1

Ottawa Light Rail Pilot Project (adapted from Region of Ottawa-Carleton: 1999a)

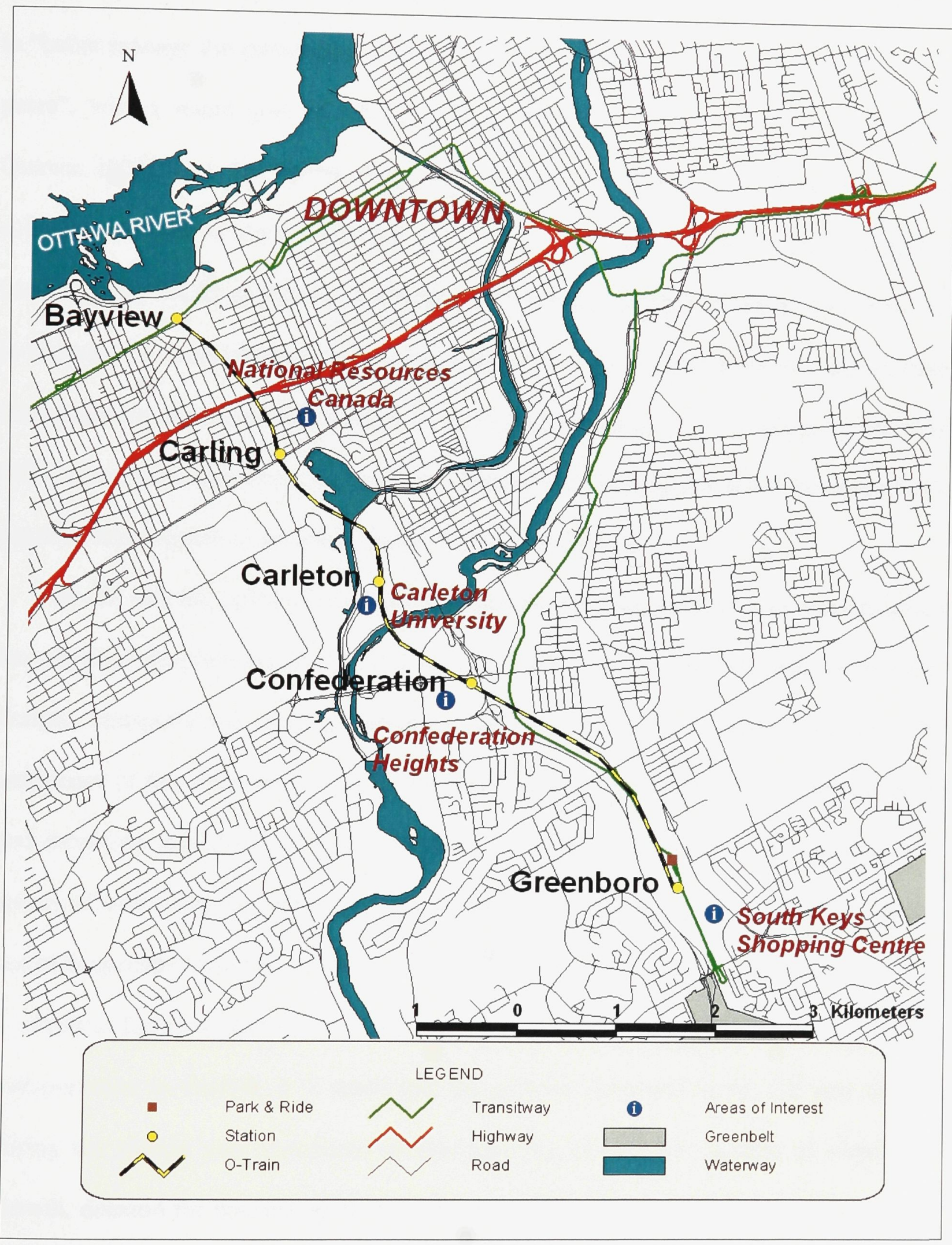




\subsubsection{Ottawa Official Plan}

In May 2003, the City of Ottawa adopted a new Official Plan (OP) to prepare the city to "better manage the growth and change that it will experience over the next twenty years", with a stated goal of achieving sustainable development for the city (City of Ottawa: 2003f, 1.1). The vision of the OP is to have a "compact city... where people and activities are located along rapid transit corridors... areas that can be accessed by quality transit service" (City of Ottawa: 2003c, p. 4). The transit-based orientation of the new OP is intended to accommodate the projected increase in population from the approximate current figure of one million people to a projected increase to 1.2 million by the year 2021, along with addressing the expected changes and challenges that will be created as a result of this population growth (City of Ottawa: 2003f, 1.1).

The OP sets the policy framework for managing growth in Ottawa in order to guide the physical development in the city to 2021 , with a focus on land use, community design, transportation, and infrastructure policies. In addition, and confirming the pertinence of this research, the OP emphasizes urban intensification (increasing density) and increased mixed-use development that is located near rapid transit corridors as a means of addressing travel demand issues, and to "discourage single occupancy vehicle use as the preferred mode of peak period travel" (City of Ottawa: 2004f, p. 5).

Prior to further explanation of Ottawa's new OP and subsequent documents regarding transportation in Ottawa, it is noted that the policies contained in the OP may change during the twenty year timeframe of this plan due to changes in rates of population growth, demand for housing, economic factors, and the supply of land. Furthermore, the OP states that its policies may be altered if individuals or corporations obtain an "Official 
Plan Amendment" (City of Ottawa: 2003f, 1.7). Nonetheless, this planning document $(\mathrm{OP})$ is regarded as the principal planning measure for the future growth of Ottawa, and the policies contained within the Plan are designed to "guide the day-to-day decisionmaking on land use issues in the city" (City of Ottawa: 2003f, 1.7).

This next section focuses solely on transportation-related issues within the OP. The Plan acknowledges the importance of the link between land use planning and transportation planning, and emphasizes the need for connecting high quality transit to employment nodes and a strengthening of the link between public transit and development (City of Ottawa: 2003f, 1.7). Further, the Plan supports the underlying premise of this research that the relationship between the aforementioned types of planning is important when planning the future growth of the city.

According to the Official Plan, the future growth of the city is to be directed towards specific locations that will contain a combination of housing, employment, and recreation (i.e., mixed-use development), and these locations are to be within walking distance of public transit (City of Ottawa: 2003f, 2.1). In addition, within the urban zones of Ottawa, growth is to be directed to locations that include those centred on the city's rapid transit network (City of Ottawa: 2003f, 2.23).

The importance of the relationship between land use planning and transportation planning is specifically demonstrated in a number of initiatives described in the OP, such as the planning of mixed-use Town Centres in proximity to the proposed light rail corridors in the suburban areas of Orleans, Kanata, and South Nepean. It is intended that these Centres provide intensified land use development in the form of housing and employment close to the proposed light rail corridors (City of Ottawa: 2003f, 2.23). The 
Plan also calls for an intensification of infill development for lands within 600 metres of proposed rapid transit stations, in order to develop these areas as compact, mixed-use and pedestrian-accessible development nodes (City of Ottawa: 2003f, 2.23).

The examples above illustrate that the main planning document for future growth in Ottawa acknowledges the spatial link between transportation planning and land use planning. Further, by extension, the OP confirms the legitimacy of an inquiry into the opinions of municipal elected officials on the spatial aspects of the link between land use planning and transportation planning when formulating light rail expansion policies and plans.

\subsubsection{Public Transportation Plans for Ottawa}

The 2003 Transportation Master Plan (TMP) is a supporting document to the Official Plan that was adopted to manage transportation demand within the city up to the year 2021 (City of Ottawa: 2003b, p. 2). The main objective of the TMP is to assess how to achieve the OP's goal of increasing the transit modal share during peak hours to $30 \%$ by 2021 from the current share of $17 \%$. To meet this goal, the TMP stresses the need for an expansion of the city's rapid transit network, including a proposal to construct three new light rail routes in the city (City of Ottawa: 2003b, p. 107). The rationale given in the TMP for constructing these routes is to provide a "high-quality... transit linkage accessibility to major employment uses" and to provide service between the downtown core and established communities, and to serve various developing suburban communities such as Riverside South and South Nepean (City of Ottawa: 2003b, p. 107).

The TMP, in addition to the OP, discusses the need for merging the components of 
land use planning and transportation planning. Section 4.1 of the TMP states that urban land use and transportation systems strongly influence each other, and that mixed-use development nodes are considered to be "a building block in the foundation of a transitsupportive environment" (City of Ottawa: 2003b, p. 29). To make these strategies work within the city, the TMP asserts that the city will focus on building compact, mixed-use developments at strategic locations, including rapid-transit stations, in order to satisfy residents' daily needs within a local area (City of Ottawa: 2003b, p. 30).

The Rapid Transit Expansion Study (RTES) is another transportation study conducted in association with the OP, and it focuses specifically on the rapid transit segment of the TMP, namely the identification of potential rapid transit corridors. Approved by Ottawa City Council in February 2003, the purpose of this planning study is to develop a longrange strategic plan for rapid transit in Ottawa, taking into consideration the growth projections of the city (City of Ottawa: 2003d, p. 20). The RTES used population and employment forecasts to identify the strongest travel demand patterns for future rapid transit corridors (City of Ottawa: 2003e, Appendix G: p. 2).

The RTES selected thirteen separate rapid transit corridors to be studied for the implementation of an integrated LRT and BRT system and were identified from previous transportation plans, public consultations and field observations. The corridors were then subjected to a screening process, which in the case of the LRT were narrowed down to three corridors. These selected corridors were chosen based on the following evaluation factors:

- $\quad$ Transportation (transit efficiency)

- $\quad$ Land use (service to major centres, development support)

- $\quad$ Economic impacts (accessibility to employment areas)

- $\quad$ Natural environment (impact on ecological features, air quality) 
- Social environment impacts (neighbourhood cohesion)

- $\quad$ Project costs (capital and operating costs)

- Implementation considerations such as right-of-way availability

(City of Ottawa: 2003e, p. 7-1).

The process of determining the importance of evaluation factors was accomplished by assigning each factor a relative weight, and then comparing the factors with one another based on comments provided by municipal committee groups and the public (City of Ottawa: 2003e, p. 7-1).

One other relevant document related to the proposed light rail expansion in Ottawa is the Ottawa Rapid Transit Expansion Program (ORTEP) Implementation Strategy, completed in July 2003. The purpose of this document was to develop an implementation strategy for the city's long-term rapid transit plan, including identification of all the planning, design, and construction steps required for each rapid transit expansion project, along with providing timelines, funding and partnership options, and financial implications (City of Ottawa: 2003c, p. 5). Essentially, the ORTEP study provides an indepth examination of the corridors selected in the RTES project. The proposed light rail corridors are described in detail, including suggested expansions not included in the RTES, with an emphasis on the physical infrastructure required for the corridors, funding requirements, and the timelines for the staging of operations.

\subsection{Proposed LRT Routes}

The proposed LRT expansion for Ottawa consists of three separate corridors, two of which are included in this research for reasons mentioned in the previous chapter. In addition, the present research is confined to the areas within the proposed corridors that 
exist exclusively within the City of Ottawa, excluding any proposed expansion of light rail transit from Ottawa into Gatineau, Quebec.

The two LRT corridors included in this study are referred to as the North-South Corridor LRT Priority Project (N-S LRT) and the East-West Corridor LRT Project (E-W LRT). The characteristics of each corridor are summarized as follows.

\subsubsection{North-South LRT Corridor}

The North-South LRT corridor is the first transportation corridor considered for the proposed expansion to Ottawa's rapid transit network. It has been identified as a "priority project" intended to alleviate the increasing volume of vehicular traffic congestion between the southwest suburban corridor and Centretown in the inner city of Ottawa (City of Ottawa: 2003c, p. 48). The corridor being considered for the proposed N-S LRT is illustrated in Figure 3.2.

This proposed corridor is an extension of the existing, approximately 8 kilometre OTrain route that operates from Greenboro Station, which is adjacent to the South Keys shopping centre in the south end of the city, to its northern terminus at Bayview Station. Each terminus is connected via walking paths to the city's Transitway. The expansion will slightly more than triple the length of the current route to 26 kilometres, including a potential two kilometre airport spur. Of these 26 kilometres, approximately 12 kilometres are to be built on land outside of railway ROW (City of Ottawa: 2004f).

The existing plans recommend an extension from the current northern terminus at Bayview Station eastwards into the city's downtown core. From the current southern terminus at Greenboro Station, there is to be a southward extension to the developing 
Figure 3.2

Proposed North-South Light Rail Transit Corridor (adapted from City of Ottawa:
2004)

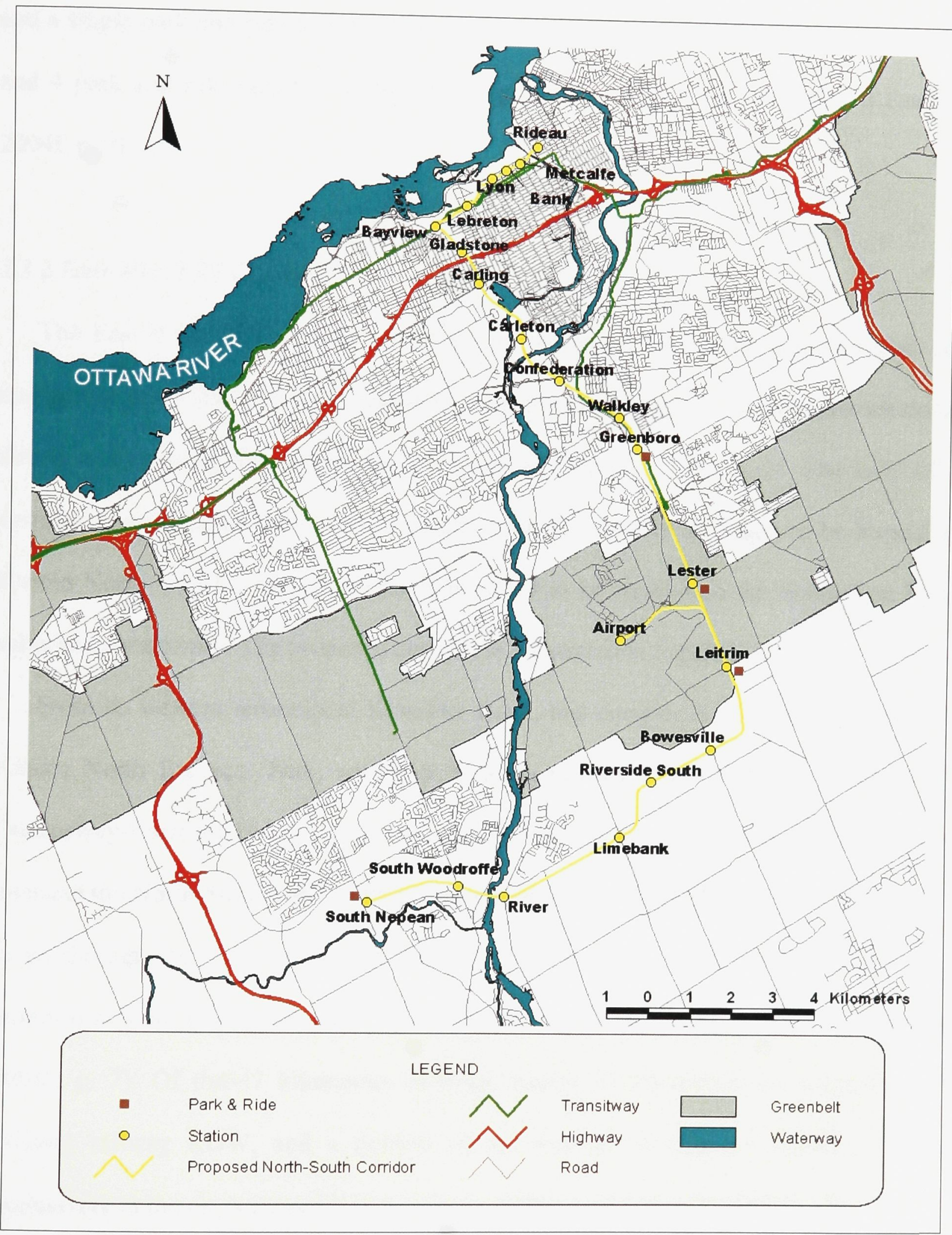

Note: Location of Stations and Park \& Rides are shown as illustrated in various LRT planning documents 
suburban communities of Riverside South and South Nepean (Barrhaven), as well as a spur line to the MacDonald Cartier International Airport. Including the existing stations and a single park and ride facility on the O-Train line, there is to be a total of 19 stations and 4 park and ride facilities within the proposed N-S LRT Corridor (City of Ottawa: 2004f, p. 7).

\subsubsection{East-West LRT Corridor}

The East-West LRT corridor is the second proposed LRT route being planned for integration into Ottawa's rapid transit system. It is to operate in a northwest-southeast direction, bypassing the downtown core (City of Ottawa: 2004c, p. 2). The E-W LRT corridor is approximately $47 \mathrm{~km}$ in length, with the western terminus to be located in Kanata North, and the eastern terminus intended to be situated in the South-East Innes suburban community. The proposed corridor is illustrated in Figure 3.3.

From its western terminus at Klondike Road, this corridor is to operate through the Kanata North Business Park, within an existing railway ROW that is adjacent to the Queensway-Carleton Hospital Campus and Colonnade Road Business Park, and is to intersect the North-South LRT route at Greenboro Station. East of Greenboro, the route is to go through the Walkley Freight Yard, and travel south of Blackburn Hamlet to its terminus at Trim Road along the Cumberland section of the Transitway (City of Ottawa: 2004c, p. 7). Of the 47 kilometres of track, nearly 30 kilometres are located within existing railway ROW, and a portion of the rest of the planned corridor, (almost exclusively in the city's east end) is to operate within road and hydro ROWs. The 
Figure 3.3

Proposed East-West Light Rail Transit Corridor (adapted from City of Ottawa: 2004c)

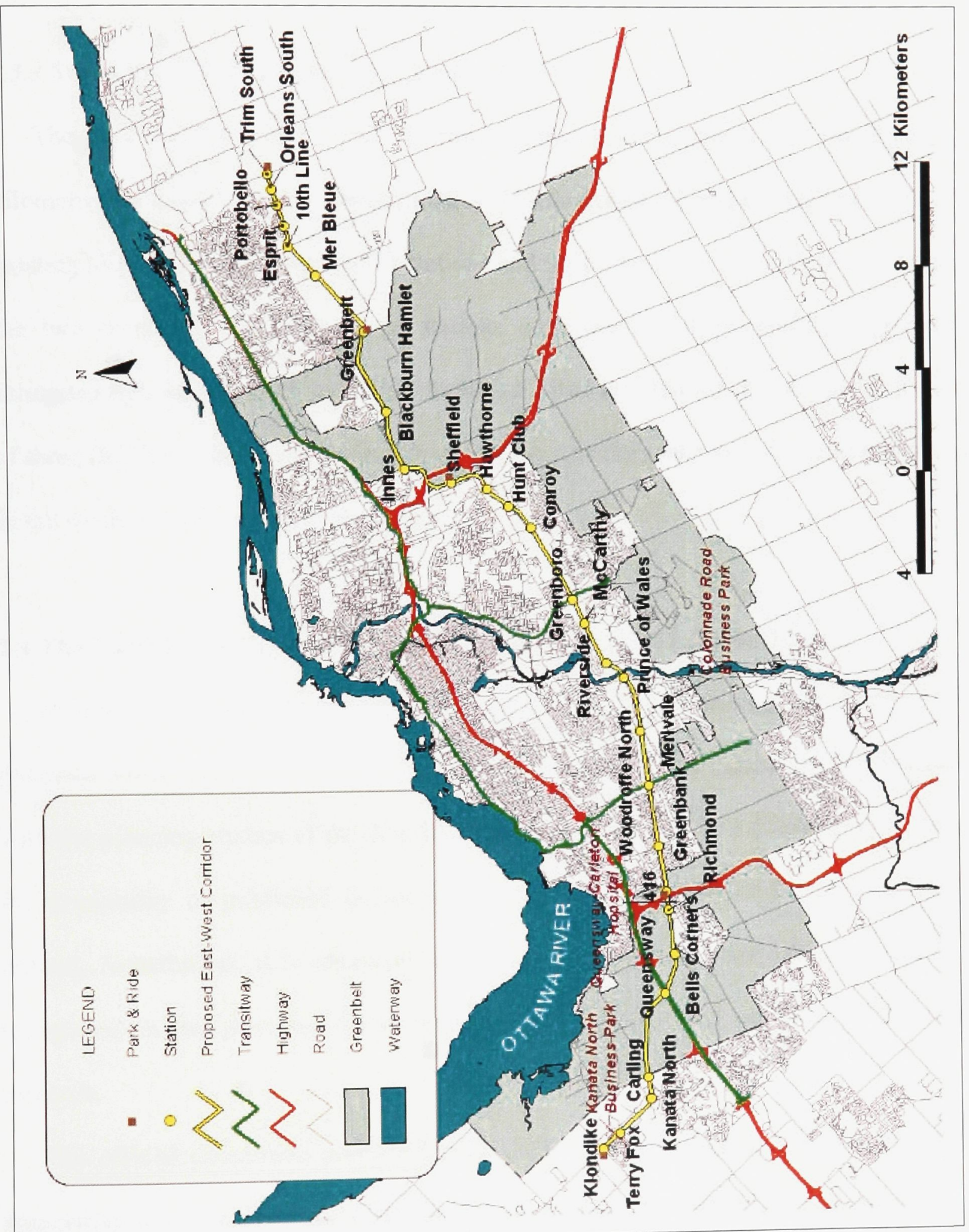

Note: Location of Stations and Park \& Rides are shown as illustrated in various LRT planning documents. Station names are not provided in LRT plans, named after features of the surrounding station locations. 
proposed infrastructure for this corridor includes 25 stations and 5 park and ride facilities (City of Ottawa: 2004c, p. 7).

\subsubsection{Summary of $N-S$ LRT and E-W LRT Corridors}

The N-S LRT and E-W LRT corridors together are projected to operate on 73 kilometres of track, of which approximately 54 kilometres are planned to be built within existing railway ROW. A total of 44 stations and 9 park and ride facilities are planned for the two corridors. The number of stations and park and ride facilities are merely estimated figures; however, as to date there is limited information on the precise location of these facilities. As illustrated in Figure 3.4, the corridors intersect at Greenboro Station in the south-central section of the city.

\subsection{The Land Use and Transportation Planning Link for LRT in Ottawa}

Examination in this study of the link between land use planning and transportation planning within the context of the proposed LRT expansion is occurring simultaneously with the planning studies of the N-S LRT Corridor and E-W LRT Corridor. As a result, the availability of published documents related to this subject at the present time is limited. Nonetheless, it is necessary to assess the extent to which this link has been recognized in the planning documents that were available at the time of the thesis research.

The official documents produced by the City of Ottawa refer to the importance of associating land use planning with transportation planning with respect to the proposed N-S LRT Corridor. The rationale for this corridor, as explained in ORTEP, indicates that 
Figure 3.4

Proposed North-South Light Rail Transit and East-West Light Rail Transit Corridors (adapted from City of Ottawa: 2003e).

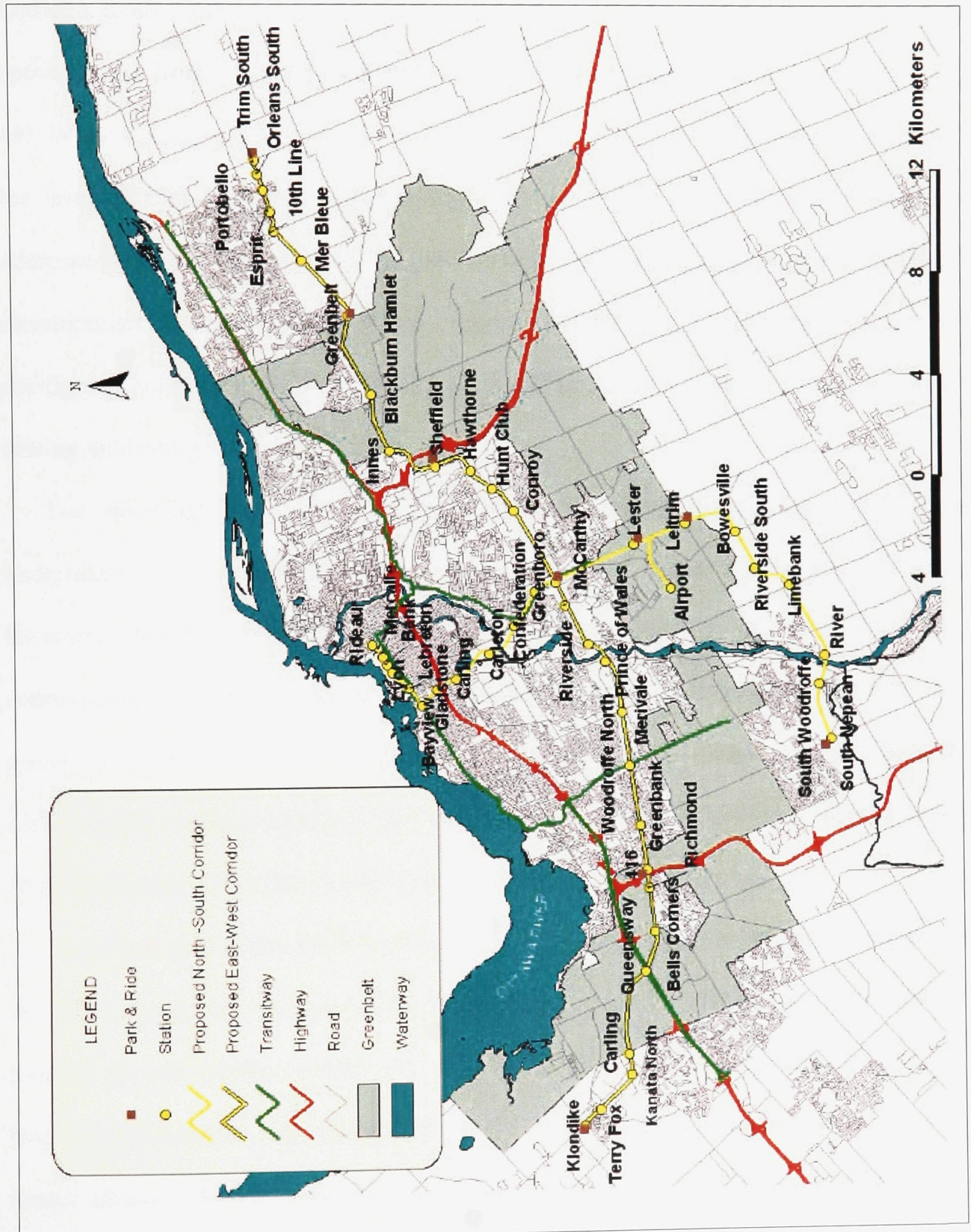


the extension of the current $\mathrm{O}$-Train route would attract new transit riders by serving the developing community of Riverside South (and through park and rides for those from farther a field), Ottawa's international airport, and it would provide an attractive travel option to and from Ottawa's Central Business District (CBD) (City of Ottawa: 2003c, p. 49). While discussion of the spatial factor in relation to this proposed corridor is limited, the issue of accessibility to adjacent land uses in the CBD section of this corridor is addressed, and the plans call for the corridor to provide access to a proposed mixed-use development Town Centre in South Nepean. Furthermore, a detailed study of the developing community of Riverside South has been produced, which includes plans for linking its development with the LRT corridor.

The Riverside South Rapid Transit Study, completed in December 2003, was undertaken with the intention of determining how to serve the rapidly expanding Riverside South community with rapid transit. Although the population was approximately 5,500 in 2004 (Parker: 2004, Personal Communication), this community is projected to become the fastest growing area within the city, with an increase from the current 1,900 dwelling units to 17,600 dwelling units, and a population of approximately 50,000 people by 2021 (McCormick Rankin Corporation: 2003, p. i).

The stated goal of the Riverside South Rapid Transit Study is to identify a corridor for the LRT, so that land use planning and development within that community is able to proceed in conjunction with a set of predetermined long-term planning objectives (McCormick Rankin Corporation: 2003, p. i). The key factors identified in making rapid transit attractive to this new community are the planning considerations for the entire area, and in particular the designing of a Town Centre (McCormick Rankin Corporation: 
2003, p. ii).

According to this study, the Town Centre in Riverside South is to be the catalyst for making this area a Transit-Oriented Development (TOD) community. The Town Centre is to be designed as a pedestrian-friendly place, which is to be achieved by integrating mixed-use development with the LRT at grade, and integrating LRT with urban bus transit (McCormick Rankin Corporation: 2003, p. 35). It is anticipated that the Town Centre will be the core of this community, in that the Centre will be a compact, walkable area that features a mixture of commercial enterprises, professional services, and residential units (McCormick Rankin Corporation: 2003, p. 37).

Consideration of the spatial link between land use planning and the planning of the EW LRT Corridor in official planning documents is evident, but is discussed only at the scale of the entire corridor as opposed to a neighbourhood-by-neighbourhood analysis. City-approved planning reports for this LRT corridor discuss the need for strategically locating park and ride facilities as a key to achieving high quality rapid transit service, and meeting expected ridership levels within this corridor (City of Ottawa: 2004c, p. 9). The intention of integrating this LRT route with existing rapid transit routes is considered in the City report entitled "E-W LRT Project Environmental Assessment" as this report stipulates the importance of integrating Transitway lines and the N-S LRT corridor with this LRT corridor to create rapid transit transfer facilities (City of Ottawa: 2004c, p. 9).

Planning documents related to this proposed LRT corridor discuss serving the nearby employment market. Currently, there are several employment areas alongside this E-W LRT corridor, from the Orleans Industrial Park in the eastern section of the corridor to the Kanata North Business Park in the western-most section of the corridor (City of Ottawa: 
2004c, p. 9). The planning documents cite the importance of serving these employment areas, as projections indicate that employment will almost double within these areas from the current level of 40,000 jobs to 70,000 jobs by 2021 (City of Ottawa: 2004c, p. 9). In addition, the documents address the concept of accessibility in relation to serving this large employment market. One planning report comments that in order to serve this market effectively, there has to be an integration of the LRT route and adjacent buildings, as well as creating pedestrian access between these employment areas and the LRT trains (City of Ottawa: 2004c, p. 10).

Overall, the available planning documents for the LRT corridors contain a mixture of commentary and observation on the spatial link between land use planning and the development of this LRT route. On a macro scale, the plans for the proposed corridors to date discuss such ideas as the importance of public accessibility to the LRT routes, the requirement for mixed-use development in proximity to LRT stations, the development of a town centre in a developing community, park and ride facilities, and the importance of walking accessibility to employment areas. With the exception of the Riverside South community, which is studied on a local scale, only a limited amount of information is available on the detailed planning and implementation of the land use plans in association with the planning of the LRT corridors. In spite of the limited amount of detailed information on specific areas within the city, as demonstrated in Figure 3.5 a substantial share of the planned residential and employment expansion is located near the proposed light rail corridors, including all of the developing communities outside of the Greenbelt. 
Figure 3.5

Planned Residential and Employment Areas in Ottawa (adopted from City of
Ottawa: 2003f)

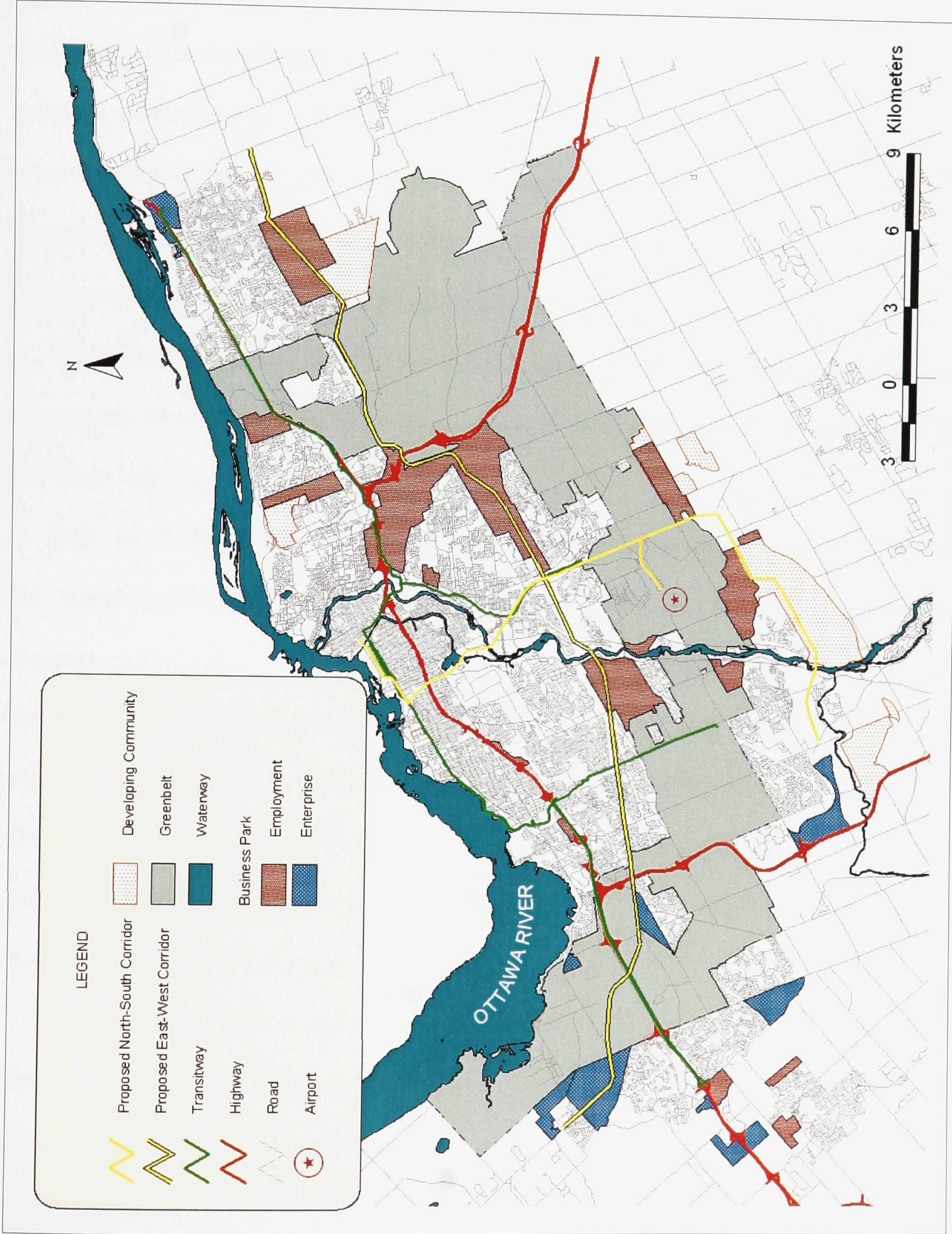

Note: Developing Community comprises planned residential and mixed-use employment areas 


\subsection{Light Rail Decision-Making Process in the City of Ottawa}

At a general level the political dimension of the light rail expansion decision-making processes may be summarized as follows. The municipal elected officials of Ottawa, consisting of the mayor and council, decide on behalf of citizens whether the light rail proposal should proceed, what corridors are to be used, in which order of priority, and at what level(s) of funding. The "flow" of this process is indicated by Figure 3.6. For emphasis, the flow diagram components representing municipal elected officials in a decision-making role are shown with a green/red background.

The following comments provide a brief guide to the flow diagram, and to the connections between and among the key components affecting the political dimensions of the "flow" process.

First, the Transportation Committee is the Standing Committee of interest in Figure 3.6. Standing Committees, comprised solely of municipal elected officials, are appointed to assist council deliberations by issues and making recommendations to council. It is at the Standing Committee level that the general public may have direct input into the decision-making process and to the decisions made by Standing Committees (City of Ottawa: 2004g). As indicated, the Transportation Committee carries the institutional burden of taking the lead in preparing the way for informal decision-making by council throughout the light rail decision-making process.

Second, while the Transportation Committee does what is frequently referred to as the "heavy lifting" on behalf of the council, all councillors have a duty to participate fully in the decision-making process for its duration, because the light rail decisions affect residents in every ward in the city. As a result, it needs to be emphasized that the city 
Figure 3.6

Light Rail Decision-Making Process for Proposed North-South LRT Corridor (adapted from Gault: 2004)

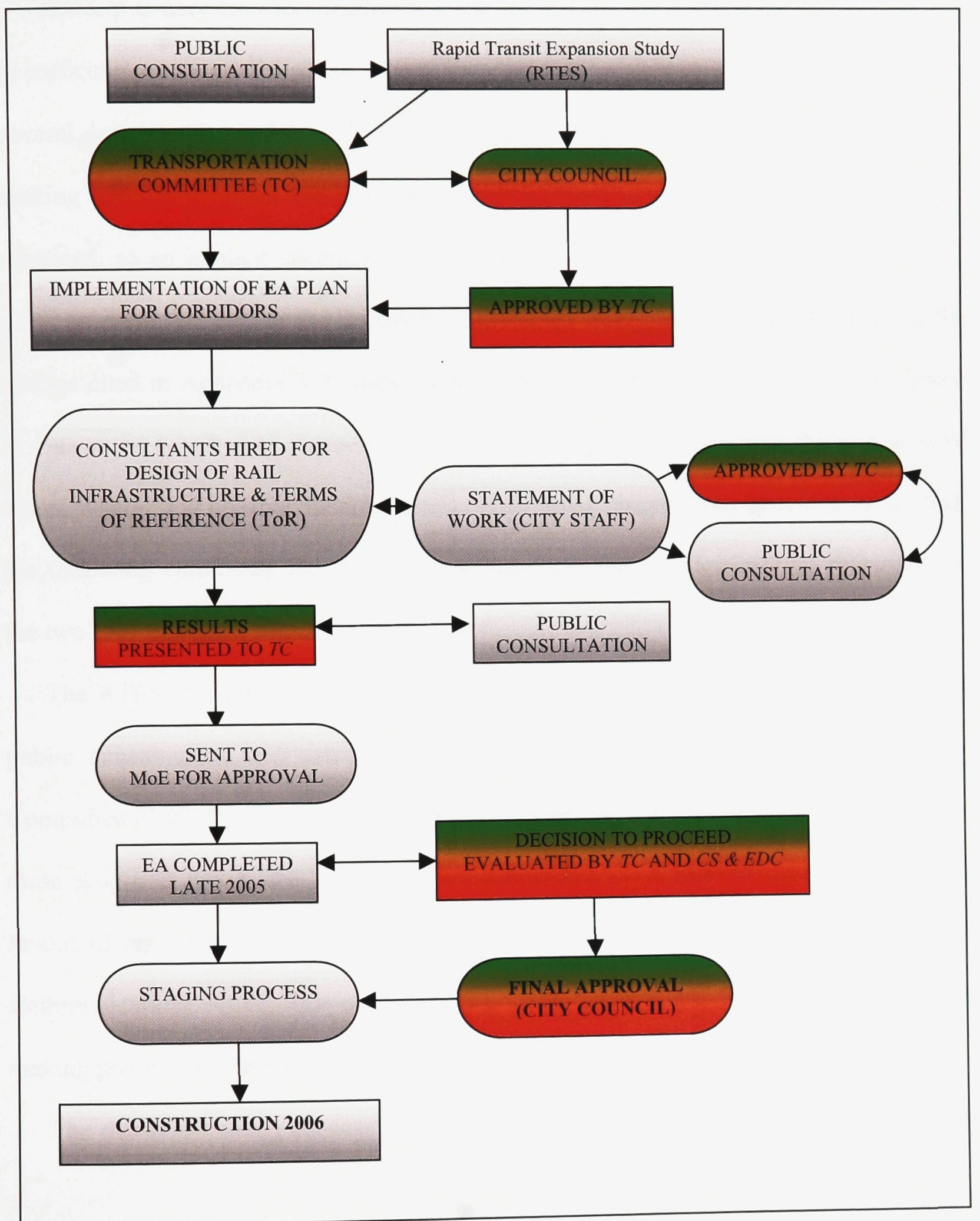

Note: Green/red background indicates step where municipal elected officials are in a decision-making role concerning light rail expansion 
council component is shown at the beginning and end of the process to represent collective decision-making.

Third, it is necessary to emphasize that transit in general, and the light rail expansion in particular are very public matters, and have received a great deal of media attention for several decades. Figure 3.6 could be construed as suggesting that the light rail decisionmaking process is based solely on technical reports and what is discussed in council meetings, so an explicit statement to the contrary is in order. That is, media coverage plays an important role in the decisions made by the municipal elected officials, and the articles cited in Appendix VIII attest to the influence of the media in shaping the debate in Ottawa on whether to proceed with a light rail expansion, including the questions of when, where, and at what funding levels. With those observations provided as context, the following comments use Figure 3.6 to overview the decision-making processes for the two LRT corridors featured in this study.

The RTES, a wide-ranging review of the proposed rapid transit network, including public consultation, was established in part through the Transportation and Transit Committee (T\&TC) and city council ${ }^{4}$. After determining that there was public support for these proposed routes, the Transportation Committee (TC) and city council decided in favour of an Environmental Assessment plan for the corridors (Gault: 2004, Personal Communication). At the time of this writing that stage has been reached in the decisionmaking process for the proposed expansion.

The decision-making process of the proposed light rail expansion is to occur in the

\footnotetext{
${ }^{4}$ In April 2004 the T\&TC changed its title to "Transportation Committee" (TC)
} 
following manner. The Environmental Assessment has been approved by the Transportation Committee with the next step involving the hiring of consultants to design the rail infrastructure, and produce the Terms of Reference (ToR), which include describing the proposed areas and the study area. After the ToR have been completed, they will be presented to the Transportation Committee for approval before being sent to the Ontario Ministry of Environment (MoE) to ensure that they meet provincial requirements (Gault: 2004, Personal Communication).

In conjunction with the ToR, a Statement of Work (including public consultation feedback) will be prepared by city staff and sent to the Transportation Committee for review. This Statement of Work discusses the study area, addressing major issues such as serving extensive employment markets, integration with other modes of transportation, and the development of alternative corridors. It is anticipated that the Environmental Assessment for the N-S LRT Corridor will be completed in late 2005 , followed by the staging process, with construction of the line commencing in 2006. The staging process identifies a strategy that "maximizes transit ridership, maximizes cost-effectiveness, and minimizes disruption to existing transit services" and other transportation traffic (City of Ottawa: 2004i). The staging of the E-W LRT Corridor will be similar in form, with the scheduling of this process being approximately one year behind the N-S LRT corridor.

The decision of whether or not to proceed with the implementation of the north-south and east-west light rail routes will be evaluated first by the Transportation Committee and the Corporate Services and Economic Development Committee (CS\&EDC). These committees will analyze the policies and direction of the proposal. This process will involve a series of joint meetings between these two committees to determine the 
feasibility of these projects. Upon completion of these deliberations, the final decision on whether to approve building the routes within these corridors will be made by the Ottawa City Council (Gault: Personal Communication 2004).

\subsection{Summary}

This chapter provides an overview of the link between land use planning and transportation planning in regard to the proposed light rail expansion in Ottawa. In addition, a summary of the general land use components surrounding the LRT corridors selected for this study, and a rundown of the LRT decision-making processes for Ottawa is introduced.

This overview of the plans and policies of the proposed light rail expansion shows that there is substantial documentation of the selected LRT corridors and on the integration of land use planning and transportation planning within these LRT corridors. This is a critical preliminary finding, as these documents provide a basis from which to assess the responses provided by the municipal elected officials during the interview phase of the study. Prior to presenting and examining the interview results, Chapter 4 discusses the methodological process that was adopted in order to assess these interview responses, as well as to answer the research question and achieve the research objectives presented in Sections 1.2 and 1.3 respectively. 


\section{CHAPTER 4 RESEARCH METHODOLOGY}

This chapter presents the research methodology used to ascertain and assess the extent of knowledge of municipal elected officials in Ottawa concerning the spatial link between land use planning and transportation planning for the proposed light rail expansion. Within the broad methodological framework, three research techniques are used in this study. The first technique consists of interviewing members of selected groups associated with the light rail expansion. The second technique consists of producing a set of original maps that illustrate the proposed light rail corridors, along with the current and proposed residential and employment areas along the corridors. The third technique uses content analysis to assist in reviewing local planning documents and assessing the municipal elected officials' knowledge about why and how the spatial factor affects land use planning and transportation planning for the light rail expansion.

\subsection{Methodology}

The organization and structure of the research conducted in this study follows the design model developed by Ackoff (1953), and the operational and empirical research activities follow the approach developed by Wellar in his work on the Walking Security Index project $(1998,2000 \mathrm{a}, 2002)$. Additional operational research activities follow the format applied to the 2003 Rapid Transit Expansion Study (RTES). The primary means of ascertaining the municipal elected officials' knowledge of the proposed light rail expansion is through interviews. Maps and media articles are used to assist in assessing the municipal elected officials' knowledge of why and how the spatial links affect land use planning and transportation planning for the light rail expansion. 
Prior to any further discussion on the research design, however, it is necessary to introduce a list of key spatial factor terms/phrases compiled for the research. This list is considered a critical part of the methodological process, as it is used to measure and assess the extent to which the spatial factor is incorporated in planning for the light rail expansion. The key terms/phrases used in this study are shown in Table 4.1, and a detailed explanation of these key terms/phrases is described in Section 4.2.1.

\subsection{Research Methodology by Phase}

As noted, this investigation follows the research design initially specified by Ackoff (1953), with an addition of an interview phase and results evaluation phase that follows the procedures established by Wellar $(1995,1997,2002)$. The five, interrelated phases are labelled as follows:

(1) Pilot study

(2) Pretest

(3) Trial run

(4) Interviews of municipal elected officials

(5) Assessment of Interview results

In the following section each of the phases is considered in turn. However, since there is a flow between the phases, it is necessary to describe briefly how they "fit together" for the purposes of this study.

The three design-evaluation phases (pilot study, pretest, trial run) serve two related purposes. First, they provide a methodologically-based procedure for developing and testing the questions to be used in the interviews. Second, they provide a basis for ascertaining whether the information needed for the study can be obtained from the interview process. 
Table 4.1

Key Spatial Factor Terms/Phrases for Light Rail Expansion*

\begin{tabular}{|ll|}
\hline 1. & Accessibility (employment centres) \\
2. & Clustering (around rail/transit stations, of neighbourhood facilities) \\
3. & Concentration of development (within walking distance of stations) \\
4. & Compactness (development, communities, residential living) \\
5. & Compatibility \\
6. & Convenience \\
7. & Densification \\
8. & Development \\
9. & Development growth near station locations \\
10. & Diverse housing choices \\
11. & Employment nodes \\
12. & Employment Areas \\
13. & Enterprise Areas \\
14. & High-density development patterns \\
15. & Highly specialized nodes \\
16. & Inclusive development \\
17. & Infill development \\
18. & Intensity, intensified, intensification \\
19. & Land use (restructuring and/or regeneration, intensification) \\
20. & Mixed use centres \\
21. & Mixed-use development \\
22. & Park and Ride facilities \\
23. & Smart growth \\
24. & Station-area development \\
25. & Sustainability \\
26. & Sustainable development \\
27. & Sustainable transportation network \\
28. & Transportation hub/ Intermodal connections \\
29. & Town Centres \\
30. & Transit-focused development \\
31. & Transit-supportive (land use patterns, jobs) \\
32. & Zoning \\
\hline & \\
\hline
\end{tabular}

* Listed in alphabetical order 
The first three phases are largely preparatory and allow for screening, critiquing, and testing the questions in order to check for errors, and to allow for alternative suggestions. The final two phases consist of the main interview phase, followed by the assessment of responses. This process is explicitly designed to evaluate the formulated operational procedures, investigate possible alternative procedures to conduct the research, and provide a final check of the operational plan before the actual interviews occur (Ackoff: 1953). The steps in each phase of the design-evaluation process are indicated in Figure 4.1 and are then briefly discussed in the text.

For the interview process of the research, two different approaches were adopted: email interviews and semi-structured face-to-face interviews. E-mail was used in the preliminary stages of the interview process, as it provided a practical and convenient means of collecting information.

The interview process consisted of a series of interviews initiated by an e-mail letter sent to all Ottawa municipal elected official candidates in advance of the city council election in November 2003. This letter inquired about the candidates' positions and opinions regarding the O-Train expansion, and the level of importance given to the light rail expansion issue by each candidate. The letter was sent prior to the municipal election, as this would provide an indication of whether or not the light rail expansion issue was a topic being discussed during the municipal campaigns. Once the election was completed, a follow-up e-mail was sent to the elected municipal officials inviting them to participate in a study involving the location, design, and implementation of Ottawa's proposed light rail system.

Thirteen of the twenty-two municipal elected officials expressed interest in 


\section{Figure 4.1}

Phases of the Design-Evaluation Process for Interviewing Municipal Elected Officials

\section{Pilot Study}

- Interviews with selected participants

- Initial screening of questions

- Screening of key terms/phrases

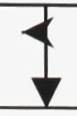

\section{Pretest}

- 2-3 city councillors participating (2 participants from Transportation Committee)

- $\quad 2^{\text {nd }}$ phase of screening questions

- List of questions modified

Trial Run

- 3-4 city councillors participating

- Participants are a subset of interview population

- Final check on questions

- Results determine legitimacy of conducting interviews

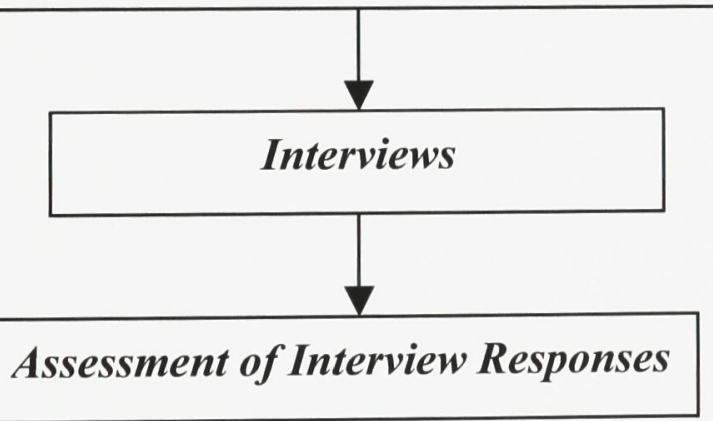


participating in this project. Based on their responses, it was concluded that a feasible research project could be designed using this group of municipal elected officials, as this group is considered a suitable sample of municipal elected officials in that it comprises more than fifty percent of the total city council population. As a result, a series of semistructured interviews were conducted with a selection of municipal elected officials. The interviews were designed to explore whether there is a connection in the minds of the municipal elected officials between the spatial aspects of the proposed light rail expansion and land use planning and transportation planning in the city of Ottawa.

In addition to the questions posed in the interviews, a critical feature of the research design was the creation of a list of key terms/phrases, adapted from the research design by Wellar $(1996,2000 a)$, that would assist in measuring the extent to which the spatial factor is associated with land use planning for the proposed light rail expansion. These key terms/phrases are contained in written materials dealing with the proposed light rail expansion, and are derived from newspaper articles, the academic literature on land use planning and transportation planning, municipal planning documents, and council meeting records. The pilot study participants are asked to select from this list of key term/phrases those which best express or represent their positions or understanding of the land use planning aspect of the proposed light rail expansion.

The details of each research phase are presented in the following sections, along with a description of the list of key terms/phrases used to assess municipal elected officials' knowledge about the spatial aspects of land use planning. 


\subsubsection{Pilot Study}

In this phase of the design-evaluation process, representatives from a pre-defined list of groups are presented a list of preliminary questions designed to identify the extent of regard that municipal elected officials in Ottawa have for the spatial factor related to the proposed light rail expansion. An initial list of interview questions was compiled by the author, and then subjected to evaluation by thesis supervisors to ensure that the questions were pertinent to the study's research questions and objectives. Once the questions had been validated, they were presented to the pilot study participants, who were selected on the basis of their perceived knowledge of the proposed light rail expansion in Ottawa. Representatives from the following groups were identified as key sources of guidance for the interview process:

(I) Community group associations whose wards may contain the proposed light rail corridors (The number of participating community associations is to comprise at least ten associations, all located in proximity to an LRT corridor)

(II) Transport 2000 (national public transit advocacy group)

(III) Municipal public transportation advocacy groups (City Centre Coalition, Federation of Community Associations)

(IV) Academics (university professors selected from Carleton University and the University of Ottawa with a background in urban public transit, land use planning, transportation planning)

Pilot study participants were asked to screen the questions to be posed to the municipal elected officials. This process was successfully used in the Walking Security Index project (Wellar: 1997, 2002), in previous transportation planning design projects (Regional Municipality of Ottawa-Carleton: 1998d, City of Ottawa: 2003e), and to evaluate the transportation corridors to be selected for future rapid transit expansion (City 
of Ottawa: 2003e). Participants were asked to place the questions into one of three categories: (1) Retained (2) Provisional (3) Not Carried Forward, as per the RTES procedure.

The Retained category contains those questions that the participants believe should be retained for future consideration, as they have been deemed pertinent for obtaining the municipal elected officials' knowledge of the spatial factor involved in the light rail expansion. The Provisional category contains questions that show less potential than the first category regarding the indicated subject; however, they may be reconsidered at a later stage. The Not Carried Forward category contains questions that are not regarded as relating to the subject at hand.

As mentioned in Section 4.1, a critical feature of this design-evaluation process is the screening list of key terms/phrases, presented in Table 4.1. These key terms/phrases reveal the extent to which the spatial factor is incorporated in planning for the light rail expansion, and are a central element of the interview process. Briefly, the participants in the pilot study are asked to identify ten terms/phrases from this list that they consider the most important to the land use planning aspect of the light rail expansion. Once all of the participants have selected their ten terms/phrases, a relative numerical weight is assigned to each of the key term terms/phrases, as shown in Figure 4.2. This weight is based on the number of times a particular term/phrase was selected by participants involved in the pilot study stage of the design-evaluation process.

After assigning weights to the terms/phrases, the numerical value representing the number of times a key term/phrase is selected is then multiplied by the assigned weight of each factor to produce a weighted ranking score. The term/phrase with the highest 


\section{Figure 4.2}

Screening Process Used for Identifying Key Terms/Phrases in Design-Evaluation Process
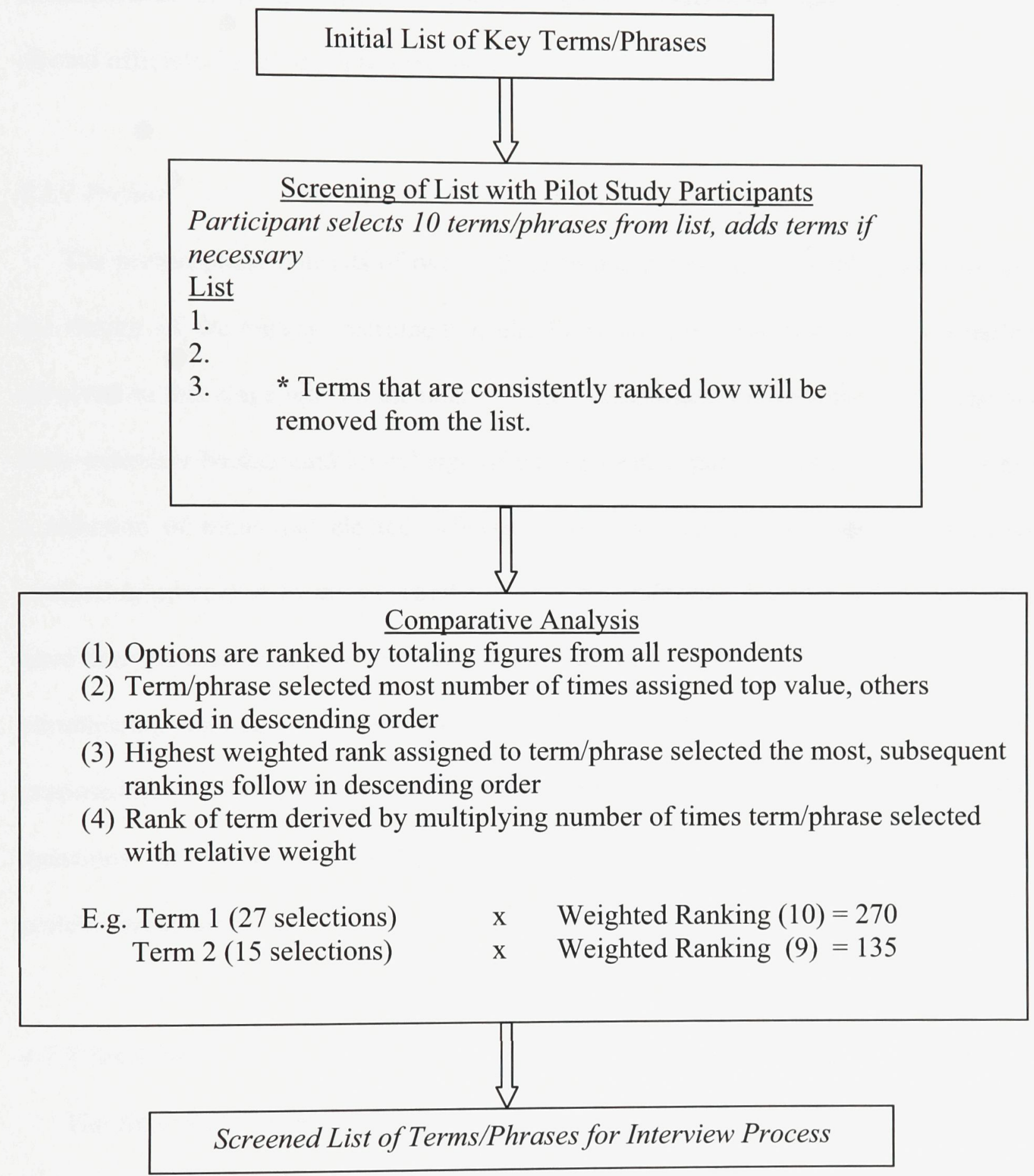
score is rated the most favourable on the list, and those with lower scores are ranked accordingly in descending order. Upon completion of ranking the list of key terms/phrases, the revised list is used to examine the answers provided by the municipal elected officials during the interview process.

\subsubsection{Pretest}

The pretest phase consists of two or three municipal elected officials participating in the design of the survey instrument itself. Preferably, at least two of the councillors involved in this stage will be members of the Transportation Committee (TC), and will have extensive background knowledge of the light rail expansion. The purpose of asking a selection of municipal elected officials to be involved in this stage of the designevaluation process is to assess whether or not the questions from the pilot study phase have been phrased in such a way that they are deemed suitable to be submitted to all the participating municipal elected officials. In this phase, feedback and comments on the proposed questions are encouraged, with an emphasis on the structure and wording of the questions. Any necessary modifications are made based on the input provided by the pretest participants.

\subsubsection{Trial Run}

The final phase of the design-evaluation process serves to confirm whether or not the research will be conducted as planned. Three or four councillors are involved in this phase of the research, including at least one member on the $\mathrm{TC}$ and at least one member who is not on the TC. Both groups of councillors (TC members and non-TC members) 
are included in order to assess whether municipal elected officials not directly involved in municipal transportation affairs are able to evaluate the questions in a manner consistent with municipal elected officials who are members of the Transportation Committee.

The trial run is a critical phase in the design-evaluation process, because it permits an overall evaluation of the research design prior to the main interview phase (Ackoff: 1953; Wellar: 1995). Ideally the original participating councillors from the pretest phase would also be involved in the trial run. The purpose of conducting a trial run with the councillors from the pretest phase (a "sample" of the interview population) is to determine the validity of conducting interviews with all of the municipal elected officials who have indicated a willingness to participate in the research project.

By this stage of the design-evaluation process the interview questions should closely approximate those to be used in the main interview phase. It is anticipated that minor revisions may be required from the feedback provided during the trial run. Upon completion of the trial run, it is expected that the questions are structured in a manner such that the study can proceed with confidence to the interview stage.

\subsubsection{Interviews}

In the interview phase the spatial aspects of the questions on the proposed light rail expansion are posed to the participating municipal elected officials in a semi-structured format. The interviews themselves are situated in an environment that suits the participants, notably their place of employment. In terms of recording the responses a tape-recorder is used, with written dictation and note-taking being employed as a backup procedure in case of technical problems related to the recording device. It was determined 
prior to the interview phase that the interviews would be restricted to a one-on-one format between the researcher and the politicians. Staff members would not be allowed to participate, as this could result in a skewing of the interview responses.

The answers provided by each participant are considered to "speak" only for the person being interviewed. The answers provided are not disclosed to the other participants, in that Councillor X cannot use the answers from Councillor Y. In addition, the questions posed to participating municipal elected officials are presented in an identical manner, and in the same order.

The municipal elected officials who participated in the pretest and trial run stages are not interviewed in the final stage if their answers from the earlier phase(s) are considered sufficient by the researcher. Further, another interview may be deemed unnecessary by the participants if they indicate that they are satisfied with their earlier answers

\subsubsection{Assessment of Interview Responses}

The responses provided by the municipal elected officials in the interviews are subjected to an assessment process. This process involves comparing the responses with the terms/phrases compiled in the pilot study phase, and in plans and documents for the proposed light rail expansion. Media articles are also included, as they are believed to provide another relevant source of reference to the light rail expansion discussions. Further, the responses are also evaluated against maps illustrating the existing and planned residential and employment areas in Ottawa. 
As shown in Figure 4.3, the first element of the assessment process involves determining whether or not the participants mention any of the key terms/phrases from the list derived from the participating groups during the pilot study stage. The key terms/phrases used by the municipal elected officials in the interviews are then compared with the ranked key terms/phrases derived from the written materials dealing with the proposed light rail expansion to determine if the terms/phrases the municipal elected officials use are rated as important in terms of land use planning. That is, this comparison shows the extent to which the terms/phrases provided by the municipal elected officials in their interviews are considered to be associated with the subject of incorporating the spatial factor with the proposed light rail expansion.

The second element of the interview assessment process is to compare the responses of the municipal elected officials with the terms used in the documents for Ottawa's light rail expansion, along with a series of maps illustrating existing and planned residential and employment areas in this city. These maps are designed to visually document the spatial configuration of the proposed light rail expansion corridors, including stations and park and ride facilities relative to the land use component of the city and population distribution within the city. These maps are based on information derived from existing maps produced by the City of Ottawa, information found in documents relating to the light rail expansion, as well as current and projected population figures documented in city planning records. 
Figure 4.3

Phases for Assessment of Municipal Elected Officials Interview Results

Key Terms/Phrase Included in Municipal Elected Officials

Response to Interview Questions

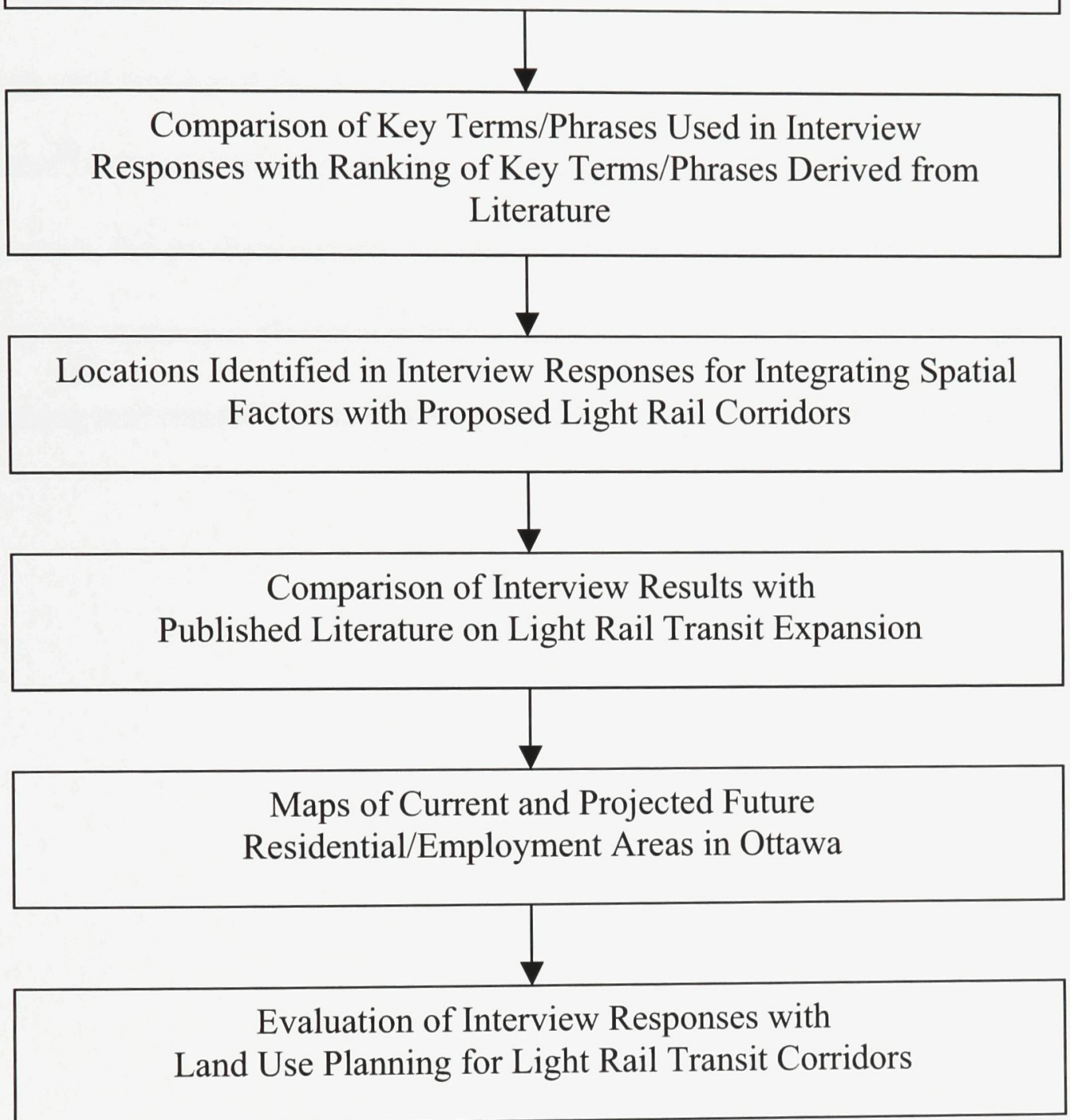




\subsection{Summary}

This chapter discusses the methodological procedures and the research techniques that are implemented in this study. The research design is structured around five interrelated phases that are arranged in an organized pattern to allow for screening, critiquing, and testing of the interview questions, the interviewing of participants, and the assessment of the interview responses. The research techniques consist of several rounds of interviews, the production of a set of original maps, and the use of content analysis for assessing the municipal elected officials' knowledge for the spatial factors that affect land use planning and transportation planning for the proposed light rail expansion. 


\section{CHAPTER 5 DESIGN-EVALUATION PROCESS RESULTS}

This chapter discusses the findings obtained from the operational design process discussed in Chapter 4. The results include an indication of how the list of key terms/phrases identified by the pilot study participants was modified, and a summary of the assessment of the responses provided by municipal elected officials (MEOs) during the interview process. The interview responses are assessed by matching the terms/ phrases used by the respondents with the list of key terms/phrases ranked by the pilot study participants. Further, the responses to the interviews are compared to the literature regarding the spatial factors associated with the proposed light rail expansion in Ottawa. The results are presented in the order in which they were generated in the designevaluation process.

\subsection{Pilot Study Feedback}

As described in Chapter 4, the pilot study phase of the research-design process had two main components. The first component consisted of the participants screening the list of questions to be presented to the MEOs during the interview phase. The second component involved the participants selecting from the overall list of key terms/phrases the ten terms/phrases they considered the most pertinent for assessing the regard shown for the spatial aspect of the proposed light rail expansion.

\subsubsection{Evaluation of Interview Questions}

The participating groups involved in the pilot study phase satisfied several of the predetermined criteria. From the community association groups, the individuals contacted 
Table 5.1

Participation of Pilot Study Contacts

\begin{tabular}{|c|c|c|c|}
\hline \multicolumn{4}{|c|}{ Community Group Associations } \\
\hline WARD & \multicolumn{2}{|c|}{$\begin{array}{l}\text { COMMUNITY } \\
\text { ASSOCIATION }\end{array}$} & Response* \\
\hline 2 Innes & \multicolumn{2}{|c|}{ Blackburn } & Yes \\
\hline 3 Bell- South Nepean & \multicolumn{2}{|c|}{ Southpointe } & \\
\hline & \multicolumn{2}{|c|}{ Barrhaven } & Yes \\
\hline 4 Kanata & \multicolumn{2}{|c|}{ Bridlewood } & Yes \\
\hline & \multicolumn{2}{|c|}{ Fallowfield } & Not Participating \\
\hline & \multicolumn{2}{|c|}{ Katimivik-Hazeldean } & \\
\hline 9 Knoxdale-Merivale & \multicolumn{2}{|c|}{ Merivale Gardens } & \\
\hline 10 Gloucester-Southgate & \multicolumn{2}{|c|}{ Riverside South } & Yes \\
\hline & \multicolumn{2}{|c|}{ Upper Hunt Club } & \\
\hline 14 Somerset & \multicolumn{2}{|c|}{ Dalhousie } & \multirow{2}{*}{ Yes (2 narticinants) } \\
\hline 16 River & \multicolumn{2}{|c|}{ Riverside Park } & \\
\hline 17 Capital & \multicolumn{2}{|c|}{ Heron Park } & Yes \\
\hline & \multicolumn{2}{|l|}{ Glebe } & \multirow[b]{2}{*}{ Yes } \\
\hline & \multicolumn{2}{|c|}{ Old Ottawa South } & \\
\hline & \multicolumn{2}{|c|}{ Hunt Club } & Yes \\
\hline 18 Alta Vista & \multicolumn{2}{|c|}{ Ottawa East } & Yes \\
\hline & \multicolumn{2}{|c|}{ Alta Vista } & Yes \\
\hline 19 Cumberland & South E: & st Innes & Yes \\
\hline Other Organizations/Inc & viduals & & \\
\hline DESCRIPTON & & NAME & Response \\
\hline Public Transit Advocacy & roup & Transport 2000 & Yes \\
\hline $\begin{array}{l}\text { Municipal Public Tran } \\
\text { Advocacy Groups }\end{array}$ & ortation & City Centre Coalition & Yes \\
\hline & & $\begin{array}{l}\text { Federation of Community } \\
\text { Associations }\end{array}$ & \begin{tabular}{|l|l|}
$y$ & Yes \\
\end{tabular} \\
\hline Academics & & Carleton University & Yes (2 participants) \\
\hline
\end{tabular}

* A blank cell indicates no response to invitation. Not Participating means the organization indicated that it would not participate in the research study. 
belonged to community associations that are located either beside or in close proximity to the proposed light rail corridors. In addition, they had some background knowledge of the issues regarding the land use planning aspect of the light rail expansion. For the other groups that were contacted, the participating individuals had a sound knowledge of the proposed light rail expansion, and a background on public transit issues. Table 5.1 shows which groups participated in the pilot study phase.

A total of fifteen associations/groups (seventeen individuals) were involved in the pilot study phase of the research-design process. This was considered a sufficient number of representatives from a series of public groups and institutions, as more than half of the contacted community association groups participated, as did several organizations that have an interest in public transportation issues in Ottawa. The participants' task was to screen the initial list of questions proposed for the interviews with the municipal elected officials, as shown in Table 5.2

Table 5.2

Potential Questions for Municipal Elected Officials

1. In your opinion, what are the major factors that determine where the location of the proposed light rail routes should be?

2. List five objectives that you would deem necessary in selecting the optimum location for these routes ( 1 being the most important, 5 being the least important).

3. Do you agree with the location of the proposed routes? Please explain.

4. Are there viable alternative corridors that in your opinion would be better suited for the proposed light rail expansion? If so, why?

5. In terms of land development, will the proposed light rail routes have any effect on established communities within the city? Please explain.

6. Will the location of the proposed light rail routes be integrated with future planned residential and employment growth? Please explain your answer. 
The participants were asked to screen the questions for their pertinency in obtaining information on municipal elected officials' knowledge of the spatial factor involved in the light rail expansion. The participants were asked to rate the question and assign them to one of the following categories:

(1) (R)-Retained

(2) (P)-Provisional

(3) (N)-Not Carried Forward

In addition to the above broad assessment of each question, the participants were encouraged to provide detailed feedback on the questions, and suggest any additional questions they thought should be included in the list. Whether a question was revised or discarded altogether depended on how the respondents classified it, and their verbal feedback. For example, if it was generally believed that a particular question should be retained and the verbal feedback was positive, then little revision was necessary. On the other hand, if all of the participants thought that a certain question needed to be substantially revised, then this was done prior to the pretest phase. The feedback provided by these individuals was used to answer the question about whether major alternative procedures would have to be conducted in order to satisfy the research question. The results of the screening process for each question are provided in Table 5.3.

The questions were then modified based on the assignments and the comments. Additional questions for the interview phase were also proposed by several participants. This set of additional questions was subsequently analyzed to determine if they were suitable for inclusion in the next step of the research-design process. Upon completion of a pertinency test, consisting of assistance from academic supervisors in reviewing the relevancy of these questions, it was decided that none of the additional questions 
Table 5.3

\section{Results of Feedback on Interview Questions*}

\begin{tabular}{|l|l|l|l|l|}
\hline QUESTION & $\begin{array}{l}\text { (R) } \\
\text { RETAINED }\end{array}$ & $\begin{array}{l}\text { (P) } \\
\text { PROVISIONAL }\end{array}$ & $\begin{array}{l}\text { (N) } \\
\text { NOT CARRIED } \\
\text { FORWARD }\end{array}$ & RESULT \\
\hline \hline $\mathbf{1}$ & 12 & 3 & 0 & slight revision \\
\hline $\mathbf{2}$ & 5 & 9 & 1 & major revision \\
\hline $\mathbf{3}$ & 6 & 6 & 3 & major revision \\
\hline $\mathbf{4}$ & 10 & 4 & 1 & moderate revision \\
\hline $\mathbf{5}$ & 7 & 8 & 0 & major revision \\
\hline $\mathbf{6}$ & 7 & 6 & 2 & major revision \\
\hline
\end{tabular}

*Two participants were unable to complete this section of the pilot study

would be included for future evaluation. A full illustration of how the questions were modified for the pretest phase is provided in Appendix II, and the redesigned questions are illustrated in Table 5.4.

\subsubsection{Evaluation of Key Terms/Phrases}

The second section of the pilot study phase asked participants to evaluate a list of key terms/phrases associated with the land use planning aspect of the proposed light rail expansion, as shown earlier (Table 4.1). This list was derived from a variety of sources that deal with the spatial factor associated with land use planning for the proposed light rail expansion, including the learned literature, official plans, municipal documents and newspaper sources. The participants' task was to select ten terms/phrases from the list that they regarded as most pertinent to the land use planning aspect of the light rail expansion. 
Table 5.4

\section{Revised Interview Questions from Pilot Study Participant}

1. In your opinion, what are the major factors/aspects that determine where the location of the proposed light rail routes should be?

2. Please list five objectives that you would deem necessary in selecting the optimum location for the proposed routes ( 1 being the most important, 5 being the least important).

3. Assuming the proposed routes will be built, do you support the location of the proposed North-South expansion and the East-West routes as displayed in the city's transit plans? Please explain why.

4. In your opinion, are there alternative corridors that are viable (workable) in an overall sense that would be better suited for the proposed light rail expansion?

5. In terms of land use development, (if you prefer, within and in proximity to your respective ward), will the proposed light rail routes have any significant effect on the established communities within the new City of Ottawa? Please explain.

An example of an established community is one whose residential and institutional infrastructure has been completed (such as Alta Vista, Glebe, Bells Corners, unlike communities in Riverside South, South East Innes area).

6. How will the location of the proposed light rail routes be integrated with future residential and employment growth? Please explain your answer.

Once all of the participants had completed this selection process, the individual terms/phrases were ranked according to the number of times it had been selected by the participants. That is, the terms/phrases selected the most were ranked the highest, while the terms/phrases that were selected the least number of times were ranked the lowest. The rankings are shown in Table 5.5, with the complete responses of individual participants appearing in Appendix III. The terms/phrases were grouped into three categories; Highly Related, Moderately Related, and Less Related. As suggested, the groupings assign the terms/phrases relative positions with regard to their perceived ability 
Table 5.5

\section{Categorization of Key Terms/Phrases from Pilot Study Evaluation}

\begin{tabular}{|l|c|l|c|c|c|}
\hline \multicolumn{1}{|c|}{ HIGHLYRELATED } & & MODERATELY RELATED & & LESS RELATED & \\
\hline & VOTES & & VOTES & & VOTES \\
\hline Park-and-Ride facilities & 11 & Convenience & 6 & Densification & 3 \\
\hline $\begin{array}{l}\text { Land Use (restructuring and/or } \\
\text { regeneration, intensification) }\end{array}$ & 10 & Employment Areas & 6 & Infill Development & 3 \\
\hline Transportation hub & 9 & Mixed use centres & 6 & Station-area development & 3 \\
\hline $\begin{array}{l}\text { Transit-supportive } \\
\text { (land use patterns, jobs) }\end{array}$ & 9 & $\begin{array}{l}\text { Clustering (around rail stations, } \\
\text { of neighbourhood facilities) }\end{array}$ & 6 & Compatibility \\
\hline $\begin{array}{l}\text { Accessibility } \\
\text { (employment centres) }\end{array}$ & 8 & $\begin{array}{l}\text { Compactness (development, } \\
\text { communities, residential living) }\end{array}$ & 5 & $\begin{array}{l}\text { High-density } \\
\text { development patterns }\end{array}$ & 2 \\
\hline $\begin{array}{l}\text { Concentration of development } \\
\text { (within walking distance of } \\
\text { stations) }\end{array}$ & 8 & Diverse housing choices & 5 & Inclusive development \\
\hline $\begin{array}{l}\text { Development growth } \\
\text { near station locations }\end{array}$ & 7 & $\begin{array}{l}\text { Intensity, intensified, } \\
\text { intensification }\end{array}$ & 2 \\
\hline Employment nodes & 7 & Sustainability & 5 & Mixed-use development & 2 \\
\hline Town centres & 7 & Sustainable development & 5 & Highlyspecialized nodes & 1 \\
\hline & & Smart Growth & 4 & Enterprise Areas \\
\hline
\end{tabular}

to represent the most pertinent spatial factors associated with the proposed light rail expansion. The total number of times a key term/phrase was selected determined the placement of this term/phrase into what was deemed the appropriate category.

The exercise of ranking the key terms/phrases by the pilot study participants yielded a wide variety of responses. It was initially considered that the top ten selections would be included in the interview process. However, due to the significant number of "ties" in the voting for the selections, this consideration was revised. Instead, the terms/phrases selected in the Highly Related and Moderately Related categories are retained for analysis with the interview process. These terms/phrases are given the utmost importance when evaluating the responses to the interview questions. Entries in the Less Related category are not completely disregarded, even though the terms/phrases in this category were deemed by the pilot study participants to be marginally related to the language used in 
associating land use planning with the light rail expansion. The reasoning here is that these terms/phrases are prominent in the literature, so if the responses from the interviews include these terms/phrases, then they deserve some consideration in the evaluation of the interviews.

\subsection{Pretest Feedback}

Three municipal elected officials (MEOs) participated in this phase of the designevaluation process, and all were members of the Transportation Committee. These participants assessed the list of questions screened during the pilot study phase to determine if the language and the formatting of the questions were structured in a manner suitable for the interview participants. This exercise produced only one minor alteration to the questions. It was noted that the questions should be using the word corridors instead of routes, because the corridors are a more pressing issue. This stems from the fact that the corridors must be selected first prior to any deliberations on the location of the specific routes, and the routes are the paths built within the specified corridor. The revised list of questions is provided in Appendix IV.

In planning the design-evaluation process, the participants of the pretest phase were initially only to screen the questions that had been revised during the pilot study phase, in order to ensure that the questions were pertinent for the interviews, and to identify any potential, alternative operational procedures. While it would be up to the pretest participants to indicate what sort of alternative procedures they would favour, one example could have been changing the order of the questions. 
Prior to conducting the pretest phase however, procedures were modified. During the scheduled appointments with the pretest participants, they were provided the option of responding to the interview questions during this same meeting period. All three participants agreed to this option, and therefore the MEOs who participated in the pretest phase of screening the questions provided responses during one scheduled meeting for both the pretest evaluation and the interview questions. The responses of the pretest participants to the revised interview questions are presented in Section 5.4.

One question that arises with this procedure is how was it possible for the participating MEOs to respond and revise the questions simultaneously. For example, what if the third participant suggested revising the questions, therefore making it necessary to set up another round of interviews with the two other pretest participants? Fortunately, this situation did not occur, and as a result another set of interviews was not required.

\subsection{Trial Run}

The trial run is the third and final phase of the design-evaluation process, and it provides a means to make final adjustments in the research procedures, and to decide whether the research is to be conducted as planned. In other words, it evaluates the operational plan of this research procedure in its entirety prior to the final stage (Ackoff: 1953, p. 337), which in this research study involves interviews with the municipal elected officials.

Four officials participated in the trial run phase, with two of the participants being members of the Transportation Committee. This was considered an ideal selection of 
municipal elected officials, as half of the participants were regularly employed in discussions about the proposed light rail expansion, while the other half were not. Therefore, the verification as to whether the research would proceed as planned would be evaluated by two councillors who already had the opportunity to be aware of the updated issues surrounding the proposed O-Train expansion, and by two councillors who presumably had a knowledge of this expansion, but were not serving on a committee dedicated to transportation issues.

The participants were requested to evaluate the set of revised questions from the pretest phase, to provide feedback on the list of questions, and advise whether or not all of the MEOs invited to participate in the interview process would likely have a common understanding of the language and structuring of the questions. The feedback and comments did not suggest a revision of questions or a change in the order of questions.

Similar to the procedure of the pretest phase, and again in the interests of time and to accommodate busy schedules, the councillors were provided the option of responding to the interview questions during the initial meeting. All four councillors accepted this offer and again, as in the pretest phase, the participants provided their responses to the set of questions immediately following the screening exercise.

\subsection{Interview Responses}

Several months passed between the invitation extended to the MEOs asking for their participation in this research project and the actual interviews being conducted. Initially, twelve of the twenty-two MEOs indicated that they would participate in the research project, and with a participation level of more than $50 \%$, the research study proceeded. 
Ultimately, only eleven municipal elected officials participated in the study. Table 5.6 shows the list of municipal elected officials who actually participated in the interview process.

To ensure comparability of the answers provided by the respondents, the wording and the order in which the questions were asked were almost completely identical (see below) for each participant to avoid influencing responses as much as possible. Although a sample of the interview candidates participated in two phases of the design-evaluation process, the results of the screening process in these phases did not produce any substantial changes to the wording of the interview questions, with the lone exception of substituting the term corridors in place of routes as described in Section 5.2. The set of questions presented to the MEOs after the completion of the final revision process is shown in Table 5.7.

All of the MEOs answered each question, which eliminated the need to guess or estimate how to deal with missing answers. In the following pages, each question is presented, followed by a description of the range of responses provided by the participants, and then by an overall assessment of the responses. The complete responses of each municipal elected official are documented in Appendix V. 
Table 5.6

List of Municipal Elected Official Participants in Interview Process

\begin{tabular}{|l|l|l|}
\hline COUNCILLOR & WARD & RESPONSE ** \\
\hline Kreling, H. & 1 Orleans & \\
\hline Bloess, R. ${ }^{*}$ & 2 Innes & Yes \\
\hline Harder, J. & 3 Bell- South Nepean & \\
\hline Feltmate, P. & 4 Kanata & Yes \\
\hline El-Chantiry, E. ${ }^{*}$ & 5 West Carleton & Yes \\
\hline Stavinga, J. ${ }^{*}$ & 6 Goulburn & \\
\hline Cullen, A. ${ }^{*}$ & 7 Bay & Yes \\
\hline Chiarelli, R. & 8 Baseline & \\
\hline Hunter, G. & 9 Knoxdale-Merivale & \\
\hline Deans, D. & 10 Gloucester-Southgate & Yes \\
\hline Bellemare, M. & 11 Beacon Hill-Cyrville & Yes \\
\hline Bedard, G. ${ }^{*}$ & 12 Rideau-Vanier & Yes \\
\hline Legendre, J. ${ }^{*}$ & 13 Rideau-Rockliffe & Yes \\
\hline Holmes, D. & 14 Somerset & Not Participating \\
\hline Little, S. & 15 Kitchissippi & \\
\hline McRae, M. ${ }^{*}$ & 16 River & Yes \\
\hline Doucet, C. ${ }^{*}$ & 17 Capital & Yes \\
\hline Hume, P. & 18 Alta Vista & Yes \\
\hline Jellet, R. & 19 Cumberland & \\
\hline Thompson, D. ${ }^{*}$ & 20 Osgoode & \\
\hline Brooks, G. & 21 Rideau & \\
\hline Chiarelli, B. ${ }^{*}$ (ex officio) & Mayor & \\
\hline & & \\
\hline
\end{tabular}

* Indicates Transportation Committee member

** A blank cell indicates either no response to follow-up invitation or unable to participate on account of time constraints. Not Participating means the councillor indicated that they would not participate in the research study. 
Table 5.7

Interview Questions Presented to Municipal Elected Officials

1. In your opinion, what are the major factors/aspects that determine where the location of the proposed light rail corridors should be?

2. Please list five objectives that you would deem necessary in selecting the optimum location for the proposed corridors ( 1 being the most important, 5 being the least important).

3. Assuming the proposed corridors will be built, do you support the location of the proposed North-South expansion and the East-West routes as displayed in the city's transit plans? Please explain why.

4. In your opinion, are there alternative corridors that are viable (workable) in an overall sense that would be better suited for the proposed light rail expansion?

5. In terms of land use development, (if you prefer, within and in proximity to your respective ward), will the proposed light rail corridors have any significant effect on the established communities within the new City of Ottawa? Please explain.

An example of an established community is one whose residential and institutional infrastructure has been completed (such as Alta Vista, Glebe, Bells Corners, unlike communities in Riverside South, South East Innes area).

6. How will the location of the proposed light rail corridors be integrated with future residential and employment growth? Please explain your answer. 


\section{Question 1}

In your opinion, what are the major factors/aspects that determine where the location of the proposed light rail corridors should be?

\section{Response}

Several major factors/aspects were identified, such as the availability of corridors in which to operate the LRT, the distribution of the current residential population, the location of future residential growth, the results of the Environmental Assessment (EA), the need for development hubs around the light rail stations, and cost. The answers that were mentioned by at least two participants were: availability of corridors, current population/future population growth, and the results of the EA should determine the location of the light rail corridors. Almost half of the participants considered the availability of corridors and the current population/future population to be the major factors/aspects associated with location.

\section{Question 2}

Please list five objectives that you would deem necessary in selecting the optimum location for the proposed corridors (1 being the most important, 5 being the least important).

\section{Response}

This exercise in the ranking of objectives indicated that no single objective is highly ranked by all of the participants. In fact, each participant had a different idea about what should be the most important objective in selecting the optimum location for the proposed corridors. However, included in the highest ranked objectives were: connectivity between growth areas and employment areas; cost; advanced community planning around the LRT lines; shortened transit time; complete integration with rapid transit system in Ottawa; and corridors have to serve certain densities of the city's population. 
Although the respondents could not agree on a single most important objective, the most frequently mentioned objectives are, in order from highest count to lowest: cost considerations, ridership, operating through major growth areas, influencing future residential/employment growth, environmental issues, integration with current rapid transit infrastructure, and compact development around transit stations. Each objective listed above received at least two "votes".

While cost was the objective most frequently mentioned, it only received one highest ranking vote, with the rest of the votes occurring towards the bottom of the list. This is not meant to portray cost as an unimportant main objective, but simply to observe that it was predominantly a lower-ranked objective.

\section{Question 3}

Assuming the proposed corridors will be built, do you support the location of the proposed North-South expansion and the East-West corridor as displayed in the city's transit plans? Please explain why.

\section{Response}

Ten of the eleven participants supported the location of the North-South expansion, with one participant in disagreement of this expansion. Nine participants supported the proposed location of the East-West corridor, with two in disagreement. A variety of reasons for supporting or not supporting the locations of the proposed corridors were given, although respondents usually gave an overall opinion for both corridors, rather than for each corridor individually. The reasons for being supportive/unsupportive included: wanting to build towards growth areas in the southern end of the city (supportive); servicing fastest growing areas of city (supportive); corridors run through dense residential/employment areas (supportive/unsupportive); planned corridors are 
cheapest option (supportive); and the corridors have a great potential to change development patterns in new growth areas (supportive).

\section{Question 4}

In your opinion, are there alternative corridors that are viable (workable) in an overall sense that would be better suited for the proposed light rail expansion?

\section{Response}

Most of the respondents ( 8 of 11) stated that there were no alternative corridors that could be considered suitable for the light rail expansion, citing a number of reasons. The most frequently mentioned reason was the cost associated with other corridors. In addition, a few respondents believed that possible alternative corridors are those without existing tracks in place, and therefore it would be much too costly to build within these corridors. Other reasons were that land would have to be expropriated from landowners (costly for City to purchase land), and that there are no other viable corridors.

Participants who thought that there are possible alternative corridors, primarily identified for the proposed East-West corridor, stated that the proposed corridor does not properly serve the existing residential communities along parts of the line. Comments speaking against the current proposed corridor included such feedback as the proposed East-West corridor runs along the fringes of residential areas (not considered sufficient), and that regional road corridors could be a more optimal solution. One other respondent in favour of selecting an alternative corridor contended that the corridors for the light rail expansion should serve residential populations where they are located, and should take into account the travel preferences of the residents of this city. 


\section{Question 5}

In terms of land use development (if you prefer, within and in proximity to your respective ward), will the proposed light rail corridors have any significant effect on the established communities within the new City of Ottawa? Please explain.

\section{Response}

With the exception of one response, all of the participants thought that the proposed corridors would have a significant effect on land use development within existing communities. The initial reply to this question prior to the respondents' explanation portrayed a strong belief in the answers provided, as many of the responses began their responses with the terms "definitely" and "absolutely". Those participants who hold this opinion provided a variety of reasons, with the main reasons summarized as follows. Several participants indicated that the light rail expansion will encourage intensification of residential communities and development projects, and the development of businesses and employment areas in proximity to the LRT corridors. Some of the responses emphasized that there will be a greater transportation choice for people, that the rail service will provide a better transportation choice, allow for more people to move more easily around the city, and will decrease the number of cars on the roads and the costs associated with maintaining the automobile-related infrastructure.

\section{Question 6}

How will the location of the proposed light rail corridors be integrated with future residential and employment growth? Please explain your answer.

\section{Response}

All of the participants replied that in some form the location of the proposed light rail expansion would generate a positive relationship with future residential and employment growth. Most of the responses provided by the municipal elected officials indicated that the selection of the corridors would result in intensified growth occurring around the 
rapid transit stations. The replies included ideas such as mixed-use growth, integrating the light rail lines with town centres and employment nodes, and high density residential areas developed around the stations. In addition, it was suggested by a few respondents that the light rail corridors would cause future growth of housing and employment to be located in proximity to the lines and the stations.

\subsection{Comparison of Interview Responses with Key Terms/Phrase}

The first stage in evaluating responses provided by municipal elected officials on their knowledge of the spatial aspect of the proposed light rail expansion compares their responses with the screened list of key terms/phrases. The nature of this examination is illustrated by Table 5.8 .

The matching of key terms/phrases to the responses of the interview questions is not meant to represent a complete evaluation of the extent of the municipal elected officials' knowledge on the research topic. Rather, its purpose is to create a record of whether or not municipal elected officials are using terms and phrases that are commonly associated with land use planning. The associated interpretation is that while use of the "proper" language is not sufficient to conclude that the municipal elected officials have seriously considered the link between land use planning and the proposed light rail expansion, it is an indication that they might have done so.

A potential problem arises however, if the interview questions did not elicit any or very few of the listed key term/phrases in the participant's responses to the six questions. This could be interpreted in one of two different ways, either the questions were not phrased properly, or the lack or absence of key terms/phrases mentioned is related to 
Table 5.8

Key Terms/Phrases Included in Municipal Elected Officials

Responses to Interview Questions

\begin{tabular}{|c|c|c|c|c|c|c|}
\hline \multicolumn{7}{|c|}{ KEY TERMS/PHRASES USED IN INTERVIEW RESPONSES * } \\
\hline PAR & TICIPANT & & QUESTION & & & \\
\hline & 1 & 2 & 3 & 4 & 5 & 6 \\
\hline A & NR & $\begin{array}{l}\text { concentration of } \\
\text { development }\end{array}$ & NR & NR & park and ride facilities & $\begin{array}{l}\text { (1) mixed use development } \\
\text { (2) land use intensification } \\
\text { (3) employment nodes } \\
\text { (4) densification } \\
\text { (5) diverse housing choices }\end{array}$ \\
\hline B & NR & employment areas & NR & NR & $\begin{array}{l}\text { (1) land-use } \\
\text { intensification } \\
\text { (2) compactness } \\
\text { (residential living) } \\
\end{array}$ & $\begin{array}{l}\text { (1) development growth } \\
\text { near stations } \\
\text { (2) densification }\end{array}$ \\
\hline C & NR & $\begin{array}{l}\text { (1) convenience } \\
\text { (2) accessibility } \\
\text { (3) concentration of } \\
\text { development }\end{array}$ & $\begin{array}{l}\text { (1) convenience } \\
\text { (2) mixed-use } \\
\text { centres }\end{array}$ & NR & $\begin{array}{l}\text { (1) clustering } \\
\text { (2) mixed-use centres } \\
\text { (3) sustsainable } \\
\text { development }\end{array}$ & NR \\
\hline D & $\begin{array}{l}\text { (1) accessibility } \\
\text { (2) densification }\end{array}$ & NR & NR & NR & $\begin{array}{l}\text { (1) accessibility } \\
\text { (2) employment areas }\end{array}$ & $\begin{array}{l}\text { (1) transit-supportive } \\
\text { (land-use patterns) } \\
\text { (2) transit-focused } \\
\text { development }\end{array}$ \\
\hline E & $\begin{array}{c}\text { park and ride } \\
\text { faciliities }\end{array}$ & accessibility & NR & NR & NR & NR \\
\hline $\mathbf{F}$ & $\begin{array}{l}\text { land-use } \\
\text { (intensification) }\end{array}$ & \begin{tabular}{|l|} 
(1) transit-focused \\
$\quad$ development \\
(2) densification \\
(3) employment areas \\
(4) transit-supportive \\
(land-use patterns)
\end{tabular} & NR & NR & $\begin{array}{l}\text { (1) intensification } \\
\text { (2) land-use } \\
\text { (restructuring) }\end{array}$ & $\begin{array}{l}\text { (1) land-use (restructuring) } \\
\text { (2) mixed-use development } \\
\text { (3) employment nodes } \\
\text { (4) intensification } \\
\text { (residential) }\end{array}$ \\
\hline G & NR & NR & densification & NR & NR & $\begin{array}{l}\text { (1) town centres } \\
\text { (2) station-area development }\end{array}$ \\
\hline $\mathrm{H}$ & NR & NR & NR & convenience & NR & $\mathrm{NR}$ \\
\hline I & NR & $\begin{array}{l}\text { transit-focused } \\
\text { development }\end{array}$ & NR & $\begin{array}{l}\text { (1) development } \\
\text { (2) densification }\end{array}$ & NR & $\begin{array}{l}\text { (1) transit-focused } \\
\text { development } \\
\text { (2) zoning }\end{array}$ \\
\hline$J$ & $\begin{array}{l}\text { (1) transit-focused } \\
\text { development } \\
\text { (2) development } \\
\text { growth near } \\
\text { station locations }\end{array}$ & $\begin{array}{l}\text { (1) compactness } \\
\text { (development) } \\
\text { (2) development } \\
\text { growth near station } \\
\text { locations }\end{array}$ & $\begin{array}{l}\text { (1) transit- focused } \\
\text { development } \\
\text { (2) employment } \\
\text { areas }\end{array}$ & NR & $\begin{array}{l}\text { intensification } \\
\text { (development) }\end{array}$ & $\begin{array}{l}\text { (1) development } \\
\text { (2) transit-focused } \\
\text { development } \\
\text { (3) densification } \\
\text { (4) development growth } \\
\text { near station locations } \\
\text { (5) mixed-use centres } \\
\text { (6) transit-supportive } \\
\text { (land-use patterns) }\end{array}$ \\
\hline K & NR & $\begin{array}{c}\text { (1) densification } \\
\text { (2) transit-focused } \\
\text { development }\end{array}$ & NR & NR & mixed-use development & $\begin{array}{l}\text { transit-focused } \\
\text { development }\end{array}$ \\
\hline
\end{tabular}

* NR: Response did not include key term/phrase 
the responses provided by the interview participants. In the latter case, the lack or absence of key terms/phrases being mentioned has to do with the response side and not with the questions that are posed. Since the interview questions were designed via the design-evaluation process (as outlined in Chapter 4) to enable the interview participants to structure their responses to include a spatial context, it is believed that any potential lack of key terms/phrases mentioned in the MEOs responses stems not from the wording of the questions, but instead is due to the responses provided.

The comparison of interview responses to the list of key terms/phrases may then also be used as a post-interview validity test on the interview questions. That is, the validity of each question can be tested against the language that is used in relation to land use planning for the proposed light rail expansion. In brief, if the responses to all six questions include any of the listed key terms/phrases, then this finding can be taken to demonstrate that the questions were successfully structured to yield responses regarding the municipal elected officials' views on the spatial aspect of the proposed light rail expansion.

One other item to address in this regard is whether it is possible that the participant(s) could be very aware intuitively of the spatial factor associated with the proposed light rail expansion, but may not have been able to express their ideas clearly in spatial terms in their responses to the interview questions.

This issue needs to be fully addressed prior to the evaluation stage of the interview responses, as it could be construed that the results discussed in this study would not accurately portray how the MEOs consider the link between land use planning and transportation planning in regard to the proposed light rail expansion. That is, if a lesser 
number of key terms/phrase were provided by the interview participant(s) in their responses, then it could reasonably be argued that these participants have less of an appreciation for the spatial factor of the proposed light rail expansion than the participants who included a large number of key terms/phrases in their responses.

The tables and written documentation to follow do not necessarily allow for a full interpretation of the responses. However, the face-to-face interviews provided a strong indication as to the amount of knowledge that a politician has on a particular topic, regardless of the specific language used in responses. That is, if the responses to any of the six interview questions were limited in terms of the length of answers, the participant(s) did not provide examples when asked, and did not elaborate on responses, then all signs point in the direction of limited knowledge on the research topic. And conversely, if a participant's responses were presented at great length, and contained various key terms/phrases, they could then be construed to have a larger appreciation for the spatial factor related to the proposed light rail expansion.

Returning to the assessment of the interview responses with the screened list of key terms/ phrases, as noted previously in this section, Table 5.8 lists the key terms/phrases as they appear in the revised list, although the actual language used by the participants might differ slightly. This "editing" procedure is applied in cases where the exact phrase used by the participant varies slightly from those on the list. This is done in order to avoid confusion as to which terms are applied to the association between land use planning and the proposed light rail expansion. It is emphasized that the participant's responses were not being modified, but that assignment of responses was necessary in order to properly assemble and interpret the results of the interviews. 
Table 5.8 displays the various key terms/phrases that were used in the MEOs responses to the interview questions, and demonstrates the wide range in the use of key terms/phrases by the respondents. For example, Participant $\mathbf{J}$ included a variety of key terms/phrases in the responses to five questions, while Participant $\mathrm{H}$ included a key term/phrase in the response to one question. The average number of questions in which the respondents used a key term/phrase was 2.9 , or in slightly less than half of the questions.

With the list of key terms/phrases having been categorized during the pilot study phase of the design-evaluation process, this revised list can be utilized in analyzing the interview responses. Key terms/phrases from the screened list were mentioned a total of sixty-four times ( including duplicates), with some of the terms/phrases duplicated within one participants' own responses to the set of questions, and duplicated within their fellow participants' responses. Of the thirty-two key terms/phrases included in the screened list, twenty-two were mentioned in the MEOs answers. A classification of the key terms/phrases mentioned during the interview responses is illustrated in Table 5.9.

A brief evaluation of the grouping of the key terms/phrases used in the MEOs answers demonstrates that a substantial majority of the terms/phrases are found under the highly or moderately related headings. This finding illustrates the fact that in the responses provided by Ottawa's MEOs, almost $80 \%$ (50/64) of the mentioned terms/phrases are relevant when they are discussing the spatial factor associated with the proposed light rail expansion. 


\section{Classification of Key Terms/Phrases Mentioned in Interview Responses}

\begin{tabular}{|l|c|c|}
\hline Category & $\begin{array}{c}\text { Key Terms/Phrases } \\
\text { mentioned (total } \\
\text { number of terms) }\end{array}$ & $\begin{array}{c}\text { Total Count of } \\
\text { Key } \\
\text { Terms/Phrases }\end{array}$ \\
\hline Highly Related & 8 of 9 & 23 of 64 \\
\hline Moderately Related & 10 of 13 & 27 of 64 \\
\hline Less Related & 4 of 10 & 14 of 64 \\
\hline
\end{tabular}

The other fourteen terms/phrases mentioned should not be completely disregarded, because as noted above, they can still be found in the literature on the relationship between land use planning and transportation planning. Therefore, although they were not considered to be the most popular terms for municipal elected officials to use when discussing the land use planning component of the proposed light rail expansion, the fact that they are used on an occasional basis calls for their inclusion in the evaluation of the interview results.

An interpretation of the findings from the key terms/phrases mentioned in the interview responses provides a more in-depth evaluation of the responses provided by the MEOs. Since the MEOs were asked six questions during the interview, on average almost half (2.9) of the questions had a reply that included the consideration of the spatial factors associated with this proposed light rail expansion. The number of questions that each MEO responded to that included key terms/phrases is reported in Table 5.10.

Interpretation of Table 5.10 suggests that for the purposes of the research, it is appropriate to begin the interpretation phase by creating two classes of responses: those which included any of the key terms/phrases in their response to four or more questions, and those that answered three or fewer questions using any of the key terms/phrases. This 
Table 5.10

Number of Responses Containing Key Terms/Phrases

\begin{tabular}{|l|c|c|c|c|c|c|c|c|c|c|c|}
\hline & \multicolumn{10}{|c|}{ PARTICIPANT } \\
\cline { 2 - 10 } & $\mathrm{A}^{*}$ & $\mathrm{~B}^{*}$ & $\mathrm{C}^{*}$ & $\mathrm{D}$ & $\mathrm{E}^{*}$ & $\mathrm{~F}$ & $\mathrm{G}^{*}$ & $\mathrm{H}$ & ${ }^{*}$ & $\mathrm{~J}$ & ${ }^{*} \mathrm{~K}$ \\
\cline { 2 - 10 } $\begin{array}{l}\text { RESPONSES } \\
\text { CONTAINING KEY } \\
\text { TERMS/PHRASES }\end{array}$ & 3 & 3 & 3 & 3 & 2 & 4 & 2 & 1 & 3 & 5 & 3 \\
\hline
\end{tabular}

* Transportation Committee Member

division into two classes between the numbers 3 and 4 was selected as this represents the halfway mark in the number of interview questions. As shown in Table 5.10, only two MEOs answered four or more questions with responses that included key terms/phrases, while nine participants used key terms/phrases in three or fewer questions. Moreover, six of the eleven participants mentioned key terms/phrases in three of the responses, which further emphasizes the "centrality" of the responses: median $=3$, mode $=3$, mean $=2.91$.

One preliminary interpretation is that since fewer than half of the responses to the interview questions included any key terms/phrases related to the land use planning aspect of the proposed light rail expansion, the interviews could be pointing to a potential lack of understanding of this topic by Ottawa's municipal elected officials. However, a more robust interpretation of the findings is provided by evaluating the MEOs' responses within the context of the documented planning of the light rail expansion, a topic that is pursued in Chapter 6. At this stage, however, it appears appropriate to repeat the overall finding from the MEOs responses to the interview questions. On average, responses from the MEOs who participated in the interviews tended to be limited in the frequency that they mentioned the link between land use planning and transportation planning when considering light rail expansion. 
To obtain a more complete understanding of the uses of the key terms/phrases in the MEOs' answers, it is necessary to identify which MEOs are on the Transportation Committee. This is considered critical to the evaluation of the research findings, as it provides an indication of whether or not the members of the Transportation Committee, which is responsible for the O-Train expansion plans, responded differently from MEOs who are not on that committee.

Seven of the eleven respondents are members of the Transportation Committee, and they mentioned key terms/phrases in an average of 2.7 responses, which is below the average for all participants. The MEOs who are not members of the Transportation Committee averaged 3.3 corresponding responses.

While the averages of these two groups cannot be directly comparable due to the difference in the numbers within each group, (seven on the Committee, four not) it seems noteworthy that the participants not belonging to the Transportation Committee achieved the higher scores in this exercise. This finding suggests that some members of the Transportation Committee may not be as knowledgeable on the topic of land use planning in the context of the light rail expansion as those who are non-members, thereby discounting the notion that the MEOs who are members of the Transportation Committee might have an superior knowledge on this topic.

Several significant findings resulted from this phase of the research, and are summarized as follows. First, the design-evaluation process was successful in that the feedback and comments provided in the pilot study phase and subsequent phases allowed for the advancement to the next phase. Second, the number of MEOs (11) who participated in the interview process proved to be sufficient. That is, this number of 
participants allowed for a test of the questions, and they provided information on the extent to which key terms/phrases from the literature are used by MEOs when considering land use planning as an element in light rail expansion.

As for the issue of whether or not the questions would be relevant to the MEOs, this was answered in two different ways. The first was via the pretest and trial run phases in which the participating MEOs screened the questions themselves prior to responding to the questions. And, the second part of the relevancy test was achieved through an evaluation of the key terms/phrases with the interview responses. As shown in the six interview questions, the participants responded by using terms/phrases associated with the spatial factor when discussing the light rail expansion.

The last set of findings presented in this chapter pertains to the assessment of the key terms/phrases used as the vocabulary in the MEOs responses to the interview questions. The findings illustrate that for all of the interview participants, slightly fewer than half of the responses to the questions included terms/phrases that are commonly associated with the spatial aspect of transportation planning. Further in-depth analysis of the responses also reveals that Transportation Committee members as a group did not "out perform" their non-member council colleagues when it came to the vocabulary used to respond to the survey questions. In fact, some members of the Committee "under-performed" in regards to terms/phrases usage. The associated finding, therefore, is that although some of the participants are directly involved in the plans for expanding Ottawa's light rail infrastructure, by virtue of being on the Transportation Committee, they appear to be limited in their understanding of the land use planning aspect, which as noted in Chapter 2 is a critical component of transportation planning. 


\subsection{Summary}

Within this chapter, the findings are discussed following the format of the designevaluation process outlined in Chapter 4. The findings include the evaluation and screening of the interview questions, the categorization of key terms/phrases and the responses to the interview questions. A summary of the range of responses provided by the municipal elected officials is included, followed by a comparison of the interview responses with the key terms/phrases. 


\section{CHAPTER 6 COMPARISON OF PARTICIPANTS' RESPONSES WITH PUBLISHED LITERATURE}

This chapter compares the participants' responses with the published literature on the proposed light rail expansion as well as providing maps that depict the current and proposed residential and employment areas to be developed within the city. An assessment of the participants' responses is provided solely in the context of the spatial factor, and allows for a final evaluation of the extent that municipal elected officials (MEOs) consider the spatial factor in association with light rail corridor deliberations and decisions.

\subsection{Spatial Factor Connection with Planned Growth}

The results of the evaluation process presented in Chapter 5 provides a layer of insight into the consideration that MEOs have given to the land use planning issues related to the proposed light rail expansion. To gain further insight into the extent of knowledge the MEOs have for the link between land use planning and the planned light rail corridors, the next step in the research process is to compare their responses with the contents of published reports which discuss the land use planning issues affecting the proposed light rail expansion.

The point of emphasis therefore, is to examine the interview responses to ascertain whether or not the MEOs provided indications of the location of land use developments in relation to the proposed light rail corridors. Table 6.1 identifies the responses that included an indication of where land use in the city would be associated with proposed light rail corridors. 
Table 6.1

Locations Identified by Municipal Elected Officials' for Integrating

Spatial Factors with Light Rail Transit Corridors

\begin{tabular}{|c|c|c|c|c|c|c|}
\hline \multirow[t]{2}{*}{$\begin{array}{c}\text { MEO } \\
\text { INTERVIEW }\end{array}$} & \multicolumn{4}{|c|}{ QUESTION/RESPONSES* } & \multirow[b]{2}{*}{5} & \multirow[b]{2}{*}{6} \\
\hline & 1 & 2 & 3 & 4 & & \\
\hline A & NR & $\begin{array}{c}\text { Yes } \\
\text { (Kanata, } \\
\text { Barrhaven, } \\
\text { Riverside } \\
\text { South) }\end{array}$ & NR & NR & $\begin{array}{c}\text { Yes } \\
\text { (South } \\
\text { Orleans) }\end{array}$ & $\begin{array}{l}\text { Yes } \\
\text { (Innes) }\end{array}$ \\
\hline B & NR & \begin{tabular}{|c|} 
Yes \\
(dow ntow $n$ ) \\
\end{tabular} & NR & NR & $\begin{array}{c}\text { Yes } \\
\text { (unspecified) }\end{array}$ & $\begin{array}{c}\text { Yes } \\
\text { (Cumberland) }\end{array}$ \\
\hline C & NR & $\begin{array}{c}\text { Yes } \\
\text { (airport) }\end{array}$ & $\begin{array}{c}\text { Yes } \\
\text { (South } \\
\text { Gloucester) } \\
\end{array}$ & NR & $\begin{array}{c}\text { Yes } \\
\text { (unspecified) }\end{array}$ & NR \\
\hline D & $\begin{array}{c}\text { Yes } \\
\text { (Kanata North } \\
\text { Business } \\
\text { Park) } \\
\end{array}$ & NR & NR & NR & $\begin{array}{c}\text { Yes } \\
\text { (Kanata North } \\
\text { Business } \\
\text { Park) }\end{array}$ & $\begin{array}{c}\text { Yes } \\
\text { (North } \\
\text { Kanata) }\end{array}$ \\
\hline$E$ & $\begin{array}{c}\text { Yes } \\
\text { (unspecified) }\end{array}$ & $\begin{array}{c}\text { Yes } \\
\text { (unspecified) }\end{array}$ & NR & NR & NR & NR \\
\hline$F$ & $\begin{array}{c}\text { Yes } \\
\text { (Riverside } \\
\text { South) } \\
\end{array}$ & $\begin{array}{c}\text { Yes } \\
\text { (Riverside } \\
\text { South) } \\
\end{array}$ & NR & NR & $\begin{array}{c}\text { Yes } \\
\text { (unspecified) }\end{array}$ & $\begin{array}{c}\text { Yes } \\
\text { (unspecified) }\end{array}$ \\
\hline G & NR & NR & $\begin{array}{c}\text { Yes } \\
\text { (unspecified) }\end{array}$ & NR & NR & $\begin{array}{c}\text { Yes } \\
\text { (unspecified) }\end{array}$ \\
\hline H & NR & NR & NR & $\begin{array}{c}\text { Yes } \\
\text { (unspecified) }\end{array}$ & NR & NR \\
\hline I & NR & \begin{tabular}{|c|} 
Yes \\
(South Keys, \\
Barrhaven) \\
\end{tabular} & NR & $\begin{array}{c}\text { Yes } \\
\text { (unspecified) }\end{array}$ & NR & $\begin{array}{c}\text { Yes } \\
\text { (unspecified) }\end{array}$ \\
\hline $\mathbf{J}$ & $\begin{array}{c}\text { Yes } \\
\text { (unspecified) }\end{array}$ & $\begin{array}{c}\text { Yes } \\
\text { (unspecified) }\end{array}$ & $\begin{array}{l}\text { Yes } \\
\text { (Riverside } \\
\text { South, } \\
\text { Letrim) }\end{array}$ & NR & $\begin{array}{c}\text { Yes } \\
\text { (Alta Vista, } \\
\text { Ottaw a East, } \\
\text { Ottaw a South) }\end{array}$ & $\begin{array}{c}\text { Yes } \\
\text { (Riverside } \\
\text { South) }\end{array}$ \\
\hline K & NR & $\begin{array}{c}\text { Yes } \\
\text { (unspecified) }\end{array}$ & NR & NR & $\begin{array}{c}\text { Yes } \\
\text { (old Rockliffe } \\
\text { air base) } \\
\end{array}$ & $\begin{array}{c}\text { Yes } \\
\text { (old Rockliffe } \\
\text { air base) } \\
\end{array}$ \\
\hline
\end{tabular}

* NR: Response did not include key term/phrase, Yes: Key Term/Phrase included in response (location) 
As shown in Table 6.1, a significant number of the MEOs' responses included a locational aspect. The total number of responses that mentioned key terms/phrases was thirty-two. Of these thirty-two mentions, eighteen (or slightly above 56 percent of the total) mentioned places where proposed residential and/or employment areas would be located. In three of the eleven interviews however, the participants (E, G, H) discussed issues regarding land use planning but did not identify specific locations in Ottawa where this land use development would occur. While it is beyond the purview of this research project to investigate the reasoning behind the MEO responses, the very fact that three of the eleven councillors did not include locations suggests that these respondents have a very limited regard for the spatial factor in the light rail expansion plans and discussions.

One matter to raise regarding the planned land use development locations in relation to the light rail corridors involves questions 5 and 6 , which refer specifically to land use development in the city. Question 5 asks:

"In terms of land use development......will the proposed corridors have any significant effect on the established communities within the City of Ottawa? Please explain".

Of the seven responses to this question that included any reference to land use planning, four of them $(A, D, J, K)$ cited specific locations where this land use development might occur. Again, as with other questions previously mentioned, only slightly more than half of the councillors specified a location with their response.

Question 6 refers to future land use development in the city in relation to the proposed light rail corridors:

"How will the location of the proposed light rail corridors be integrated with future residential and employment growth? Please explain your answer". 
Of the eight participants who responded to this question with a reference to land use planning, five (A, B, D, J, K) cited a location. To the extent that the responses to this question accurately reflect the views of MEOs on how future development growth in the city would be integrated with the proposed light rail corridors, the responses indicate a relatively low level of appreciation of how the N-S LRT and E-W LRT corridors can be successfully integrated with future residential and employment areas.

Upon making the above comment, an explanation is provided in order to justify this claim. The wording of Question 6 was carefully designed so that while its content would be clear, it would not guide the participants and prompt them into providing responses that they might perceive the researcher was seeking. By way of elaboration, Question 6 did not specifically ask for locations, per se, but instead, asked the participants to "please explain".

The development of this question via the design-evaluation process indicated that the inclusion of such wording as "identify location(s)" was not advisable. That is if the interview participants were prompted for locations, they may have just listed off any number of locations in Ottawa without giving much thought to the actual question. However, since this question was designed to ascertain whether or not the MEOs had considered the extent to which the proposed light rail corridors would be integrated with future residential and employment growth in Ottawa, it would have been counterproductive for the question to explicitly ask for locations to be provided in their responses. 


\subsection{Comparison with Published Literature}

The final method for evaluating the extent to which municipal elected officials in Ottawa consider the link between land use planning and the proposed O-Train expansion is to compare their responses with what is written in the literature on rapid transit expansion in Ottawa, specifically regarding the spatial factor. While previous investigations by Wellar (1996) reveal that there are at least seven different kinds of literature which may be pertinent to the present research, the study design took into account time and resource constraints, and thereby limited the literature to what might be termed "in-house" literature materials, and the popular literature search conducted in Section 2.6. Acknowledging, therefore, that a more comprehensive study should follow the Wellar model and include the learned literature, popular literature, professional literature, and so on, we now examine the two bodies of in-house literature used in this process, that is the Ottawa Official Plan and the Rapid Transit Expansion Study.

\subsubsection{Official Plan Land Use Planning Proposals}

Examination of the Official Plan reveals a series of measures designed to integrate land use planning with transportation planning. Within the urbanised area of Ottawa, plans call for the intensification of land uses within the existing areas of development, and for the development of greenfields with densities higher than they have been developed in the past (City of Ottawa: 2003f, 2.2.3). Future development is to be directed to "locations with significant potential", including areas designated as Mixed-Use Centres, Employment/Enterprise Areas, and Developing Communities, with 
approximately half of these areas to be situated along rapid-transit routes (City of Ottawa: 2003f, 2.2.3).

All of the areas mentioned above are identified in the Official Plan as having significant potential for future development, and consist of residential and/or employment areas. A Mixed-Use Centre is defined as a high density centre containing a mixture of housing, jobs, and commercial activities. In suburban areas outside the city's Greenbelt, Town Centres are proposed for Orleans, Kanata, and South Nepean (City of Ottawa: 2003f, 2.2.3). A Town Centre is essentially a very large Mixed-Use Centre that employs up to 10,000 people, contains mixed-use development, and is located within walking distance of shops, civic services, jobs, and transit. It is intended for these areas to be located along rapid-transit routes, such as the light rail corridors, in order to make these public transit routes more efficient (City of Ottawa: 2003f, 2.2.3).

Enterprise and Employment Areas serve as commercial, office, and industrial uses, containing at least 2000 jobs within these defined areas. The difference between the two is that Employment Areas are promoted as having much higher employment densities than their Enterprise counterparts, and may include medium to high density residential development (City of Ottawa: 2003f, 3.6.5). Developing Communities (new communities) are to be located on undeveloped lands (commonly referred to as greenfields), and are projected to be developed as mixed-use areas. These Developing Communities are intended to have higher densities than those communities previously built in Ottawa's greenfields (City of Ottawa: 2003f, 2.2.3). All the areas are intended to become intensified, with an emphasis on "lands within 600 metres of future or existing 
rapid-transit stations with potential to develop as compact, mixed-use and pedestrianfriendly cores" (City of Ottawa: 2003f, 2.2.3).

\subsubsection{RTES Land Use Planning Proposals}

As one of its many criteria in evaluating a lengthy list of proposed rapid transit corridors, the RTES used existing residential and employment populations from 2001 and projected figures for 2021. Among the numerous communities whose existing and projected populations were assessed by RTES, are several that are in close proximity to the selected light rail corridors. Adjacent to the N-S LRT Corridor, the communities in South Gloucester (including Riverside South and Leitrim) and Nepean South are projected to increase their residential populations substantially. South Gloucester is projected to increase from a population of 20,500 in 2001 to 86,500 by 2021, and South Nepean is projected to increase from 40,500 to 108,000 during the same time span (City of Ottawa: 2003e, 3-2). Employment numbers for these communities are also projected to increase substantially in the same period: from 10,700 jobs in 2001 to 35,600 by 2021 in South Gloucester, and from 6,900 jobs in 2001 to 51,100 in 2021 within the community of South Nepean (City of Ottawa: 2003e, 3-3).

In terms of the communities in proximity to the E-W LRT Corridor, the area with the largest projected increase for residential and employment populations is Kanata. Residential population estimates are for Kanata to expand from 72,000 people in 2001 to 186,000 by 2021 , with some of this residential increase to be in close proximity to the light rail corridor. Projections suggest an employment boom in Kanata, with the predicted numbers of jobs to increase from 37,000 in 2001 to 91,100 by 2021. Again, while it is not 
known how many of these jobs will be located near the light rail corridor, it is anticipated that at least a small percentage will be situated within the Kanata North Business Park.

With the most recent residential and employment population figures and their projected figures for 2021 outlined in a major transportation-based city document such as the RTES study, a substantive body of documentation exists on where population growth is intended or projected to occur within Ottawa for almost the next twenty years. These population figures therefore provide a context or basis for measuring and assessing MEOs' responses regarding the location(s) of where land use planning and transportation planning are to be integrated through light rail expansion.

\subsection{Mapping Proposed Residential and Employment Areas}

The preceding sections provide an indication of the development projects that have already started, or are proposed for the near future throughout the city. The current development plans for Ottawa call for much of the growth outside the Greenbelt in the newest suburban areas to be mixed-use development, at increased densities. Figures 6.1 and 6.2 illustrate the most current land use composition and planned future development areas within Ottawa, and their relationship with light rail expansion.

Figure 6.1 portrays the relationship between the current and future (projected) land use areas of the city and the proposed LRT corridors. The land use types found most often in proximity to the proposed LRT corridors (in no particular order) are the following: residential, business parks (Employment and Enterprise Areas), Developing Communities, and the Greenbelt. In terms of the land use cover in proximity to the E-W LRT Corridor inside of the Greenbelt, this is composed mainly of future business parks in 


\section{Figure 6.1}

\section{Land Use Composition of Ottawa}

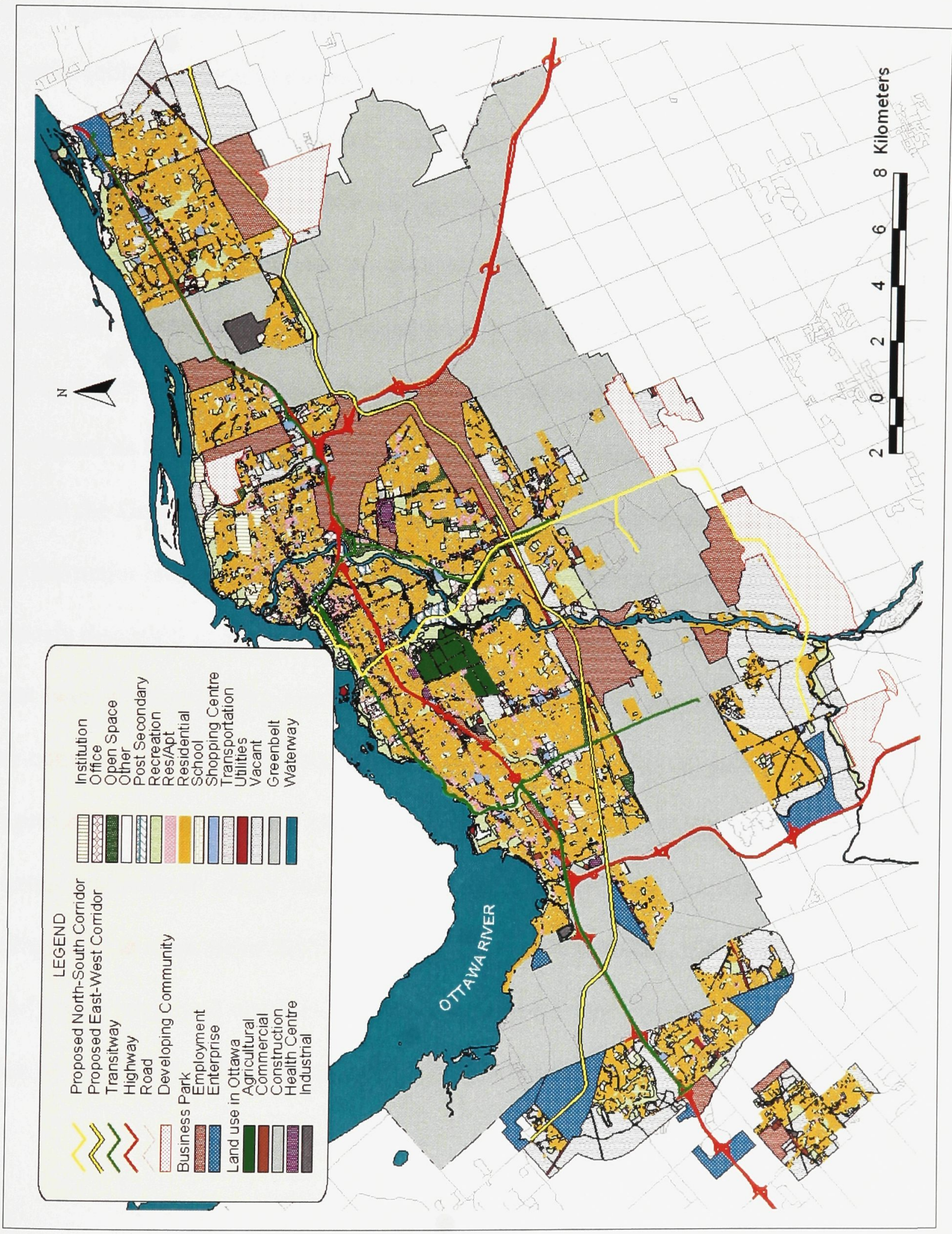

Note: Land Use feature for City of Ottawa based on most recent electronic files, last updated in 1995 
the form of Enterprise Areas, and residential communities. Within or beyond the Greenbelt, the land use composition in proximity to this LRT corridor consists to a large extent of agriculture and scrubland, and future business parks, with a limited number of residential (either existing or planned) areas.

As for the N-S LRT Corridor, within or beyond the Greenbelt the land use composition is limited to agriculture and scrubland, and residential communities either in the process of being developed or planned mixed-use development in the form of "Developing Communities". The vacant area in the southern section of the N-S LRT Corridor is new residential and commercial development that was completed after the City released its latest version of Ottawa's land use composition maps.

Inside the Greenbelt, the land use composition is shown in more detail in Figure 6.2. While the major land uses in proximity to the current O-Train corridor have been previously discussed in Section 3.1, the downtown section of this proposed extension has not yet been addressed. The route shown in Figure 6.2 is but one of the possible routes under consideration in the downtown sector within this corridor. In general, this corridor is in proximity to high-density housing and numerous multi-story apartment complexes, numerous multi-level office buildings, as well as significant commercial and retail buildings. These maps show that the proposed N-S LRT Corridor, if implemented, would be fairly well integrated with the land use plans for the city, particularly in the southern section of this corridor, where proposed development is greatest. 
Figure 6.2

\section{Land Use Composition of Ottawa (Downtown)}

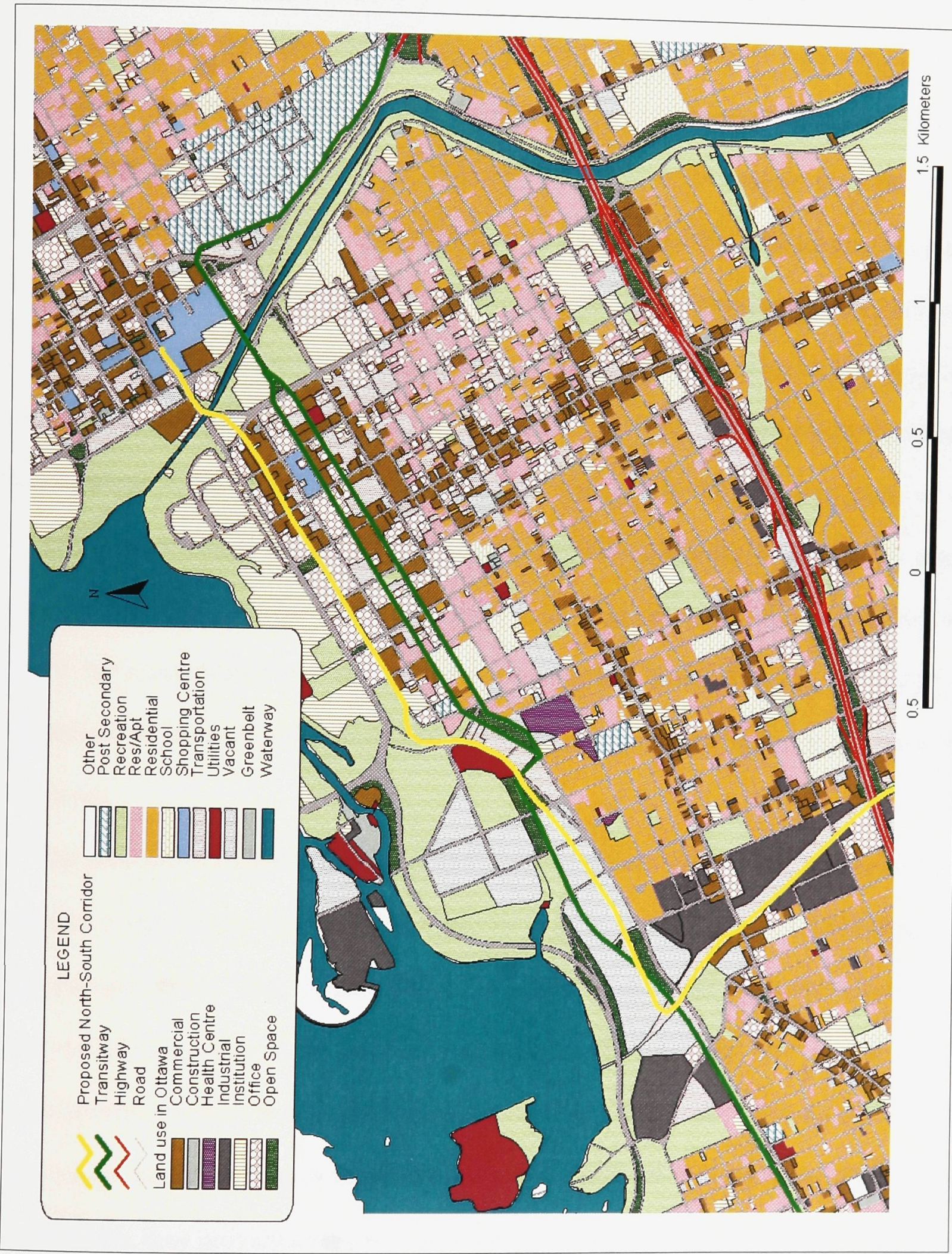

\section{Notes:}

(1) Land Use feature for City of Ottawa based on most recent electronic files, last updated in 1995

(2) Proposed route within North-South LRT Corridor in downtown sector not yet identified; map uses one of several possible downtown route scenarios 


\subsection{Evaluation of Interview Responses with Land Use Planning for LRT Corridors}

The previous two evaluation sections examined the extent to which spatial terms were used in responses, and where land use planning might occur along the light rail corridors. This part of the evaluation process goes the next step by examining whether the interview responses have due regard for the proposed land use developments that are to be integrated with the light rail expansion, as documented in the official city planning documents. The final evaluation phase of the responses of the municipal elected officials is to combine the contents of existing plans for land use development around light rail corridors (as described in the official documents) with the list of key terms/phrases, and then to compare that compilation with the MEOs' responses to the interview questions.

It is acknowledged that MEOs' responses may differ from what is stated in the city's development plans. However, for this study it is imperative to ascertain whether the MEOs have considered the official development plans associated with the light rail expansion. As a result, consistency rather than exactness is the criterion for assessing responses.

The purpose of grouping the contents of city documents with the key terms/phrases is to create a substantive argument which can be used to manage and assess the interview responses of MEOs. That is, the official documents identify the kinds and locations of land use planning that is to occur in proximity to the corridors, and the list of key terms/phrases contains a set of expressions that are among the most widely used in discussions about the link between land use planning and transportation planning. In combination, they provide a means of critically assessing the extent to which MEOs have 
considered the spatial aspect of the link between current and future land use planning and current and future transportation planning for the proposed light rail expansion in Ottawa.

Table 6.2 contains the interview responses that refer specifically to the actual land use development plans along the proposed light rail corridors. A response is included in this table only if it satisfies two conditions:

1. It discusses the spatial factor involved in the light rail expansion, and,

2. The location and type of land use planning mentioned are consistent with what is contained in official planning documents.

The findings displayed in Table 6.2 show that out of the original thirty-two responses containing a key term/phrase, only nine identified a land use development location that is within the city's plans. Answers by participants ranged from Participant J stating in three of six responses where land use development in regard to the light rail corridors would take place, to Participant I who did not specifically discuss where light rail-oriented land use development would occur. As for Questions 5 and 6, which focus on land use planning in developed and future communities respectively, the responses tend to suggest an underlying lack of regard for the planning documents and the key terms/phrases since these questions deal directly with the issue of where future development is to occur. By way of elaboration, and examining the responses in the Question 5 column, of the seven MEOs who included any mention of land use planning terms/phrases, only three of them $(\mathrm{D}, \mathrm{J}, \mathrm{K})$ discussed actual planned developments. And the responses for Question 6 show that only two (A, J) of the eight participants who included any land use planning terms/phrases also spoke to the question of where future residential and employment growth will occur within the city. 
Table 6.2

Comparison of Municipal Elected Officials' Responses with Official Documents

\begin{tabular}{|c|c|c|c|c|c|c|}
\hline \multirow[b]{2}{*}{ PARTICIPANT } & \multirow[b]{2}{*}{1} & \multicolumn{3}{|c|}{ QUESTION/RESPONSES* } & \multirow[b]{2}{*}{5} & \multirow[b]{2}{*}{6} \\
\hline & & 2 & 3 & 4 & & \\
\hline A & NR & NA & NR & NR & NAA & $\begin{array}{c}\text { Mixed-Use } \\
\text { Development } \\
\text { (Innes) } \\
\text { PLANNED }\end{array}$ \\
\hline B & NR & 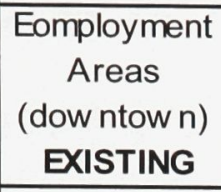 & NR & NR & NA & NA \\
\hline C & NR & NA & $\begin{array}{c}\text { Mixed-Use } \\
\text { Centres } \\
\text { (South } \\
\text { Gloucester) } \\
\text { PLANNED } \\
\end{array}$ & NR & NA & NR \\
\hline D & $\begin{array}{c}\text { Business } \\
\text { Park } \\
\text { (Kanata North } \\
\text { Business } \\
\text { Park) } \\
\text { PLANNED } \\
\end{array}$ & NR & NR & NR & \begin{tabular}{|c|} 
Employment \\
Areas \\
(Kanata North \\
Business \\
Park) \\
PLANNED \\
\end{tabular} & NA \\
\hline$E$ & N/A & NA & NR & NR & NR & NR \\
\hline $\mathbf{F}$ & NA & $\begin{array}{c}\text { Employment } \\
\text { Areas } \\
\text { (Riverside } \\
\text { South) } \\
\text { PLANNED } \\
\end{array}$ & NR & NR & N/A & NA \\
\hline $\mathbf{G}$ & NR & NR & NA & NR & NR & NA \\
\hline $\mathbf{H}$ & $\mathrm{NR}$ & $\mathrm{NR}$ & NR & $\mathrm{N} / \mathrm{A}$ & NR & NR \\
\hline $\mathbf{I}$ & $\mathrm{NR}$ & NA & $\mathrm{NR}$ & N/A & NR & NA \\
\hline$J$ & NA & NA & $\begin{array}{l}\text { Employment } \\
\text { Areas } \\
\text { (Riverside } \\
\text { South, } \\
\text { Letrim) } \\
\text { PLANNED }\end{array}$ & NR & $\begin{array}{c}\text { Intensification } \\
\text { (Alta Vista, } \\
\text { Ottaw a East, } \\
\text { Ottaw a South) } \\
\text { PLANNED }\end{array}$ & $\begin{array}{l}\text { Mixed-Use } \\
\text { Centres } \\
\text { (Riverside } \\
\text { South) } \\
\text { PLANNED }\end{array}$ \\
\hline K & NR & NA & NR & NR & \begin{tabular}{|c|} 
Mixed-Use \\
Development \\
(old Rockliffe \\
airbase) \\
PLANNED \\
\end{tabular} & NA \\
\hline
\end{tabular}

* NR: Response did not include key term/phrase 
Again, it is important to emphasize the careful wording in Questions 5 and 6. The issue is whether or not it is possible to draw conclusions based on the interview participants' responses to these two questions, as they did not specifically ask for locations to be mentioned. Instead, the questions were designed to encourage the participants to "explain" their answers. If the questions specifically asked the MEOs to identify locations in their responses, then the problem of "leading questions" would likely arise. That is, it could be argued that the questions were prompting officials to produce a list of locations where the proposed light rail expansion could potentially be integrated with current and future residential and employment areas. As these two questions were intended to allow the MEOs to consider the significance of the spatial factor associated with the proposed light rail corridors, any specific prompting for "locations" would have altered the purpose of asking these specific questions.

Several general comments can be derived from Table 6.2. Less than one-third of the participants' responses identified planned land use developments that are to be built in Ottawa. The small number of responses that included the identification of planned land use development projects in collaboration with the light rail corridors indicates a lack of awareness of the relationship between land use planning and the proposed O-Train expansion. Focusing specifically on the results of comparing the MEOs responses with the proposed land use development plans, it appears fair to comment that the municipal elected officials as a group did not demonstrate a high level of knowledge on this topic. 


\subsection{Summary}

This chapter provides a comparison of the municipal elected official's responses with published literature, along with two maps that depict the land use composition of Ottawa in association with the proposed light rail corridors. The findings focus specifically on the connection between the spatial factor and planned growth in Ottawa and comparison between the participants responses and published literature on light rail expansion in this city. In addition, an evaluation of the interview responses examines whether the participants have due regard for the proposed land use development that are to be associated with the light rail expansion. Based upon the findings presented in this chapter, a series of general comments are presented that assist in answering the research question posed in Section 1.2. 


\section{CHAPTER 7 ASSESSMENT AND IMPLICATION OF SPATIAL \\ FACTORS IN O-TRAIN DELIBERATIONS}

This chapter presents the responses provided by the MEOs during the interview process in the context of an assessment and discusses the implications of the MEOs perception of the spatial factor in the light rail expansion deliberations. A two-part process is used consisting of:

1. An overall assessment of the interview responses, and

2. The implications of these responses for the light rail expansion deliberations

\section{1 Concluding Assessment of Interview Responses}

An overall assessment of the interview responses can begin by first discussing what the MEOs appear to know, and then what they appear not to know about the spatial factor associated with the proposed light rail expansion.

The MEOs as a group appear to have a moderately strong regard for key terms/phrases that deal with the spatial factor associated with land use planning for the light rail expansion. Although the smallest number of terms/phrases provided by a participant in responding to all six of the questions combined was one (Participant I), the highest number of terms/phrases mentioned without duplication was 10 (Participant F). From the results obtained in Table 5.9, six MEOs (A, B, C, D, F, J,) included in their response a total of five or more unduplicated key terms/phrases, and an overall group average of 5.2 terms/phrases were mentioned per interview. In addition, out of the eleven 
interview participants, seven (A, B, C, D, F, I, J) included two or more key terms/phrases with their response in at least two of the six questions.

The following provides an overview for the relevance of the key terms/phrases included in the MEOs' responses. Focusing on the interview group as a whole, out of the list of thirty-two key terms/phrases, twenty-two were mentioned (22/32) during the interviews. Of the number of key terms/phrases mentioned, eighteen of the twenty-two (18/22) can be placed into the Highly Related or Moderately Related classification groups. Based on these findings, it would appear that as a group the interview participants have a fairly adequate knowledge of the vernacular used when describing the spatial factor associated with the proposed light rail expansion in Ottawa.

In general, the interview participants also appear to recognize that the spatial factor is an important component to consider when selecting the optimum location for light rail corridors, as eight participants (A, B, C, E, F, I, J, K) included a key term/phrase in their list of objectives when responding to Question 2. Of these eight participants, six of them are on the Transportation Committee (TC), providing an indication that spatial factors are given some consideration by the TC members when identifying the necessary components involved in selecting light rail corridors in Ottawa.

Having identified what the MEOs appear to know regarding the spatial factor associated with the proposed light rail expansion, it is now appropriate to discuss what they appear not to know on this topic.

As illustrated in Table 6.2, only three (D, J, K) of the eleven interviewees discussed actual planned developments that are to occur within the already developed areas in the city. Of these three participants, only one of them is on the Transportation Committee 
(TC). When responding to Question 6, only two (A, K, both TC members) of the eight participants who included key terms/phrases with their responses to any of the questions, spoke to the question of where future residential and employment growth would be potentially situated in the city. Furthermore, as these participants (A, K) constitute two of the seven TC members who participated in this study, there appears to be a clear lack of knowledge on the part of the members of the Transportation Committee regarding the location and the description of the spatial factors that are planned to be integrated with the light rail expansion. This is stated due to the fact that the other five TC participant's responses to Question 6 did not provide any relevant discussion on this particular matter.

The feedback provided on this matter demonstrates that as a group, the MEOs who participated in this study appear to be lacking knowledge on the location and type of spatial factors that are proposed for integration with the proposed light rail corridors, even though the details are provided in official planning documents. That is, when the questions referred specifically to how the spatial factor is considered in the link between land use planning and the light rail expansion, the MEOs as a group were unable to make a clear connection. Therefore, the responses provided by the interview participants is seen to indicate a high lack of awareness for the spatial aspect associated with the proposed light rail expansion.

\subsection{Implications of Interview Responses on O-Train Deliberations}

Having assessed the MEOs responses regarding the spatial factor associated with the link between land use planning and the proposed light rail expansion, it remains to assess the extent to which the spatial factor will be integrated in O-Train deliberations and 
discussions. Further, the likelihood that integrated land use planning and transportation planning, and development will result from O-Train discussions and deliberations will be addressed. The O-Train discussions and deliberations refer specifically to the future decision-making processes involved in the proposed light rail expansion, as shown in Section 3.5, which consist of future city council meetings and deliberations, technical reports produced by the City and consulting firms, public consultation and media coverage.

To determine the implications of the MEOs' perceptions for the regard shown for the spatial factor in the O-Train deliberations, it is necessary to refer to the interview responses once again. The majority of the interview participants $(8 / 11)$ mentioned a key term/phrase in their top five objectives for determining the optimum location for a light rail corridor. Of those eight participants, six of them are on the Transportation Committee, thereby providing some indication that members of the Transportation Committee are considering spatial factors when discussing the location of light rail corridors.

In spite of the above finding, though, few responses identified the proposed land use development projects that are to be built in association with the light rail projects. Only three of the eleven MEOs (including one member of the TC) were able to specify where in the already developed areas of Ottawa land use planning would be integrated with the proposed light rail corridors. In addition, only two MEOs specified where future planned residential and employment growth would occur in conjunction with the O-Train expansion, and both respondents are members of the TC. 
The reason for emphasizing the response of the Transportation Committee members in this section is due to their relationship with Ottawa's city council. It is recalled that the Transportation Committee is a Standing Committee appointed by City Council to study transportation matters and make recommendations to the Council (City of Ottawa: 2004h). Once the Transportation Committee makes its recommendation on a specific issue, such as the proposed light rail expansion, City Council then proceeds to reach a decision on this issue. Since this is the process by which the MEOs in Ottawa make a transportation-related decision, it is obvious that the Transportation Committee is an integral component of the light rail decision-making process. As this is the case, when an issue related to the light rail expansion reaches the decision-making stage of City Council deliberations, it is presumed that if this issue is considered important to the TC, in most situations the rest of City Council will accede the TC's opinion when a decision is required.

Based on the responses to the interview questions, from a Transportation Committee standpoint there are conflicting issues associated with the consideration given to the spatial factors that are linked with the light rail expansion. While key terms/phrases that deal with the land use planning of the light rail expansion are identified as priority objectives in selecting optimum light rail corridors by the majority of the TC participants, only two TC participants related the spatial factor to current and future residential and employment areas in relation to the proposed corridors. Therefore, since seven of the nine TC members participated in this study, the responses provided in the interview questions represent the majority of the opinions held by the TC as a whole. 
It is deduced that although the TC members who participated in the interview process included some mention of spatial factors, it did not appear to be a top priority to them when answering the questions. Since only a small share of the TC participants discussed the spatial factor associated with planned development that is addressed in the official planning documents, it does not appear that this Standing Committee has considered the spatial factor to be an integral aspect of the proposed light rail expansion. As a result, the likelihood that integrated land use planning and transportation planning, and development will result from O-Train deliberations and discussions is limited. That is, while the integration of spatial factors between land use planning and transportation planning may be addressed in O-Train deliberations, based on the results of this study it is not likely that this topic will be a critical issue in the deliberations. Rather, while this topic might be mentioned in future light rail expansion deliberations and discussions, the impression is given that the spatial factor will not be given much weight based on the research findings in these decision-making sessions.

This lack of confidence for the integration of the spatial factor in future light rail discussions and deliberations is not to categorically presume that this integration will not occur. Rather, based on the findings in this study, it is unlikely that this integration will originate from the municipal elected officials. Referring once again to Section 3.5, it is not just City Council that is involved in the light rail decision-making process. The parties outside of City Council that contribute to this process include city staff, the Government of Ontario, the federal government, consulting firms, and the general public, via public consultation. Concerning the general public's contribution, this is provided in 
two critical ways, either through personal feedback, or through the news media, and especially letters to newspaper editors.

Therefore, it is quite plausible for these parties involved in the light rail decisionmaking process to influence the likelihood that land use planning and transportation planning and development will result from future O-Train deliberations and discussions. That is, since the findings reveal that there is a lack of confidence on the part of the MEOs to integrate the spatial factor in future light rail discussions and deliberations, this integration will have to be emphasized by those outside of city council that are apart of the decision-making process for the proposed light rail expansion, to ensure that the spatial factor is recognized as a critical component of transportation planning in Ottawa.

\subsection{Summary}

A final assessment of the interview responses is provided in this chapter that reviews what the interview participants appear to know and not know about the spatial factor associated with the proposed light rail expansion. This review includes a brief discussion of the responses provided by the Transportation Committee, as this group is singled out based on the premise that they have a vested interest in transportation matters in Ottawa. In addition, an assessment of the extent to which the spatial factor will be integrated in future light rail discussions and deliberations is addressed. 


\section{CHAPTER 8 CONCLUSION}

\subsection{Summary}

This study investigated the extent to which municipal elected officials consider the spatial aspect of the link between current and future land use planning and current and future transportation planning for the proposed light rail expansion in Ottawa, Ontario. The study's research objectives were as follows:

1. Review and summarize the current plans of the proposed light rail expansion in Ottawa through analysis and synthesis of existing literature.

2. Identify the factors used to select the proposed light rail corridors

3. Elicit the opinions of municipal elected officials on the spatial aspects of the link between land use planning and transportation planning when formulating light rail expansion policies and plans.

4. Assess whether the municipal elected officials consider this link a significant issue when selecting the location of the proposed light rail corridors.

The questions used in the interviews were derived from an adaptation of the designevaluation process developed by Ackoff (1953). In the first phase, referred to as the pilot study, members of neighbourhood community groups, public transportation advocacy groups, and academics contributed to the framing and testing of questions. Within this phase, a set of key terms/phrases characterizing the state of land use planning and transportation planning was specified by this "panel of experts". During the subsequent phases of pretest and trial run, the questions formatted in the pilot study were reviewed by a selection of councillors to ensure acceptance and understanding by their council 
colleagues. Upon verification that the list of questions was appropriate to submit to the municipal elected officials, the interviews were conducted.

The interview phase consisted of posing the verified list of questions to the eleven municipal elected officials who expressed an interest in participating in this study. The interviews themselves were presented in a semi-structured format. While two of the intended participants withdrew from the study due to scheduling complications, this did not affect the design-evaluation process. In terms of the responses provided by the participants, all eleven of them answered all of the questions, thereby avoiding any potential problems arising from missing responses.

In order to measure and assess the extent to which municipal elected officials have regard for the spatial factor in the light rail expansion deliberations, a procedure developed by Wellar (1998) was applied. This procedure involves deriving a list of keywords, terms or phrases from the literature and/or a panel of experts, and then using the list to perform a content analysis of the degree of correspondence between official documents and newspaper articles, and the results of interviews with municipal elected officials.

The first phase in analyzing the results of the interviews compared the responses with the list of key terms/phrases on the spatial factor associated with land use planning for the O-Train expansion. The second phase of the analysis investigated whether the responses provided by the municipal elected officials indicated the location of possible land use development projects that was or would be coordinated with the light rail corridors. The third phase of the analysis compared the responses provided by the municipal elected officials with the existing plans to integrate land use planning with the proposed light rail 
expansion. This final stage in the evaluation of the interview results provides the basis for assessing the extent to which the municipal elected officials have considered the spatial aspect when thinking about voting on planned land use developments that are to be constructed in proximity to the light rail corridors.

Overall, based on the responses provided in the interviews, it is concluded that Ottawa's municipal elected officials have only a limited regard for the spatial factors associated with the link between land use planning and transportation planning. However, there are two different sides to this conclusion. That is, several MEOs demonstrated a commanding grasp of this topic, while for others it appears that they had not considered this link to be an important component of light rail expansion policies and plans.

Within the group of participating MEOs are members of the Transportation Committee, whose responsibilities include optimizing "accessibility to employment, housing" (City of Ottawa: 2004h). However, the interview participants belonging to the Transportation Committee did not produce superior results compared to their participating council colleagues who are not on this committee. Therefore, the consideration given by the municipal elected officials to the spatial factors involved in the land use planning initiatives for the proposed light rail expansion is assessed as low, which calls for significant changes in order for the MEOs to understand the vital importance of this link as an element in achieving the city's goal of a sustainable city, which is discussed in Chapter 1 .

The findings from the third phase of the analysis may appear to be contradictory, in the sense that the MEOs appear to have a limited awareness of the spatial link that is being investigated, while this link is explicit in the main planning documents that have 
either been produced by the City of Ottawa, or for the City by consulting firms. There is however a straightforward explanation of this seeming contradiction, which is that the official planning documents and light rail expansion plans were produced by city staff, and the other documents were produced by consulting firms. Futhermore, despite the fact that the official planning documents were implemented by Ottawa city council as planning guidelines for the City, these documents were approved prior to the election of the current group of municipal elected officials. Although more than half of the councillors were re-elected from the previous administration $(15 / 21)$, because of differences in the various responsibilities assigned to the MEOs, it may not be realistic to expect them to retain all the information that is contained in the official city documents on the spatial link between land use planning and the proposed light rail expansion. Moreover, since the MEOs as a group did not pass these planning documents and the six new members of this group may not be aware of all of their contents, there may be other reasons to account for the seeming contradiction between what is documented in the plans and the findings from the interviews.

As discussed in Section 7.2, the key implications arising from participating MEOs lack of regard for the spatial factor associated with the proposed LRT expansion is that it could lead to future O-Train deliberations and discussions yielding only a limited integration of land use planning and the O-Train expansion. That being the case, then it would be impossible or at best very difficult for the City of Ottawa to achieve the initiatives it developed during the Ottawa Smart Growth Summit held in 2001, and the stated goals in the Official Plan that include achieving sustainable development, and 
managing the growth of the city, via the improvement and expansion of its existing public transportation infrastructure (City of Ottawa: 2003f, 1.1).

\subsection{Limitations}

Limitations of this research were noted in the text as the matters arose. The following comments are intended to properly qualify the research process and conclusions, and to provide guidance for anyone contemplating a similar study.

First, the responses to the questions by the interview participants are considered limited due to the fact it was not possible to have the participants elaborate on the land use planning issues without potentially biasing the overall results. Consequently, it was not possible to discern whether the MEOs had included in their responses all of what they knew about the research topic.

Second, not all of the MEOs participated in the interviews and it is difficult to determine the extent to which the responses of those interviewed are representative of the views of the MEOs as a whole.

Other factors that could potentially limit the validity of this research are related to the projected residential and employment figures, and the planned development projects in this city for 2021. By virtue of being projections, the figures presented by the City of Ottawa are subject to change. As for the planned development projects, these too can change due to the postponement of projects, modification of plans, or outright cancellations, as the result of unforeseen economic, social, and environmental issues. Further, the priority placed on the integration of land use planning and transportation planning in the city's official documents could become a more or less critical issue for 
the City, resulting in greater or lesser interest in either rapid transit expansion and/or mixed-use developments constructed around transit stations.

\subsection{Potential Future Work within Study Area}

The adaptation of the research methodology applied to this study has the ability to assist in future research on the spatial factor associated with local decision-making for public transportation issues. While it is acknowledged that the appreciation for the spatial relationship between land use planning and transportation planning from a municipal decision-making perspective was only partially examined, this study was able to address one aspect of this spatial relationship through the adoption of successful methodological processes.

Possible future work in this field could examine other important aspects affecting the municipal elected officials' (MEOs) decision-making process on public transportation development issues. A possible avenue of research is to investigate what influences the MEO's views when deciding on these issues, since previously indicated in this study, MEOs make their decisions based on the input from several different groups, and are thereby influenced by a variety of groups. Further investigation on this topic could determine the extent to which their views are influenced by internal groups such as city staff, and external groups such as transportation lobby groups and community associations. In particular, a fruitful avenue of research would be an investigation of the role that city staff has on transportation planning and land use planning decisions in Ottawa. 
Based on these suggested avenues of research, it appears fair to suggest that further investigation in this field could lead to a significantly greater understanding of the extent to which the spatial aspects of the link between land use planning and transportation planning should be taken into consideration at a municipal decision-making level when formulating public transportation policies and plans. 


\section{BIBIOGRAPHY}

Ackoff, Russell, 1953, The Design of Social Research, University of Chicago Press, Chicago, Illinois, U.S.A., 420p.

Adam, Mohammed, 2004, Value for Money: Taxpayers Must Decide Series: How the City Works, Ottawa Citizen, March $16^{\text {th }}, 2004 ;$ p.C.1

Advance Urban Transportation Systems, 1970, Transportation Research Institute, Carnegie-Mellon University, Pittsburgh, Pennsylvania, U.S.A., 148p.

Alexander, Donald and Tomalty, Ray, 1994, Urban Policy for Sustainable Development, Institute of Urban Studies, University of Winnipeg, Winnipeg, Manitoba, 75p.

Alston, Liviu, L, 1984, Railways and Energy, World Bank Staff Working Papers, Number 634, The World Bank, Washington D.C., U.S.A., 80p.

Barry, Michael, 1991, Through the Cities: The Revolution in Light Rail, Colour Books, Dublin, Ireland, 255p.

Bartsch, Charles and Hudson, Christopher, 2001, Strategies for Successful Infill Development, Northeast Midwest Institute and The Congress for the New Urbanism, Washington D.C., U.S.A., 130p.

Batty, Michael, 2002, Thinking about Cities as Spatial Events, Environment and Planning B: Planning and Design 2002, London, England, Vol. 29, pp. 1-2

Batty, Michael, 2003, The Emergence of Cities: Complexity and Urban Dynamics, Centre for Advanced Spatial Analysis, Working Paper 64, University College London, London, England, 16p.

Batty, Michael and Besussi, Elena, 2003, Representing Multifunctional Cities: Density and Diversity in Space and Time, Working Paper 71 Centre for Advanced Spatial Analysis, University College London, London, England, 16p.

Batty, Michael and Besussi, Elena, 2003, Traffic, Urban Growth and Urban Sprawl, Working Paper 70, Centre for Advanced Spatial Analysis, University College London, London, England, 12p.

Black, Alan, 1995, Urban Mass Transportation Planning, McGraw-Hill Inc., Montreal, Quebec, 411p. 
Black, J.A., Paez, A. and Suthanaya, P.A.,, 2002, Sustainable Urban Transportation: Performance Indicators and Spatial Analytical Approaches, in Journal of Urban Planning and Development, American Society of Civil Engineers Publications, Reston, Virginia, U.S.A., Vol. 128(4), pp 184-209

Black, John, 1981, Urban Transportation Planning, Croom Helm Ltd., London, England, 248p.

Black, William, 2003, Transportation: A Geographical Analysis, The Guilford Press, London, England, 375p.

Blunden, W.R., Black, J.A., 1984, The Land Use Transport System, Pergamon Press, Toronto, Ontario, 250p.

Bonin, Raymond, 1998, The Renaissance of Passenger Rail in Canada, Report of the Standing Committee on Transport, House of Commons, Ottawa, Ontario, 59p.

Bruton, M.J., 1970, Introduction to Transportation Planning, Hutchinson Educational Ltd., London, England, 232p.

Bullard, Robert D., 2000, Sprawl City, Island Press, Washington D.C., U.S.A., 236p.

Cameron, Nairne, 1995, Defining and Measuring the Spatial Dimension of Accessibility, University of Ottawa, Ottawa, Ontario, 174p.

Canadian Chamber of Commerce (CCC), 2002, 2002 Policy Resolutions: Transport, retrieved September $3^{\text {rd }}, 2004$ from World Wide Web:

http://www.chamber.ca/cmslib/general/T024.pdf

Carpenter, T.G., 1994, The Environmental Impact of Railways, John Wiley \& Sons, West Sussex, England, 385p.

Cevero, Robert, 1989, America's Suburban Centers: The Land Use Transportation Link, Unwin Hyman, Winchester, Massachusetts, U.S.A., 176p.

Chapin, F. Stuart and Kaiser, Edward J., 1979, Urban Land Use Planning, University of Illinois Press, Urbana, Illinois, U.S.A., 656p.

City of Calgary, 2004, Transit Oriented Development, retrieved August 12, 2004 from World Wide Web:

http://www.calgarytransit.com/html/transit_oriented_development_guidelines.pdf

City of Ottawa, 2001a, Rapid Transit Expansion Study-Statement of Work, Report Submitted by Ned Lathrop, Ottawa, Ontario, pp. 55-63 
City of Ottawa, 2001b, Regional and Interprovincial Rapid Transit System Feasibility Study, Report Submitted by Ned Lathrop, Ottawa, Ontario, pp. 8-16

City of Ottawa, 2001c, Light Rail Pilot Project-Status Report, Report Submitted by R.T. Leclair, Ottawa, Ontario, 11p.

City of Ottawa, 2001d, Ottawa Light Rail Extensions: Colonnade Business Park to the Kanata North Business Park- Conceptual Feasibility Study, Report Submitted by McCormick Rankin Corporation, Ottawa, Ontario, 16p.

City of Ottawa, 2002a, O-Train Evaluation Report, Report Submitted by R.T. Leclair, Ottawa, Ontario 49p.

City of Ottawa, 2002b, O-Train Status Report \#2, Report Submitted by R.T. Leclair, Ottawa, Ontario, 26p.

City of Ottawa, 2002c, Vacant Urban Residential Land Survey 2002, Ottawa, Ontario, 33p.

City of Ottawa, 2003a, Transportation and Transit Committee Report 50: Ottawa Rapid Transit Expansion Plan (ORTEP) - Implementation Study, Ottawa, Ontario, 53p.

City of Ottawa, 2003b, Transportation Master Plan, Ottawa, Ontario, 125p.

City of Ottawa, 2003c, Ottawa Rapid Transit Expansion Plan (ORTEP) -

Implementation Study, Report Submitted by Ned Lathrop, Ottawa, Ontario, 49p.

City of Ottawa, 2003d, Transportation Master Plan, Draft, Ottawa, Ontario, 52p.

City of Ottawa, 2003e, Rapid Transit Expansion Study (RTES), Ottawa, Ontario, 109 p.

City of Ottawa, 2003f, Official Plan - A Component of Ottawa 20/20, Ottawa, Ontario

City of Ottawa, 2003g, Transportation and Transit Committee Report 40: Rapid Transit Expansion Study - Recommendations, Ottawa, Ontario, pp.12-47

City of Ottawa, 2003h, Light Rail Short-Term Improvements, Report Submitted by R.T. Leclair, Ottawa, Ontario, $7 \mathrm{p}$.

City of Ottawa, 2004a, North-South Corridor LRT Priority Project (Rideau Centre to Barrhaven Town Centre) Environmental Assessment - Terms of Reference, report submitted by Ned Lathrop, Ottawa, Ontario, 29p. 
City of Ottawa, 2004b, North-South Corridor LRT Priority Project (Rideau Centre to Riverside South) Environmental Assessment - Terms of Reference, Report Submitted by Ned Lathrop, Ottawa, Ontario, 21p.

City of Ottawa, 2004c, East-West LRT Project Environmental Assessment: Statement of Work, Report Submitted by Ned Lathrop, Ottawa, Ontario, 18p.

City of Ottawa, 2004d, North-South LRT Priority Project Environmental Assessment: Statement of Work (Minutes 2), Ottawa, Ontario, 4p.

City of Ottawa, 2004e, North-South LRT Priority Project Environmental Assessment: Statement of Work (Disposition 1), Ottawa, Ontario, 1p.

City of Ottawa, 2004f, North-South Corridor LRT Priority Project EA-Statement of Work, Report Submitted by Ned Lathrop, Ottawa, Ontario, 28p.

City of Ottawa, 2004g, City Council-How Does it Work? retrieved June 27, 2004 from World Wide Web: http://ottawa.ca/city_council/howcouncilworks_en.html

City of Ottawa, 2004h, Transportation Committee, retrieved May 6, 2004 from World Wide Web: http://ottawa.ca/city_council/standing_comtt/1_7_en.shtml

City of Ottawa, 2004i, Public Consultation, retrieved November $28^{\text {th }}, 2004$ from World Wide Web: http://ottawa.ca/public consult/rtr/ew/dtor/4_0_en.shtml

City of Phoenix, 2002, Report Shows Light Rail System Could Boost Development, retrieved June 27, 2004 from World Wide Web:

http://phoenix.gov/NEWSREL/uli.html

Clutterbuck, Peter, and Novick, Marvyn, 2003, Building Inclusive Communities: Cross-Canada Perspectives and Strategies, Canadian Federation of Municipalities, Ottawa, Ontario, 34p.

Cope, David L., et al. 1984, Energy Policy and Land Use Planning: An International Perspective, Pergamon Press, Oxford, England, 308p.

Daily Telegraph, Pollution Linked to Lung Damage, Calgary Herald, February 8, 2001, Page V.4

Darwin, Eric, 1976, Impacts of Railway Relocation on Urban Form, Carleton University, Department of Geography, Ottawa, Ontario 76p.

De la Berra, Tomas, 1989, Integrated Land Use and Transport Modelling, Cambridge University Press, Cambridge, England, 179p.

Demographic-Economic Facts, 2003, City of Ottawa, Ottawa, Ontario, 184p. 
Dimitriou, Harry T., 1992, Urban Transport Planning: A Developmental Approach, Routledge Press, New York, New York, U.S.A., 346p.

Duncan, Bruce and Hartman, John, 1996, Sustainable Urban Transportation Initiatives in Canada, Transportation Association of Canada, Ottawa, Ontario, 12p.

Environment Canada, 2002, Ground-level Ozone, retrieved August 14, 2004 from World Wide Web: http://www.ec.gc.ca/air/smog_e.html

Federal House in Order, 2004, Glossary, retrieved October 22, 2004 from World Wide Web: http://www.fhio-ifppe.gc.ca/default.asp?lang=En\&xml=3BD78EB5$\underline{6767-4866-9 B D 9-42 E 955276 \mathrm{~A} 1 \mathrm{~F}}$

Fell, Andy, 2000, Primate Research Shows Links Between Ozone Pollution, Asthma, in Dateline UC Davis October 13, 2000, retrieved August 14, 2004 from World Wide Web: www.dateline.ucdavis.edu/101300/DL_asthma.html

Garnet, Marcus, 2000, Commuter Rail, in Elements October 2000, retrieved October $4^{\text {th }}, 2004$ from World Wide Web:

http://www.elements.nb.ca/theme/fuels/light/rail.htm

Garrison, W.L., 1979, Urban Transportation and Land Use, in Public Transportation: Planning, Operation, and Management, Gray, George E, and Hoel, Lester A., Prentice Hall Inc., Upper Saddle River, New Jersey, U.S.A., pp. 515-526

Gault, Helen, 2004, Personal Communication, April 22, 2004

Gault, Helen, 2002, Planning and Implementing the O-Train, in ITE 2002 Annual Conference, May 2002, 25p.

Green, Rodney D. and James, David M., 1993, Rail Transit Station Area Development, M.E. Sharpe, Armonk, New York, U.S.A., 271p.

Giuliano, Genevieve, 1995, Land Use Impacts of Transportation Investments: Highway and Transit in The Geography of Urban Transportation, Hanson, Susan, Guilford Press, New York, New York, U.S.A., Ch.13, pp 305-341

Gordon A.R., 1982, Shaping Suburban Land Use With Rapid Transit, in Prospects for Planning: Coming to Grips with New Realities, Wellar, Barry, The 1982 Conference Committee Canadian Institute of Planners, Hull, Quebec, pp. 170-177

Goodall, Brian, 1987, The Penguin Dictionary of Human Geography, Facts on File Publications, New York, New York, U.S.A., 509p. 
Government of Canada, 2003, Proposal on Transboundary Air Pollution, Submission of the Government of Canada to U.S EPA, March 16, 1998 in Gurin, David, Understanding Sprawl, David Suzuki Foundation, Vancouver, B.C., 8p.

Gurin, David, 2003, Understanding Sprawl, David Suzuki Foundation, Vancouver, B.C., 23p.

Haad, Tamim, 1998, The Car in Canada: A Study of Factors Influencing Automobile Dependence in Canada's Seven Largest Cities, 1961-1991, School of Community and Regional Planning, University of British Columbia, Vancouver, B.C., 178p.

Hartman, Christopher, J., 1984, Planning For Rapid Transit in Suburban Residential Areas: Towards A More Comprehensive Approach, University of Calgary, Calgary, Alberta, 117p.

Hay, Iain, 2000, Qualitative Research Methods in Human Geography, Oxford University Press, South Melbourne, Victoria, Australia, 222p.

Hobson, Steven, 1992, The Use of Existing Rail Rights-of-Way in the Development of British and North American Light Rail Transit Systems: Excellence, Opportunity, or Potential Problem, Department of Geography, University of Manitoba, Winnipeg, Manitoba, 211p.

Hoel, Lester A., 1982. Urban Transportation in North America: Problems and Solutions, in Urban Transportation: Perspectives and Prospects, Eno Foundation for Transportation Westport, Connecticut, U.S.A., pp. 47-52

Hutchins, John, G.B., 1977, Transportation and the Environment, Elek Books Ltd., London, England, 106p.

International Development Research Council, The Local Agenda 21 Planning Guide, 1996, International Council for Local Environmental Initiatives, (ICLEI), Toronto, Ontario, 212p.

Jancewicz, Walter, 1972, Socio-Political Factors in Urban Transportation, Sir George Williams University, Montreal, Quebec, 59p.

Kenny, Michael, and Meadowcroft, James, 1999, Planning Sustainability, Routledge Press, London, England, 230p.

Kent, T.J., 1964, The Urban General Plan, Chandler Publishing Co., San Francisco, California, U.S.A., 213p.

Kuby, M., Barranda, A., Upchurch, C., 2003, Factors Influencing Light-Rail Station Boardings in the United States, in Transportation Research Part A, London, England, Vol. 38(3), pp.223-247 
Regional Municipality of Ottawa-Carleton, 1993, Environmental Review of the Regional Official Plan-Background Paper on Environment, Transportation, and Land Use, Ottawa, Ontario, p. 26

Regional Municipality of Ottawa-Carleton, 1997, Transportation Master Plan (Commuter Rail), report submitted by Dillon Consulting Limited, Ottawa, Ontario, $13 \mathrm{p}$.

Regional Municipality of Ottawa-Carleton, 1998a, Light Rail Pilot Project:

Recommended Service Concept Analysis, Ottawa, Ontario, pp.88-118

Regional Municipality of Ottawa-Carleton, 1998b, Light Rail Pilot Project: Progress Report No. 3, Ottawa, Ontario, pp. 20-23

Regional Municipality of Ottawa-Carleton, 1998c, Light Rail Pilot Project: Progress Report No. 2, Ottawa, Ontario, 5p.

Regional Municipality of Ottawa-Carleton, 1998d. Light Rail Pilot Project, Ottawa, Ontario, 9p.

Region of Ottawa-Carleton, 1999a, Light Rail Pilot Project: Recommendations for Implementation, Ottawa, Ontario, 29p.

Region of Ottawa-Carleton, 1999b, Light Rail Pilot Project: Progress Report No. 5 , Ottawa, Ontario, $3 p$.

Rodrigue, Jean-Paul, 2005, Urban Transportation in Transport Geography on the $W e b$, retrieved March $22^{\text {nd }}, 2005$ from World Wide Web: http://www.people.hofstra.edu/geotrans/

Scheurer J, Newman P, Kenworthy J, Gallagher T, 2000, Can Rail Pay? Light Rail Transit and Urban Redevelopment with Value Capture Funding and Joint Development Mechanisms, ISTP, Perth, Australia, 81p.

Soberman, Richard, and Hazard, Heather, 1980, Canadian Transit Handbook, Joint Program in Transportation, University of Toronto-York University, Toronto, Ontario, $167 \mathrm{p}$.

Steger W.A., and Lakshmanan, T.R., 1968, Plan Evaluation Methodologies: Some Aspects of Decision Requirements and Analytical Response in Urban Development Models, Highway Research Board, Washington D.C., U.S.A., pp. 33-72

Strauss, Aselm, L., 1990, Qualitative Analysis For Social Scientists, Cambridge University Press, New York, New York, U.S.A., 319p. 
Stopher, Peter, and Meyburg, Arnim, 1975, Urban Transportation Modeling and Planning, Lexington Books, Toronto, Ontario, 345p.

Szymanis, Theresa A., 1999, Guidelines for Assessing Future LRT Station Sites, Faculty of Environmental Design, Calgary, Alberta, 164p.

Transport 2021, 1993, A Medium Range Transportation Plan for Greater Vancouver, Burnaby, British Columbia, 66p.

Transurb Inc., 1994, Interprovincial Commuter Rail Appraisal Study, Report Submitted to Regional Municipality of Ottawa-Carleton, Montreal, Quebec, 82p.

Vancouver Province, Urban Smog Hurts Lungs, Sparks Asthma, January 5, 2001; Page A.4

Vickerman, R.W., 1974, Accessibility, Attraction, and Potential: A Review of Some Concepts and Their Use in Determining Mobility, in Environmental Planning $A$ Vol. 6, pp. 675-691

Vuchic, Vukan, 1999, Transportation for Liveable Cities, Center for Urban Policy Research, New Brunswick, New Jersey U.S.A., 352p.

Wellar, Barry, 1982, Prospects for Planning: Coming to Grips with New Realities, The 1982 Conference Committee Canadian Institute of Planners, Hull, Quebec, 394p.

Wellar, Barry, 1994, Transportation Planning in Canada's Medium- and Small-Sized Communities, in Transportation Solutions for: Today, Tomorrow and Beyond, Transportation Research Board, Washington D.C., U.S.A., pp. 462-475

Wellar, Barry, 1995, Design and Pre-testing of a Survey Instrument to Measure Pedestrian Levels of Safety and Comfort, Regional Municipality of Ottawa-Carleton, Ottawa, Ontario, 94p.

Wellar, Barry, 1996, Walking Security Index Project: Literature Search, Outreach, and Research Design Activities, Department of Geography, University of Ottawa, Ottawa, Ontario, $75 p$.

Wellar, Barry, 1997, Safety, Comfort, and Convenience as Principal Components of the Walking Security Index: Initial Specification, Department of Geography, University of Ottawa, Ottawa, Ontario, 71p.

Wellar, Barry, 1998, Walking Security Index, Regional Municipality of OttawaCarleton, Ottawa, Ontario, 191p. 
Wellar, Barry, 2000a, Walking Security Index: Newspapers as a Source of Fact and Opinion on Pedestrians' Safety, Comfort, Convenience: A Keyword Based Literature Search and Review, Regional Municipality of Ottawa-Carleton, Ottawa, Ontario, 263p.

Wellar, Barry, 2000b, Walking Security Index Pilot Study: Basic Walking Security Index Component. Technical Supplement, Department of Geography, University of Ottawa, Ottawa, Ontario, 246p.

Wellar, Barry, 2002, Walking Security Index Pilot Study, Department of Geography, University of Ottawa, Ottawa, Ontario, 121p.

Wellar, Barry, 2004, Personal Communication, October 21, 2004

Whitelegg, John, 1993, Transport for a Sustainable Future, Belhaven Press, London, England, 202p.

Wingo, Louden, 1961, Transportation and Urban Land, Resources for the Future, Washington D.C., U.S.A., 132p.

World Commission on Environment and Development (WCED), 1987, Our Common Future, Oxford University Press, Oxford, England, 383p.

Wyatt, David A., 2002, Canadian Street Railways, retrieved August, $5^{\text {th }}, 2004$ from World Wide Web: http://home.cc.umanitoba.ca/ wyatt/streetcar-list.html

Zerbe, Richard O., and Croke, Kevin, 1975, Urban Transportation for the Environment, Ballinger Publishing Company, Cambridge, Massachusetts, U.S.A., 140p. 


\section{APPENDICES}




\section{APPENDIX I}

\section{Glossary of Terms}

Accessibility: A combination of two elements: location on a surface relative to suitable destinations, and the characteristics of the transportation network or networks linking points on that surface (Vickerman: 1974, p. 676).

Clustering: The close proximity or grouping of settlements or other activities in any spatial distribution (Goodall: 1987, p. 73).

Concentration of development: The tendency towards location of economic activity in and around a relatively small number of urban centres (found in a specified distance from a rapid transit station).

Compactness: Where people and activities are located along RT corridors, in areas that can be accesses by quality transit service, creating a built-in market for transit (ORTEP: 2003).

Compatibility: Ensure that future land uses are compatible with existing uses to ensure an appropriate transition between existing and future uses (http://ottawa.ca/public_consult/carp_rd/plan/land use en.shtml).

Convenience: From a transportation context can be viewed through the three variables of: travel time (time required between origin and destination, not withstanding potential congestion or additional trip distance); travel distance (minimizing path between travel points); costs (limiting monetary costs, additional costs such as time and distance, terrain and mechanical breakdown). Objective is to achieve as low a limit of inputs and costs as circumstances permit or yield the best balance sheet. From a pedestrian perspective, are the initiatives that preserve or achieve fairness in decisions and actions involving the provisions of and access to transportation facilities and services (Wellar: 1997, pp. 38, 47).

Densification: A measure of the number of geographic facts (for example people) per unit area (Norton: 2001, p. 143).

Development: The construction, re-construction, erection or placing of one or more buildings or structures on land or the making of any material change in the use or intensity of the use of any building or land densities (http://ottawa.ca/2020/op/vol_1/annex2_en.shtml).

Development growth near station locations: The construction of buildings and the change in the use and intensity of buildings or land densities within a specified area from a rapid transit station. 
Diverse housing choices: The availability of a range of residential options offered in Ottawa; such as single family homes, townhouses, and apartments (http://ottawa.ca/business/facts/counts_jan_04/index_en.shtml).

Employment nodes: Nodes are points of intensive activity, which provide a focus to public life, such as a market place or community centre, and are usually created at the convergence of important paths. Nodes are often signified by distinctive urban design characteristics relative to the surrounding area or district, such as the inclusion of a landmark building (http://ottawa.ca/2020/op/vol 1/annex2_en.shtml).

Employment Areas: Commercial, office, and industry are primary land uses; primary character of these areas is to serve industries, provide for a concentration of at least 2000 jobs at varying densities, must have access to truck-access routes, could be subjected to a Mixed-Use Centre if located near Primary Transit Network (http://ottawa.ca/2020/op/vol_1/3_6_5 en.shtml).

Enterprise Areas: Commercial, office, and industry are primary land uses may also include residential areas; primary character of these areas is to serve industries, provide for a concentration of at least 2000 jobs at varying densities, must have access to truckaccess routes, could be subjected to a Mixed-Use Centre if located near Primary Transit Network, designated in business parks that are achieving or can achieve much higher employment densities than traditional Employment Areas; medium to high-density office buildings; all housing is in the form of townhouses, stacked townhouses, apartments (at least 5 stories), at least $50 \%$ of land devoted to employment (http://ottawa.ca/2020/op/vol 1/3 65 en.shtml).

Greenbelt: A 20,350 hectare band of farms, wetlands and forests located in the southern part of Ottawa. First proposed in 1950 by the French planner Jacques Greber, the Greenbelt was originally intended to protect the rural land bordering the Capital from urban sprawl. Today it offers a range of outdoor recreation and learning opportunities for city-dwellers, consisting of heritage and natural interpretation activities, walking and skiing trails, and golf clubs. Most of the Greenbelt is owned by the National Capital Commission, with the rest owned by the Federal Government and private interests (http://www.canadascapital.gc.ca/greenbelt/history_e.asp).

High-density development patterns: Residential patterns that adhere to City's density policies, up to 99 units per net residential acre, other apartments (http://ottawa.ca/2020/op/vol_2c/goulbourn/5_2_en.shtml).

Highly specialized nodes: A connecting point between several lines (transportation junction) that confines development to the least number of land uses such as high density residential and/or retail development.

Inclusive development: Housing policies increase availability of affordable housing, integration of range of housing into all neighbourhoods; community design plans will 
directly involve residents and other stakeholders; better balanced transportation network, emphasis on transit, cycling, and pedestrian facilities (Clutterbuck: 2003, p. 7).

Infill development: The creative recycling of vacant or underutilized lands within cities and suburbs; addresses traffic issues by creating communities where people live closer to work and school, and where biking, walking, and transit can substitute for auto travel (Bartsch: 2001, p. 6).

Intensification: The density of development, measured in households or employment per hectare, increases (http://ottawa.ca/2020/op/vol_1/annex2_en.shtml).

Intensification: Increasing the intensity and diversity of urban land use development in proximity to public transit stations.

Land use: All arrangements, activities and inputs (sets of human actions) undertaken in a certain land cover type (Federal House in Order: 2004).

Mixed Use Centres: Strategically located to transportation system and accessible by all modes of transportation, centred on RT stations and contained on 1 or more arterial roads; transit-supported land use: offices, secondary, post-secondary secondary schools, hotels, hospitals, large institutional buildings, community recreation/leisure centres, daycare, retail centres, entertainment, restaurants, medium/high density residential areas and mixed-use development; employment targets of at least 5000 jobs; highest density employment buildings within $400 \mathrm{~m}$ of RT stations (http://ottawa.ca/2020/op/vol_1/3_6_2_en.shtml).

Mixed-use development: A variety of uses in a building or a community in close proximity, possibly including housing, recreational, commercial, institutional, or other employment uses (http://ottawa.ca/2020/op/vol_1/annex2_en.shtml).

Park and Ride Facilities: Consists of parking facilities at transit stations, bus stops and highway onramps, particularly at the urban fringe, to facilitate transit use (http://www.vtpi.org/tdm/tdm27.htm).

Service to major centres: Rapid transit lines that run through significant employment and/or business centres.

Smart growth: A blanket term for the congruent movements to channel new growth into existing communities and build new subdivisions as compact neighborhoods as a means of curtailing sprawl and its effects (Bartsch: 2001, p41).

Spatial Aspect: The geography of a matter, situation, or process (Wellar: 2004).

Spatial Factor: The elements of the natural and built environment, as well as statements in public policies, plans, and programs that affect where things are located and where populations travel (Wellar: 2004). 
Station-area development: The development of residential and commercial areas in walking distance to rapid transit stations.

Sustainability: Idea that current way of life, based on ever-increasing consumption of resources, could not continue indefinitely, and humanity would have to find a more acceptable way of life (Norton: 2001, p108).

Sustainable development: A strategy that requires the integration of economic growth, social equity, and environmental management to ensure a better quality of life for everyone, now and for generations to come (http://ottawa.ca/2020/op/vol_1/annex2_en.shtml).

Sustainable transportation: Satisfying current transport and mobility needs without compromising the ability of future generations to meet those needs. Current transport systems not sustainable because of reliance on fossil fuels such as petroleum to meet transportation requirements (Black: 2003, p317).

Sustainable transportation network: A rapid transit network that meets the criteria for satisfying current and future public transit demands.

Transportation hub: The centre of activity on a transportation system in which transportation routes/corridors radiate outwards from a central transportation transfer station/junction station.

Town Centres: Employs up to 10,000 people, intended to focus as the central area/ "downtown" of specified urban areas (Kanata, South Nepean). Mixed-use walkable neighbourhoods consisting of neighbourhoods of housing and parks, placed within walking distance of shops, civic services, jobs, and transit (http://ottawa.ca/city_services/planningzoning/2020/op/vol_1/3_6_2_en.shtml).

Transit-focused development: Building of residential and employment areas in proximity to rapid transit corridors to ensure integration of new development with rapid transit.

Transit-oriented development: The development of walkable, mixed-used communities surrounding transit stations. The benefits of these communities involve greater pedestrian mobility, increased transit ridership and decreased vehicular congestion, reduced incentive to sprawl and an increased incentive for compact development.

Transit-supportive (land use patterns, jobs): Land use development or employment opportunities that result from accessibility to rapid transit corridors.

Zoning: The regulation of land use relating to zoning by-laws. This involves the adoption of ordinances that divide a community into various districts or zones (http://ottawa.ca/city_services/planningzoning/2020/op/vol_2a/rockcliffe/4_0_en.shtml). 


\section{APPENDIX II}

\section{Pilot Study Screening of Questions}

\section{Pre-Screened List of Questions for Municipal Elected Officials}

1. In your opinion, what are the major factors that determine where the location of the proposed light rail routes should be?

2. List five objectives that you would deem necessary in selecting the optimum location for these routes ( 1 being the most important, 5 being the least important).

3. Do you agree with the location of the proposed routes? Please explain.

4. Are there viable alternative corridors that in your opinion would be better suited for the proposed light rail expansion? If so, why?

5. In terms of land development, will the proposed light rail routes have any effect on established communities within the city? Please explain.

6. Will the location of the proposed light rail routes be integrated with future planned residential and employment growth? Please explain your answer.

\section{Rating of Questions by Pilot Study Participants}

(R) - Retained

(P) - Provisional

(N) - Not Carried Forward

\begin{tabular}{|c||c|c|c|c|c|c|c|c|c|c|c|c|c|c|c|}
\hline \multicolumn{1}{|c||}{ QUESTION } & \multicolumn{11}{c|}{ PARTICIPANT } \\
\hline \hline \multicolumn{1}{|c||}{} & $\mathbf{1}$ & $\mathbf{2}$ & $\mathbf{3}$ & $\mathbf{4}$ & $\mathbf{5}$ & $\mathbf{6}$ & $\mathbf{7}$ & $\mathbf{8}$ & $\mathbf{9}$ & $\mathbf{1 0}$ & $\mathbf{1 1}$ & $\mathbf{1 2}$ & $\mathbf{1 3}$ & $\mathbf{1 4}$ & $\mathbf{1 5}$ \\
\hline $\mathbf{1}$ & $\mathrm{P}$ & $\mathrm{R}$ & $\mathrm{P}$ & $\mathrm{R}$ & $\mathrm{R}$ & $\mathrm{R}$ & $\mathrm{R}$ & $\mathrm{R}$ & $\mathrm{R}$ & $\mathrm{P}$ & $\mathrm{R}$ & $\mathrm{R}$ & $\mathrm{R}$ & $\mathrm{R}$ & $\mathrm{R}$ \\
\hline $\mathbf{2}$ & $\mathrm{P}$ & $\mathrm{R}$ & $\mathrm{P}$ & $\mathrm{N}$ & $\mathrm{P}$ & $\mathrm{R}$ & $\mathrm{P}$ & $\mathrm{R}$ & $\mathrm{P}$ & $\mathrm{R}$ & $\mathrm{P}$ & $\mathrm{P}$ & $\mathrm{P}$ & $\mathrm{P}$ & $\mathrm{R}$ \\
\hline $\mathbf{3}$ & $\mathrm{N}$ & $\mathrm{N}$ & $\mathrm{P}$ & $\mathrm{N}$ & $\mathrm{R}$ & $\mathrm{P}$ & $\mathrm{P}$ & $\mathrm{P}$ & $\mathrm{P}$ & $\mathrm{R}$ & $\mathrm{P}$ & $\mathrm{R}$ & $\mathrm{R}$ & $\mathrm{R}$ & $\mathrm{R}$ \\
\hline $\mathbf{4}$ & $\mathrm{R}$ & $\mathrm{R}$ & $\mathrm{P}$ & $\mathrm{R}$ & $\mathrm{R}$ & $\mathrm{P}$ & $\mathrm{R}$ & $\mathrm{P}$ & $\mathrm{R}$ & $\mathrm{P}$ & $\mathrm{N}$ & $\mathrm{R}$ & $\mathrm{R}$ & $\mathrm{R}$ & $\mathrm{R}$ \\
\hline $\mathbf{5}$ & $\mathrm{R}$ & $\mathrm{P}$ & $\mathrm{P}$ & $\mathrm{R}$ & $\mathrm{P}$ & $\mathrm{P}$ & $\mathrm{R}$ & $\mathrm{P}$ & $\mathrm{R}$ & $\mathrm{R}$ & $\mathrm{P}$ & $\mathrm{P}$ & $\mathrm{P}$ & $\mathrm{R}$ & $\mathrm{R}$ \\
\hline $\mathbf{6}$ & $\mathrm{R}$ & $\mathrm{P}$ & $\mathrm{N}$ & $\mathrm{R}$ & $\mathrm{P}$ & $\mathrm{P}$ & $\mathrm{R}$ & $\mathrm{P}$ & $\mathrm{R}$ & $\mathrm{R}$ & $\mathrm{N} / \mathrm{P}$ & $\mathrm{R}$ & $\mathrm{P}$ & $\mathrm{P}$ & $\mathrm{R}$ \\
\hline
\end{tabular}




\section{Suggestions by Participants for Revising Questions}

\section{Question 1}

- What were the major factors that determined the choice of proposed routes of light rail expansion?

- Which of the following factors (give a range of choices, 10-15)

- Questions 1\&2 are hard to distinguish (may want to merge them together)

- Flexibility of routes

- Are you going to give them a list of the factors to consider? If so, don't make it as long as the list of key terms/phrases, it would probably be better if you asked them to create their own lists

- Answers may produce statements of cost, congestion, commuting patterns, location of results for social benefits

- What are the factors, difficult to determine between factors and objectives

- How many factors? (3-5)

\section{Question 2}

- Objectives could include: being able to demonstrate ridership increases, least impact on the environment, fit into future plans, energy use, provide most direct access to city core, select a route where rationalize light rail running most of the day

- Perhaps make a list of objectives

- If councillors suggest cost-effectiveness, what does this mean?

- List can be somewhat constraining

- Rephrase the question

- To prioritize the choice for these routes, instead of writing "optimum location"

- This question may be over councillor's head

- Perhaps provide a list of 9 objectives

- "List 5 objectives" is worded in a way too much like an exam

- Seems to be repeating question 1, suggests "if you consider the overall objectives of the City, such as the vision set forth in the Official Plan, are there particular objectives which you believe would be advanced by the proposed light rail expansion?"

\section{Question 3}

- What are the negative aspects of the location of the current proposed routes?

- Too general (more specific)

- Do the councillors agree with the routes? Too many, too few?

- Should be focused a bit more

- Provide a map of proposed light rail corridors

- Refer to report, what are the actual lists

- Rephrase the question

- Should try to make the question more open (try to avoid a question that can be answered with a simple "Yes")

- Map must be included (light rail routes) 
- Do you agree with... on the rapid transit map

- Answers won't be on a common understanding

- Is it clear what is on the table? Specify the routes (routes only in Ottawa)

- The object is not clearly defined

- Begin the question with "Assuming the proposed routes will be built... (assuming something goes ahead)

- Clarify the routes that I am referring to (E-W, N-S)

- Perhaps rephrase and say :"Do you support" rather than do you agree

- Explain the proposed routes/corridors

- Include maps, preamble to the actual question

\section{Question 4}

- Viable: what does this mean?

- Councillors will probably answer NO to this question

- What alternative corridors were considered?

- Established communities within the city and outlying areas

- Expansion....than the ones selected

- This is very close to question \#3

- Councillors may speak from local knowledge

- This question may not get me too far

- Might want to combine question 3 and 4, so that question becomes whether the respondent agrees With the proposed routings, or considers that there are alternatives which can be studied

\section{Question 5}

- Thinking specifically of the established communities within the city....

- Communities: well established (need to define what a community is)

- Have any specific "significant" effect on established communities

- The term "land development" should be reworded

- Are there to be any restrictions e.g. bylaws, removal of gas stations, tollbooths in city core?

- Specify, what are the effects, examples

- Reword "effect"

- Ask them about their specific ward, as well as other communities they might be familiar with, It brings the study closer to what's important to them

- Depend on local knowledge within the councillor's ward

- Councillors will more than likely comment on their wards

- With map may want to show where communities are clustered

- Very loaded question, there is something implied in this question

- State what is meant by "city", including Kanata, other suburbs

- Too vague, greater specification

- What is an established community? E.g. community that is $90 \%$ developed

- Consider asking to what effect the respondent believes the proposed routes will have on existing communities 
- To clarify this question provide examples of established communities (Glebe, Alta Vista)

\section{Question 6}

- How/should? Looking now at future....

- Creation of new communities

- This question could generate a simplistic answer

- Perhaps use the term "development parks"

- Reword

- Has the location of the....been selected based on city's long term plan?

- In your opinion, will....

- Councillors will know where growth will occur within their communities

- This question gets more at question \#5

- May generate responses such as "I don't know, can set out policies for this"

- Must figure out if I am interested in top-of-head answers, or considered answers (researched answers)

- How....

- What effect the proposed routes will have on plans for future residential and employment growth

\section{Additional Comments Provided by Participants for Shaping Questions}

- Need to understand location is one dimension of light rail planning

- Locational might be better than spatial factor (even if not quite as accurate, userfriendly)

- Perhaps 8 questions

- Might want to raise issues from OP and RTES in dialogue

- Cost is a major factor involved

- Maybe send councillors letter with Carleton overhead (mail the letter, not email)

- Contact former city councillor for participation

- Thesis does not discuss cost (this might be a fallback)

- Light rail always a question of economics

- Economic for people using cars currently in Kanata/Barrhaven

- Find where sewers are located for development, and that is where communities will be built (e.g. South Nepean)

- South Nepean and Riverside South are growing due to infrastructure

- Don't want route to dictate where development is (business development)

- Listing objectives is important, however don't want the councillors to just select terms

- Where in encouraging development, want route to have minimal impact on existing communities 
- Route should make use of existing ROW/open land

- Councillors should fully inform anybody disrupted by expansion (i.e. within a certain distance)

- Do you see certain transportation issues as serious enough to ward immediate light rail expansion

- Barrhaven, Riverside South are hindered without rapid transit

- Would you consider one of the following communities, as not linked to rapid transit access

- Whether politicians notice Orleans has Transitway link, Kanata does not

- City council is quite fiscally conservative

- Nodes in Ottawa around rapid transit stations have been a failure

- With rapid transit in Vancouver, land use more attractive around stations

- Councillors will be expressing policy view

- The councillors would expect question 6 to be a main part of the initial study by the consultants

- Make clear up front that the results of the questions are anonymous with the councillors

- Urban versus rural: comparison of results from councillors from these areas, also maybe urban core wards versus suburban wards

- No effort to integrate bus schedule with light rail expansion

- Councillors so overrun, they necessarily rely on staff for responses

- Find out Wendy Stewart's opinion of light rail expansion

- For the participating councillors, find out who is on what committee

- Give the questions before the interview

- Caution on focusing solely on councillors, as they are only in some sense in charge

- Good thesis would be critiquing advice from city staff to councillors

- Move question \#2 to the end of the list (provide a list of objectives as well)

- Will the councillors include their assistants in the interviews? (this is a possibility)

- Perhaps provided a warm-up question

- Might want to have councillors elaborate on some of their answers 


\section{Suggested Questions to Include in List as Provided By Participants}

(1) Taking into consideration the values of money, cost/benefit analysis, where is the most optimum location for the light rail?

(2) What is the city councillor's expectation of success of light rail routes?

E.g. fewer roads on the routes

(3) What accompanying bylaws/processes/restrictions do they plan? E.g. bylaws/removal of gas stations, tollbooths

(4) What is the main objective of the light rail expansion? E.g. greenhouse gases

(5) What decisions prompted councillors to select these lines?

(6) What is the rationale behind selecting the station stops? What criteria do you think should be used in selecting stations?

(7) Do you think Ottawa is a city that will embrace an expanded rapid transit system?

(8) How might federal land use policies affect decisions of the location of routes? E.g. Greenbelt

(9) In your view, service to downtown, are the routes sufficiently oriented to serving downtown core hub?

(10) Are you serving places where transit is not there? E.g. Carleton

(11) What places have intermodal accessibility? (Park and Ride, biking/walking accessibility)

(12) What is the transit demand from different sectors across the city? How would the proposed routes reach this demand?

(13) There is an influx of people into the downtown core, how close are they to the light rail terminus?

(14) To what extent would you support increasing taxes to fund and operate this project?

(15) What are the impacts of not building light rail network on future land use planning in Ottawa?

(16) Do councillors know the bottleneck areas in Ottawa?

(17) Do councillors take public transit?

(18) Integration with the buses- should there be a connection? Is there a planned connection?

(19) Are there alternative forms of rapid transit (E.g. extending the Transitway) that provide a solution of equal promise... but just not sexy and not supported by the provincial and federal governments?

(20) Is there a solid solution to routing the light rail route through downtown and to the Rideau Centre, and is there any such solution (alternative) to the streetcar? 


\section{APPENDIX III}

\section{Ranking of Key Terms/Phrases}

The following list of key terms/phrases was designed in order to assist in measuring the extent to which the spatial factor is associated with land use planning for the proposed light rail expansion. The key terms/phrases in this list are derived from written materials dealing with proposed light rail expansion. The pilot study participants were requested to select from this list ten terms/phrases that they felt best represented or expressed their position or understanding of the land use planning aspect of the proposed light rail expansion. The list is presented in alphabetical order.

\section{List of Key Terms/Phases for Light Rail Expansion}

1. Accessibility (employment centres)

2. Clustering (around rail/transit stations, of neighbourhood facilities)

3. Concentration of development (within walking distance of stations)

4. Compactness (development, communities, residential living)

5. Compatibility

6. Convenience

7. Densification

8. Development

9. Development growth near station locations

10. Diverse housing choices

11. Employment nodes

12. Employment Areas

13. Enterprise Areas

14. High-density development patterns

15. Highly specialized nodes

16. Inclusive development

17. Infill development

18. Intensity, intensified, intensification

19. Land-use (restructuring and/or regeneration, intensification)

20. Mixed use centres

21. Mixed-use development

22. Park and Ride facilities

23. Smart growth

24. Station-area development

25. Sustainability

26. Sustainable development

27. Sustainable transportation network

28. Transportation hub/ Intermodal connections

29. Town Centres

30. Transit-focused development

31. Transit-supportive (land use patterns, jobs)

32. Zoning 


\section{$\underline{\text { Key Terms/Phrases Selected by Participants }}$}

The list of key terms/phrases selected by each pilot study participant is provided below. The terms/phrases selected by each participant are shown in alphabetical order, and not in the order in which they were initially selected. This method of ordering is simply to allow for an easier read of the lists.

\section{Participant}

(1)

Accessibility, Densification, Employment Nodes, High-density development patterns, Land Use, Mixed-use development, Park and Ride facilities, Transportation hub, Transit-focused development, Zoning

Accessibility, Development growth near station locations, Diverse housing Accessibility, Compactness, Development growth near station locations, Inclusive development, Infill development, Intensity, Land Use, Mixed use centres, Town Centres, Transit-focused development, Transitsupportive (land use patterns, jobs), Zoning

Compatibility, Convenience, Densification, Development growth near station locations, Employment Nodes, Intensity, Park and Ride facilities, Station-area development, Transportation hub, Town Centres

Concentration of development, Development, Employment Areas, Highly specialized nodes, Mixed Use Centres, Mixed-use development, Sustainability, Sustainable Development, Transportation hub, Zoning

Clustering, Compatibility, Development growth near station locations, Employment nodes, Park and Ride facilities, Sustainable development, Sustainable transportation network, Transportation hub, Town Centres, transit-supportive (land use patterns, jobs)

Accessibility, Concentration of development, Convenience, Diverse housing choices, Park and Ride facilities, Sustainability, Sustainable development, Sustainable transportation network, Zoning

Concentration of development, Compactness, Diverse housing choices, Employment Areas, Inclusive development, Infill development, Land-use, Sustainable development, Transit-supportive, Zoning choices, Employment nodes, High-density development patterns, Infill development, Land-use, Mixed use centres, Park and Ride facilities, Smart Growth, Transportation Hub/ Intermodal connections, Town Centres 
(9) Accessibility, Clustering, Convenience, Employment Nodes, Intensity, Land-use, Smart Growth, Sustainable transportation network, Transportation hub/ Intermodal connections, Transit-supportive (land-use patterns, jobs)

(10) Convenience, Development growth near station locations, Employment Areas, Land-use, Park and Ride facilities, Sustainability, Transportation hub/ Intermodal connections, Town Centres, (Capacity, Travel time)

(11) Accessibility, Convenience, Employment Areas, Park and Ride facilities, Smart Growth, Station-area development, Sustainable development, Transportation hub/ Intermodal connections, Transit-focused development, Transit- supportive (land-use patterns, jobs)

(12) Clustering, Concentration of development, Compactness, Development growth near station locations, Park and Ride facilities, Station-area development, Sustainability, Transportation hub/ Intermodal connections, Transit-focused development, Transit-supportive (land use patterns, jobs)

(13) Clustering, Concentration of development, Diverse housing choices, Employment nodes, Intensity, Land-use, Mixed use centres, Smart Growth, Sustainable transportation network, Transit-supportive (land use patterns, jobs)

(14) Clustering, Concentration of development, Compactness, Employment Areas, Intensity, Land-use, Mixed use centres, Park and Ride facilities, Town Centres, Transit-supportive (land use patterns, jobs)

Accessibility, Concentration of development, Convenience, Diverse housing choices, Employment Areas, Land use, Mixed use centres, Park and Ride facilities, Sustainability, Town Centres

Accessibility, Clustering, Concentration of Development, Compactness, Densification, Development growth near station locations, Employment Nodes, Land Use, Park and Ride facilities, Transit supportive development 


\section{$\underline{\text { Key Terms/Phrases as Selected by Participants }}$}

Upon completion of the pilot study participants selecting ten key terms/phrases that they considered to be the most important to the land use planning aspect of the proposed light rail expansion, the key terms/phrases were subsequently ranked according to the number of times they were selected. This list is arranged from most to least selections, according to the number of selections a key term/phrase received in total from all of the pilot study participants.

Park and Ride facilities

(Number of Times Selected)

Land-use (restructuring and/or regeneration, intensification)

Transportation hub

Transit-supportive (land use patterns, jobs)

Accessibility (employment centres)

Concentration of development (within walking distance of stations)

Development growth near station locations

Employment nodes

Town Centres

Convenience

Employment Areas

Mixed use centres

Infill development

Station-area development

Compatibility

High-density development patterns

Inclusive development

Mixed-use development

Development

Highly specialized nodes

Enterprise Areas 


\section{Weighted Ranking of Key Terms/Phrases}

As described in Section 4.2.1, a relative numerical weight is assigned to each key term/phrase. This weight is based on the number of times a key term/phrase is selected by the pilot study participants. Upon assigning weights to each key term/phrase, the numerical value representing the number of times a term/phrase is selected is multiplied by the assigned weight of each factor to produce a weighted ranking score. The key term/phrase with the highest score is subsequently ranked the highest, the lower scores are ranked in descending order.

The scores are then grouped in to three categories: Highly Related, Moderately Related, and Not Specifically Related. The total number of times a key term/phrase was selected determined the placement of this term/phrase into what was deemed the appropriate category. The first part shows the ranking process and which key terms/phrases were placed into which category. The second part provides a brief numerical analysis for the grouping of key terms/phrases into each category.

\section{Highly Related}

\section{(Weight $x$ Times Selected $=$ Weighted Ranking) (Ranking)}

1. Park and Ride facilities

$12 \times 11=132$

2. Land-use

$11 \times 10=110$

3. Transportation hub

$10 \times 9=90$

4. Transit-supportive

$10 \times 9=90$

5. Accessibility

$9 \times 8=72$

6. Concentration of development

$9 \times 8=72$

7. Dev't growth near station locations

$8 \times 7=56$

8. Employment nodes

$8 \times 7=56$

9. Town Centres

$8 \times 7=56$

\section{Moderately Related}

1. Convenience

2. Employment Areas

3. Mixed use centres

4. Clustering

5. Compactness

6. Diverse housing choices

7. Intensity, intensified, intensification

$7 \times 6=42$

$7 \times 6=42$

$7 \times 6=42$

$7 \times 6=42$

$6 \times 5=30$

$6 \times 5=30$

$6 \times 5=30$

$6 \times 5=30$

8. Sustainability

$6 \times 5=30$

9. Sustainable development

$5 \times 4=20$

10. Smart growth

$5 \times 4=20$

11. Sustainable transportation network

$5 \times 4=20$

12. Transit-focused development

$5 \times 4=20$

13. Zoning 
Not Specifically Related

1. Densification

$4 \times 3=12$

2. Infill development

$4 \times 3=12$

3. Station-area development

$4 \times 3=12$

4. Compatibility

$3 \times 2=6$

5. High-density development patterns

$3 \times 2=6$

6. Inclusive development

$3 \times 2=6$

7. Mixed-use development

$3 \times 2=6$

8. Development

$2 \times 1=2$

9. Highly specialized nodes

$2 \times 1=2$

$1 \times 0=0$

10. Enterprise Areas

Grouping of Key Terms/Phrases Into Categories

(based on number of times selected)

Highly Related Moderately Related Not Specifically Related $\frac{=1>7}{9}$

$\frac{=1>4</ 6}{13}$ $\frac{=/<3}{10}$ 


\section{APPENDIX IV}

\section{Revised List of Questions from Pretest Phase}

1. In your opinion, what are the major factors/aspects that determine where the location of the proposed light rail corridors should be?

2. Please list five objectives that you would deem necessary in selecting the optimum location for the proposed corridors ( 1 being the most important, 5 being the least important).

3. Assuming the proposed routes will be built, do you support the location of the proposed North-South expansion and the East-West corridors as displayed in the city's transit plans? Please explain why.

4. In your opinion, are there alternative corridors that are viable (workable) in an overall sense that would be better suited for the proposed light rail expansion?

5. In terms of land-use development, (if you prefer, within and in proximity to your respective ward), will the proposed light rail corridors have any significant effect on the established communities within the new City of Ottawa? Please explain.

An example of an established community is one whose residential and institutional infrastructure has been completed (such as Alta Vista, Glebe, Bells Corners, unlike communities in Riverside South, South East Innes area).

6. How will the location of the proposed light rail corridors be integrated with future residential and employment growth? Please explain your answer. 


\section{APPENDIX V}

\section{Municipal Elected Officials Responses to Interview Questions}

This appendix documents the complete responses from each participating municipal elected official to the six interview questions. The questions are listed in ascending order as they were originally posed, followed by the responses from each participant. The ordering of the participants was based solely on the chronological order in which they were interviewed. Municipal elected officials names are withheld on account of ethical
considerations.

\section{Question 1}

\section{In your opinion, what are the major factors/aspects that determine where the location of the proposed light rail corridors should be?}

\section{Participant A}

\section{$\underline{\text { Responses }}$}

- Available corridors (overcome geography, cost, certain type of existing development can't go through)

- Where population is already based

- Orleans has highest modal split

- Where is future growth, meet with future ridership plans

- Want to accommodate present growth plus future growth (e.g. Riverside South)

- In Riverside South get people to use the rapid transit, pre-empt building of more roads

- Not enough adequate transit in east end

- Gridlock doesn't force people out of their cars

\section{Participant B}

- Where the existing rail infrastructure is

- Lost provincial funding for Transitway system, $2^{\text {nd }}$ best alternative was to make use of existing rail infrastructure

- Constrained by cost, not in a position to build new rail infrastructure

- Constrained by existing rail infrastructure in town

- Within the rail infrastructure some choices, but not many

\section{Participant C}

- Population base (is Light Rail route close to major residential areas?)

- Destination (where are we taking people)

- Financial factor-done in cost-effective manner, should make use of good (existing) infrastructure e.g. Prince of Wales bridge

- Using existing infrastructure should not have cost problem

- Public acceptance of having routes close by: done in fashion that is less intrusive to environment (noise barrier, natural) 4 factors: location, destination, use of existing infrastructure, results of environmental assessment for the routes 


\section{Participant D}
A number of factors

- $1^{\text {st }}$ is the Official Plan, use that as a guide

- Availability of corridors

- Councillor is focused on the North-South LRT, existing rail corridor

- In emerging communities: e.g. Riverside South, agreements with developers
moving forward

- Notion is to change the modal split, out of cars, onto rapid transit
- Light rail is the hook for this - Have development community working in tandem with city of Ottawa, to ensure
they're building densities along the line

- Money is always a key, is a major factor

- Affordability is also a major factor

- Availability of land

\section{Participant E}

- Existing corridors

- Cheapness of installation (least cost of installation) combined with a reasonable
ridership

- Great cost of rail lines are Rights of Way

- This is a reasonable choice

- The way the corridors are proposed (design), have a loop around the city and down the centre, not a bad way to build a skeleton service, high density service

- Loop means people can plug into it in different places

- Transit should mimic where people already live and where they already go

- Old streetcar system was very effective, served people very well, ROW was on the roads though

- Could put an East-West line down Carling Ave, are going to do this way down the line

- This proposal displaces no cars, nobody will notice the construction, ROW's are all there

- Will be a pretty good commuter service

- Old streetcar service was fully integrated, convenient, accessible service, these new lines won't be that

- This is going to be a commuter service that will be highly dependant on bus service

- Service will move a whole bunch of people

- As a second level choice it is pretty good

\section{Participant F}

- Environmental Assessment conducted for North-South route, and started study for environmental assessment for East-West route

- Location determined by population of those locations, not going to put station in rural area where there are not enough people 
- Also looking at Park and Ride to gather outlying people and gather them at
stations

\section{Participant G}

- Population density and access to work environments

- North Business Park in Kanata, want to augment existing infrastructure and expand the plan

- Other factor are environmental concerns

- Critical concern is east-west flow of traffic

\section{Participant H}

- Location is based on need

- Where is the population, either existing or proposed

- If you know a ton of people in South Keys and Barrhaven, and no roads are built out there, then have to provide a system of transportation, and light rail is the best

- Other factors are environmental assessment

- Actual location of corridors is done through EA and cost

\section{Participant I}

- Maximize the existing infrastructure, which is the current Transitway

- Idea behind Transitway is $20 \%$ cheaper to build, $30 \%$ cheaper to operate compared to LRT

- Trend in 1970's was for LRT, Ottawa went against this trend

- Greenbelt adds extra distance to where suburbs are located

- Level of BRT system has achieved a level of ridership unsurpassed in North America for a city of Ottawa's size

- Current transit modal split is $15 \%$ city-wide, $30 \%$ in east end, already achieved set target according to Official Plan

- Success is due to express bus route system- takes people directly to work from home, no need to transfer

- Major attraction for riders on public transit is not having to transfer

- With LRT might have to go from 1-2 transfers, major disincentive for attracting transit system

- Have to train people to get used to transfers, the buses would turn into a feeder system

- Sees conflict between Bus Rapid Transit and LRT

- Transitway was built so that it could be converted to light rail

- Fundamental problem is wanting to build 2 parallel systems

- LRT will serve some people within the downtown, Transitway system is other method

- Right now city staff has reported not cost-effective to convert Transitway into light rail

- $\mathrm{CN} / \mathrm{CP}$ tracks are where light rail could be located

- Problem with this is that this is not where population are located, these routes are freight tracks, only interurban rail corridors 
- Not the best way to get people where they live to where they want to go

- When making theses conversions, stuck with heavy rail based system

- Want to have a LRT system that will cross downtown

- Diesel trains will not work downtown

- Sees problem with infrastructure, technology that city is attempting to use

- Everybody is in favour of concept of light this downtown, bury Transitway under dollars, would like to see subway system in cyclists, eliminate bottlenecks of buses downtown

- Need to have something that is trolley E.g. trolley in San Francisco

- Rapid transit brings people from suburbs to downtown with least amount of transfers, least conflict with other traffic

- Believes it is correct with existing infrastructure

- Right now seem to be building hybrid heavy rail system

- Lack of integration between BRT and LRT - Factor is to locate where infrastructure is, where population is most appropriate
and where people want to travel

\section{Participant J}

- There are a couple of factors

- People get hung up on existing ridership

- Should be existing and future ridership

- Challenge in Ottawa is that transportation of all types often lags significantly

- Development patters develop in a way that is not consist that is not with transitfocused development

- Have to pick routes where there is good ridership (core of ridership), where there is significant for sustained future growth

- Will allow for development hubs

- People can them make "real" transportation choices

- Choose to ride train: efficient, effective, frequent headways, make choice not to buy second car

- Development hubs up around light rail stations

- Other factor will be sensitivity to cost

- Costs are prohibitive to some areas

- Overwhelming factor is you want light rail to be in a place where it has most significant opportunity to change development pattern, to make a difference in transportation choices in and around that community

- This has best chance of minimizing capital investment in other transportation modes, bus routes, extra buses, extra road lanes for cars, while maximizing the impact to make on the investment for the light rail route 


\section{Participant K}

- Factor in only one

- Light rail corridor can only go where a corridor is possible

- Cost drives all of this

- If you have corridor with tracks in place, this is corridor number one

- Where corridors are available, no other options

- Long strips of land in the city is limited, without expropriating large parcels of land

\section{Question 2}

Please list five objectives that you would deem necessary in selecting the optimum location for the proposed corridors ( 1 being the most important, 5 being the least important).

\section{$\underline{\text { Responses }}$}

\section{Participant A}

Issue looked at where do we already have heavy transit use, where is future growth

(1) How will rapid transit address major growth areas (e.g. Kanata, Barrhaven, Riverside South)

(2) Maintain and improve existing transit ridership (Orleans has high transit use)

- Accommodate those that are already putting pressure on the system

- What kind of roads would you build if rapid transit not built

(3) Have to look at space consideration and cost

- Availability of a corridor (cost factor)

- Looking at not having to expand roads

(4) How will these corridors influence future growth?

(5) Concentrate growth around transit stations

- Close in ranking, may be hard to rank, some may be a toss up

\section{Participant B}

(1) Conductivity between growth areas and employment areas (employment areas being downtown)

(2) Conductivity with Transitway system

(3) Ability to cross river into Gatineau (third priority), not isolated from that population, rail infrastructure link across Lemieux Island

(4) Impact in neighbouring communities

(5) What kind of interference from other users of the rail lines (integrate commercial rail traffic with transit)

- If we have major asset to transport people, that should shape planning policies in the city

- Don't build where transit can't go, build where light rail will go

- Should have an impact on official plan policies for growth and development 


\section{Participant C}

(1) Cost

(2) Relevance of ridership (are stations close by to people who are going to use them?)

E.g. spur to airport, build a hotel close to airport (make it easy for people to access light rail)

- Proximity to people who are going to use it (residential and business, hotels, tourists)

(3) Destination

(4) Results of the environmental assessment-backdrop to every criteria

(5) Looking at unique way of moving people around

\section{Participant D}

(1) Advanced planning: Riverside South community

- Get in early (LRT) on in development stages of community to shape the community

- Establish the line, and plan the community around a line, that is how to obtain the modal split

- Everything has to be easy, easier than getting into the car

- Build density along the line

- This is a long-term project: 50 years

(2) Existing travellers: businesses, schools, potential and existing users

- Build a line that goes through major employment centres: go through business parks, attract a lot of ridership

- Looking at existing and how to shape the lines to catch what is already there (ridership)

- Look to future of growth and try and plan in a reason, and look to where you want to shape the line is where people are going to be

(3) Shaping communities

- Look at people's travel patterns

- Connections are important in travel plans (North-South LRT)

- Travel plans for potential users

(4) Ease of implementation

- In the realm of possible

- Has to be affordable

- Availability of the corridor, acquiring land

(5) Building on the success of existing corridors (building on success of pilot $\mathrm{O}$ Train)

- Making sure connection to downtown

- Goes to issue of where people are going

- Look at people's destinations, concerned about those to ensure success of the LRT 


\section{Participant E}

(1) Would choose routes that were mimicked before

(2) Dedicated rights-of-way

(3) East-west travel

(4) North-south travel

(5) Major stations should never further than a frequent five minute bus ride

- Have to be really frequent e.g., Toronto: get on bus to subway to streetcar, never take longer than 1-2 minutes for the transfer

\section{Participant F}

(1) Transferring people from A to B

(2) Follow the EA to do the least damage on the environment

(3) Have a good, dependable system so people can have trust in the system (in England you don't have to drive, can take the subway downtown), this should be focus point for Ottawa system, make the LRT accessible and dependable for tourists or visitors don't have to provide your own vehicle

(4) Be able to connect the city together, have to connect all directions of the city, whether North-South route first, then East-West route after, must have system in place, to make direction of the city

(5) Cost- how can we afford the LRT system

- Keep in mind road and bridge construction costs just as much as LRT routes

- Get system up and running and not to stall the routes any longer because funds are not available

\section{Participant G}

(1) Shortening transit time

(2) Increase ridership

(3) Cost to the taxpayer (make sure costs make sense)

(4) Effect on the environment

(5) Making sure people are displaced from cars

\section{Participant H}

(1) Environmental Assessment

(2) Need (for instance if more growth in a certain area, so need factor comes in)

(3) Cost

(4) Development pressures

- If you know development is going to be in a certain area, route should be where development is going to be

(5) Community concerns

- Have to keep community sensitivity in mind (have to develop a route that is sensitive to community concerns)

- The route might have to go left or right of certain roads and conservation areas 


\section{Participant I}

(1) Completely integrated

(2) Continue to boost ridership (convince people to ride transit, ultimate objective, as

(3) Making sure frequ gets close to 1 million mark in less than a decade) level of service on one hand to service is maintained, don't want to decrease the cuts as money decreased in to help boost another system (mentions OC Transpo system at expense of existing bus systor future LRT), can't do full integrated

(4) Cost must be factored in (taxes not current bus system, very rimot enough to build a new system, or improve the

- Possible extra sources of revenue on senior levels of government) money has materialized

- With this extra money for funding make sure it is being used wisely, and not

- Transitway was built with $75 \%$ provincial subsidies

- Right now have piecemeal funding

- Want to continue building out transit system on an incremental basis

- Leary of "transit revolution"

- Parallel LRT system will compete with existing BRT system

- Sees funds being siphoned away from bus system, which is working well

- LRT system will cost billions to build

(5) Make sure technology is compatible with what currently exists, and what will evolve in the future

\section{Participant J}

(1) A high prospect of future sustained ridership

(2) Ability to change transportation patterns (giving a transportation choice)

(3) Ability change development form, more compact development around transit stations

(4) Cost

(5) Present ridership, must have a solid base of ridership, one you can work from

\section{Participant K}

(1) Corridor has to serve certain densities of population

(2) Density in proximity to corridor is a huge factor

(3) Proximity to density should mean a good level of ridership use, therefore makes huge sense, this is a criteria

- Density defined in terms of residential and business areas, these have to be adjacent to the corridor

(4) Objectives of light rail system is to serve the most people possible, this is what makes the whole thing cost-effective

(5) Even those who don't ride the light rail will benefit, as it removes a certain number of car and bus users

- One view transportation system in its totality, light rail can make the roads less congested 
- Want to have a very god transportation system: all types of rapid transit and the road system

\section{Question 3}

Assuming the proposed corridors will be built, do you support the location of the proposed North-South expansion and the East-West corridors as displayed in the city's transit plans? Please explain why. [Map of proposed corridors will be provided].

\section{$\underline{\text { Responses }}$}

\section{Participant A}

- Yes, of all the initial routes, eliminated routes that were less beneficial to growth, less beneficial to current users, probably didn't fully meet TMP and OP objectives

- These ones best met objectives of outlined for growth in city and meet current users, meets needs of projected growth

- Tried to accommodate costs, and meet corridors that are available, and less costly to acquire and convert

\section{Participant B}

- North-South (corridor) is a success, want to go to growth areas in South Gloucester

- East-West (corridor) is the next stop, cost element, in that there are gaps in the system where there is not rail

- This will create problems in terms of choice

- Will have to build Transitway out east, and have a choice between Transitway and LRT

- May not go as far east as the plan goes, based on cost

\section{Participant C}

- Yes-absolutely

- South core of Ottawa is fastest growing area of the city/Barrhaven- Strandherd bridge connection

- Strandherd light rail bridge has to diminish impact on roads

- Environmental purposes will decrease smog

- Practical to diminish use on roads. Less wear and tear on the streets, better for city capital

- Less people on the roads, more space to move goods

- Not using Transitway as effective as should be

- East-West: gridlock on 417 is a huge problem

- Cost of building interchange on 417 is very expensive

- Need to get people back and forth easily from Corel Centre

- Also important to have quality of life issues (less stress if not driving)

- Diminish number of accidents-cost effectiveness of more people riding LRT

- Effectively/efficiently get people moving from east to west 
- Light Rail needs to go near new Ex by casino, build station there-kiosks, multifunctional station, have coffee shops, dry cleaning shops, government services: license, dog permits, travel agency, some type of commerce, safety is also a critical concern

\section{Participant D}

- Yes, as a member of city council, went through considerable public consultation, and based on guiding documents, Official Plan and documents that fell out of Official Plan, established where corridors will be

- Documents went through considerable public consultation and considerable thought by member so this council

- Believes that went through all of the considerations

- Reality is based on info they had and public consultation

- Truly believes the decision council made is the correct one

- Building on the existing line, looking at the destinations, with connections to airport and downtown

- The North-South corridor is the right corridor

- What has been established to this point is supportable

\section{Participant E}

- North-South line is the right decision, because already though dense area, and already doing quite well in pilot stage

- Not convinced "we" (council) made the right decision

\section{Participant F}

- Yes, because from political point of view building a new city, only four years old

- Since amalgamation, the city has extended, very important to explain to all of Ottawa residents to ensure that citizens that they are not just paying for the NorthSouth route, vision of building whole city to merge together to help get the LRT system up and running

\section{Participant G}

- Yes, if it provides a cost-effective way to augment existing transit system

\section{Participant H}

- The routes are actually the corridors

- Supports the proposed routes as they are in a large corridor

- Support the criteria participant has listed

- Cost of roads is extremely expensive especially in corridor

- LRT proposed routes are the cheapest route (both East-West, North-South), especially East-West route

- Can stop development when decide the route, that way eliminate need to expropriate 
- North-South route more difficult as already existing population, therefore difficult in dealing with community groups, that is why EA is going to be extremely important

- Agrees with the corridors

- In the future a proposal for LRT in downtown corridor, stretch of line going through centre of city

- This kind of light rail will be different than major North-South route

- Uses Portland, Oregon as type of system, a type of tramway that maybe has dedicated rights-of-way- tramway only area

- Thinks this system can be compatible with rest of neighbourhood if planned properly

\section{Participant I}

- Descended (did not agree) with the whole system, as it will compete with existing bus system, rather than compliment it

- There are light rail routes that are literally parallel with existing bus route

- Light rail is very noisy compared to buses (example of noise barriers on the OTrain route)

- Very high cost for noise retrofitting

\section{Participant J}

- Strong existing base of ridership because of Light Rail Pilot Project

- Has great potential to change development patterns in Riverside South and Leitrim growth areas

- When it is successful, will defer capital expansion to transit network, won't have to make investments in other infrastructure, good for taxpayer

- Going downtown is critically important to go right to the Rideau centre

- Less transfers the better the rides for the customers

- Light rail connects some major shopping and employment areas, this can lead to a decrease in Additional trips (i.e. parents will not have to drive their kids around as much)

- Supportive, but less supportive, less confidence in the East-West corridor, than the North-South corridor

- Wants to figure out if it is better to implement trolley system for "better bang for our buck" than the East-West corridor on the fringes of the city

- Not opposed to East-West, has some hurdles to overcome

- Thinks North-South (route) will fundamentally change the way people move in the south end of the city

\section{Participant K}

- Yes, in terms of the North-South line, wants it to cross into Gatineau, points directly to a rail bridge, only needs some willingness and a few transit stations

- This would serve the National Capital Region, should have a National Capital Transit Authority 
- Supports the North-South route, the extensions, and service to the airport (this is very important)

- Supports the East-West route as well, since track sexist in most places, "we" are getting this at a fraction of the price that it would normally cost to implement this line

\section{Question 4}

In your opinion, are there alternative corridors that are viable (workable) in an overall sense that would be better suited for the proposed light rail expansion?

\section{Responses}

\section{Participant A}

- Yes and no answer, there are alternative corridors that are viable but not necessarily better suited for LRT expansion, for example reserve corridor for future bus transit in Blackburn Hamlet, depending on technology, this is viable, but depending on what you're running (type of equipment)

- In Innes area, corridor through Blackburn Hamlet might not be a very viable alternative even though it would serve community better, but grade problem is an issue

- There are limitations with the other alternative corridors, additional cost due to overpasses

\section{Participant B}

- Constrained by existing rail infrastructure

- Very expensive to build new track: have to expropriate land, build gradeseparated base, have to be dedicated to transit use

- Difference in capital costs between extending rail and extending Transitway is miniscule

- Not clear that money from three governments is not clear this will be sufficient for the new rail

- Appears that big money will go in electrification of rail and welded rail

- Existing corridor would be cheaper than building new rail corridors

- In terms of viable alternatives, if talking about new rail expansion, than former Transitway

- Expansion would be viable alternative corridor would be the Transitway

\section{Participant C}

- Doesn't think so

- This is based on everything read, presented officially by Ned Lathrop

- No alternative corridors for light rail 


\section{Participant D}

- Did not vote for any alternative corridors

- No viable alternatives

\section{Participant E}

- One corridor not looked at was to the south of the airport, instead of swinging around the airport, it went north of the environment (environmental assessment plans)

- Some question as to whether or not it should have been looked at

- Route is quicker, shorter to the south end; most of rail line is already in place

\section{Participant F}

- That's why doing the EA (Environmental Assessment) on this study, the EA will answer question \#4

- If EA study finds suitable way of doing this, then will fully support this

\section{Participant G}

- Concerns about alternative corridors for east-west corridor: coming down 417 would duplicate existing Transitway

- Other issue in Kanata is Kanata South is not well served (south of Queensway), people often feeling not receiving same kinds of services

\section{Participant H}

- Could build East-West route in the air, that is a possibility

- Or closer to downtown, an aerial system shooting down corridor of Queensway, this is extreme example though

- Not very realistic alternatives, too costly for other options

- Realistically the only land available is where the East-West corridor is being proposed

- When building a transit system, it encourages development; there is an increased densification along that route

\section{Participant I}

- Transitway is the best route to try light rail and investing light rail on a permanent basis

- Transitway is the spine of the city

- should be expanding north-south Transitway route, at least for now as a busway system

- Is not against light rail, what is being proposed is heavy rail system (an interurban system

- In terms of intraurban, should be looking to light rail electric systems, maglev system

- Want to make sure the rail systems are built where populations are located and where they want to travel 
- If system is built "way out in the boonies" where don't go where people want to go (where they don't work and live), then this will be a waste of a system

- System could turn out to be a mediocrity

- However LRT does have a future in Ottawa, but thinks not necessarily making right decisions for that future

- Basic premise is that Transitway should be spine of system, go from here and build out, rather than keeping Transitway as a bus system and putting LRT system parallel to that

\section{Participant J}

- In North-South (LRT corridor) identified the proper corridors

- Doesn't think the light rail has to be constrained to own right-of-way, can have semi-inclusive right-of-way that crosses roads

- In the North-South (LRT corridor) area, covers the downtown core, hubbing out to the Transitway, then out to the southernmost "Deep South" area of the city

- Shouldn't be wedded to the proposed East-West corridor opportunities

- There are regional road rights-of-way that are large enough to accommodate rail lines, could focus on picking up some of the populated areas that are in existing communities

- Thinks the East-West LRT corridor skirts the fringes of the city

- Could easily accommodate an LRT system on the Heron Road right-of-way

- Shouldn't be focused solely on corridors that have their own track

- Emphasizes that he is talking about "true" light rail, states that the O-Train is not a true light rail system

\section{Participant K}

- Doesn't know, feels less able to answer this question with an experts knowledge

- Doesn't think there are alternative acceptable corridors (e.g. would be an elevated rail corridor over the Queensway "would be an ugly beast" would not want to contemplate this corridor)

- In terms of acceptable corridors lacking only the political planning will, doesn't think they exist

- Suggestion years ago of building a tunnel downtown, perhaps could be used for light rail, unsure of this 


\section{Question 5}

In terms of land use development, (if you prefer, within and in proximity to your respective ward), will the proposed light rail corridors have any significant effect on the established communities within the new City of Ottawa? Please explain.

\section{$\underline{\text { Responses }}$}

\section{Participant A}

- The effect on existing communities will be significant improvement in transit

- Reasonable proximity to LRT, areas that are currently under serviced in transit, gets significance improvement

- South Orleans will get better service, feeder routes to LRT, and Park and Ride at beginning of Page, these areas suddenly have improvement in transit options/service

- Gives more options and better service to communities (SE Innes community)

\section{Participant B}

- Yes and no

- Going to provide a transportation choice, people already drive to take buses, if convenient to take people to work, they will migrate to that choice (LRT)

- See that change in behaviour in what route workers choose to get to work

- In terms of official plan policies, traditionally encouraged development to take advantage of these transit opportunities, therefore make sense for those communities close to the LRT routes, would see intensification in these communities

- Would make sense to increase density to take advantage of that transportation route, if not take advantage, would not increase density and end up with urban sprawl

- So would be some change, in order to take advantage of that location, but must respect characteristics of existing neighbourhoods

\section{Participant C}

- Absolutely

- Making neighbourhoods unique villages

E.g. Riverside South, got grocery stores, video stores, everything is copasetic living in these neighbourhoods

- Economic impact of having light rail is improve quality of life

- Benefit for developers- selling homes in proximity to light rail

- Multi-functional use of stations

- Want more stations in ward

- Have communities "sustainable" without having people on the road

- Too much traffic on Riverside Drive

- Impact not just on new, but current development, traffic pollution, definite ease of moving people around 


\section{Participant D}

- Yes they will have a significant impact

- Allow for intensification, redevelopment of brown fields

- Provides opportunities for these communities

- Change old habits to get people out of their cars

- Want to build a smart city

- Environmental issues are major issues in the future

- Opportunities that building the LRT provides for businesses and redevelopment

- Example is Lebreton Flats, services have been taken outside of the Greenbelt rather than located within city centre

\section{Participant E}

- For all of the older parts of the city, LRT is the only chance that we have to not be asphyxiated by the automobile

- e.g. O-Train is carrying 8000 people per day, expansion will take more traffic off Bronson and Bank

- Probably 2000-3000 cars off the road

- Big supporters of the light rail expansion

\section{Participant F}

- Yes, definitely

- Not so long ago Carp was major connection for the LRT

- Would be ideal to have whole city connected, east-west plus north-south (fringe of city to downtown core)

\section{Participant G}

- Initially where they put LRT is good

- One of reasons is to speed up service to Kanata North Business Park, right now lack of transportation issues, LRT would help provide affordable rental accommodation

E.g. government to locate out there, rapid transit system would help get people easily to meetings

\section{Participant $\mathbf{H}$}

- From perspective of land use development and making downtown core more enjoyable, definitely

- Reason: fewer roads being built in the downtown core, takes pressure off downtown communities

- This makes the communities more enjoyable to be in, results in land values increasing

\section{Participant I}

- Sees conflicts of LRT system with buses in their ward, especially if rapid transit system

- Not sure if this is the best thing for suburbs, more suited for downtown 
- Streetcar system (slow system) would be better benefited for Byward market area linking with Sparks Street and Bank Street

- People in the east end in general will not see benefits from LRT infrastructure, as LRT line is not slated until 2015 , really a far off concept for the east end, very much depended on the bus system (again siphoning off funds from "excellent" bus system, as a result bus system will degrade)

- Harder to get bus ridership back if funds are siphoned off to LRT, will be difficult to justify the new network as a success

- Doesn't see LRT adding much to service in these areas, sees conflicts, complaints with existing communities in terms of noise issues

- Better to redirect funds to bus services

\section{Participant J}

- Thinks that there will be impact in some areas adjacent to the route

- When there is transit, there will be more change, such as more intense development, because they are on right on a transit hub, gives example of how development moves around subways system in Toronto

- Real affect for community is if light rail is successful, the need for additional capital expenditures is significantly reduced, such as road widening, changing intersections, etc., not having to pay the increase in operating costs

- This is the benefit to community's right alongside to the areas adjacent to the corridor

- Might see a decrease in traffic

- This is the best way to keep property taxes down

- This is a benefit to Alta Vista, Ottawa East, Ottawa South, where the benefits will occur, "best bang for your buck"

\section{Participant K}

- Can't help but this affecting land use development

- Regional government had policies that tried to develop next to the Transitway, had very little success over the past 20 years, some is happening now, finally

- This shows the extent to which it is very difficult for a municipality even with best policies in place to actually drive, if the market is not ready, it won't do it

- This is largely why haven't yet seen development close to Transitway

- Same thing could happen with light rail, won't happen right away but it will happen, it can't help but happen

- Even if this development doesn't happen really close (uses the old Rockliffe airbase as an example)

- Rockliffe airbase will be redeveloped, business and residential development

- Major problem to be solved is transportation

- The East-West corridor will still help get people to this corridor, once on light rail or Transitway get people around the city quite quickly 


\section{Question 6}

How will the location of the proposed light rail corridors be integrated with future residential and employment growth? Please explain your answer.

\section{Responses}

\section{Participant A}

- In Innes and Riverside South area, looking at future growth intended in Official Plan, how to service this plan

- Example of mixed-growth in Innes area, corridor acts as natural buffer to industrial with residential area

- Encourage intensified growth around stations, more mixed-use growth, more residential and industrial growth, employment nodes benefit from being close to rapid transit stations

- Feeds growth that we're projecting in Official Plan, directs into specific areas, hopefully don't have to build more roads

- Get the right mix of employment, industrial, commercial, residential, and even right mix of different types of residential, more dense as you get closer to LRT route

\section{Participant B}

- Ought to be, should be

- Expectation in the city is for example Cumberland, expectation to promote development in new growth areas, both employment and residential densities close to LRT stations

\section{Participant C}

- Attractiveness in terms of economic impact/employment impact

- Attract more employees because of good way of moving people around

- Nobody wants gridlock/traffic

- Moving people around efficiently

- Discussion of long-term employment for building of light rail routes, sustained employment, development charges

- Win for residences, businesses, and developers

- All about integrating everybody's expectations, and making sure everybody gets a piece of it

- Using light rail as a selling tool for the city

\section{Participant D}

- Some industrial parks inside the Greenbelt will be redeveloped with mixed-use, residential growth (intensification)

- Want to take the lines to where employment nodes will be

- Want people to live/work/raise a family in their own neighbourhood

- Don't want people to have to travel too far to get to their work, emphasis on employment nodes 


\section{Participant E}

- Way to be integrated in the south end is not to have to build so many roads, in the same as a relief for the city centre

- Integrate the stations with Town Centres

- One thing about rail is that it is people friendly

- Electric trains are quiet, non-polluting

- People really don't have much trouble living close to them

- LRT don't take up too much space

- Move an incredible density of human cargo, make this incredibly attractive to everything from daycares right the way through to businesses

- They leave a lot of space that is to be developed for human uses

\section{Participant F}

- Question is in a way self-explanatory

- We notice that city growth is to the outlying area

- Least grown area is in downtown, Somerset area

- Majority growing area is Southgate area, Orleans area, Kanata, West Carleton, and Goulbourn

- Of course there will be integration in existing communities

- If have choice for LRT, odds are people will want to ride the trains even from fringes of the city

- Use for a car will be irrelevant if LRT routes are put in place, no real need to drive from outside of the core to the core

- Use of public transportation will be: (a) more cost-effective (b) take people less time to get in from rural areas to core

- Cost of accidents on roads plus maintenance and building of roads/bridges is about the same as building public transit

\section{Participant G}

- Have a lot of growth in north area of Kanata, planned communities right now about 15,000 people

- Corridor is supporting growth

- In current subdivision plans light rail is acknowledged

- Has to be fast enough to make it worthwhile for people (concern for the councillor)

- Building on existing infrastructure is important

- When rail lines already exist, people acknowledge that there is potential

- Certain distance will be seen as positive, nearby people will be concerned with the noise

- North Kanata will be a place for people to locate, rather than south of Kanata

- Road network to south Kanata will have to be improved 


\section{Participant $\mathbf{H}$}

- Refers to Official Plan, 20/20 Plan

- If for some reason cannot go ahead with this plan, if Ontario municipal board changes OP and demands more development in communities south of Greenbelt, on unserviced land, this will make it very problematic

- If one element changes, will have a negative effect on the rest of the plans

- Plans for future residential and employment growth along the routes

- When routes are developed, emphasis to actually develop the residential and employment growth areas

- City can have an impact on zoning

- City can have an impact on light rail system

- Transitway has created development along its route, due to easy access

- When you build something, they (riders) will come

\section{Participant I}

- Makes sense to start integrating rapid transit in these areas, bus system that could

- be converted to LRT as soon as possible

- Not very well, looking at these systems as parallel to bus systems

- Have to plan whole network as an express system or as a feeder route, multiple transfer system, doesn't see this happening

\section{Participant J}

- Whatever transportation improvements are needed to accommodate growth, has in the past always came after the main portion of the residential growth has taken place

- Significant lag that has taken place

- Development develops in the absence of transportation infrastructure

- That infrastructure doesn't have the chance to influence the type, scope, and scale of which growth occurs

- More of a chance in Riverside South that will positively influence growth

- Majority of growth hasn't yet occurred in those areas, getting light rail out to those areas earlier will have chance to affect growth in those areas

- Hopes to see commercial activity, more high density residential areas hubbing up around the stations

- Going to have dense urban villages up around those stops

- Encourage appropriate residential growth and commercial opportunities

- Create a "mobility centre" around the stations, they include laundry mats, video stores, this reduces automobile trips when people get home from work, even public services such as a library

- People can walk or ride their bike, feeder buses to the "mobility centres"

- Integrate into community with perhaps feeder buses

- This would produce development hubbing up around the transit stations in a supportive development; this has potential in Riverside South and South Nepean

- This will be a real positive signal that light rail is working well, as it changes the fabric of the emerging communities 


\section{Participant K}

- Rockliffe airbase is a future residential and employment centre (one or both)

- Expect that developers in the future would want to see an enhance d value being
close to the light rail contre (one or both)

- Their clients, residential, business, retail would see this as a big plus

- Light rail will affect future residential and employment 


\section{APPENDIX VI}

\section{Contact Letter Sent to Pilot Study Participants}

Subject: Ottawa Light- Rail Project, Master's Thesis, Ken Morrison,

Dear Sir/Madam,

I am a graduate student at Carleton University currently working on my Master's thesis, which is focusing on the proposed light rail expansion in Ottawa. Thesis preparation work in 2003 included discussions with a number of Ottawa councillors, as well as with candidates who ran in the last municipal election. In addition, I conducted a preliminary analysis of election-related and other documents (e.g. council minutes, committee reports, councillors' newsletters, newspaper items) in order to better understand the philosophies and preferences of municipal politicians -actual and potential--in regard to City of Ottawa light-rail policies, plans and programs.

After examining the results of the communications with elected officials and those seeking office, and the findings from a literature search and review, it was concluded that an intensive study along those lines is an appropriate and timely master's thesis project.

Presently I am at the stage of refining the survey instrument that is to be used for collecting information on Ottawa's proposed light rail expansion from the municipal elected councillors. It would be most appreciated, therefore, if you and/or members of your staff would be able to assist in the pilot study phase of the design-evaluation process of the thesis. Your assistance would involve selecting applicable terms from a list that are associated with the light rail expansion, and the screening of questions that are to be posed to municipal politicians at a later date.

Thank you for your consideration of this request.

Ken Morrison

Ken Morrison, Master's Candidate

Department of Geography and Environmental Studies

Carleton University

1125 Colonel By Drive

Ottawa, Ontario

K1S 5B6 


\section{APPENDIX VII}

\section{Contact Letter Sent to Municipal Elected Officials}

Dear Councillor,

Thesis preparation work in 2003 by Ken Morrison included discussions with a number of Ottawa councillors, as well as with candidates who ran in the last municipal election. In addition, Mr. Morrison conducted a preliminary analysis of election-related and other documents (eg. council minutes, committee reports, councillors' newsletters, newspaper items) in order to better understand the philosophies and preferences of municipal politicians -- actual and potential--in regard to City of Ottawa light-rail policies, plans and programs.

After examining the results of Mr. Morrison's communications with elected officials and those seeking office, and the findings from the literature search and review, it was concluded that an intensive study along those lines is an appropriate and timely master's thesis project. It would be most appreciated, therefore, if you and/or members your staff would assist Mr. Morrison should he contact you to obtain observations or materials that represent your position on light rail location, design, implementation, or related matters.

Thank you for your consideration of this request.

Barry Wellar

Professor Barry Wellar, MCIP, RPP

Department of Geography

University of Ottawa

Ottawa, ON K1N 6N5 


\section{APPENDIX VIII}

\section{Newspaper Exhibit Articles}

As discussed in Section 2.6, a search of local newspapers was conducted in order to investigate the length and nature of the debate on light rail expansion and land use planning, or even public transit and land use planning in Ottawa. As the study seeks to ascertain the extent to which municipal elected officials have considered the link between land use planning and transportation planning in relation to the spatial aspect associated with the proposed light rail expansion in Ottawa, it is relevant to show how long this link has been involved in local public records.

A sample of the more revealing newspaper headlines/articles is shown in Table 2.1, while a few newspaper exhibit articles are provided as they appeared in local newspapers in this appendix. These articles illustrate that indeed there is an ongoing discussion on the relationship between the proposed light rail expansion and land use planning, and further the debate on integrating public transit with land use planning is not a newfound argument in Ottawa, as it has been occurring since the mid 1970's.

\section{Newspaper Articles Selected to Illustrate Transportation Planning and Land Use Planning Relationship in Local Popular Literature}

1. Taking steps towards the end of the automobile era, by Barry Wellar. Ottawa, Citizen, December 9, 1975.

2. A transit alternative, by Ian McGrath. Ottawa Citizen, March 19, 2004.

3. O-Train is essential to city's growth, by Keith Parker. Ottawa Citizen, June 30, 2004. 


\section{O-TRAINIS ESSENTIIALTO CII'Y'S GROW'IH}

\section{BY KEITH PARKER}

$\mathrm{T}$

There is no doubt in my rime shat she OThain is an absolute necessity for the city of Ottawa as its porulation surpassess ont mailion. The 0 n

Tran is a significm investment witkont wheh our city's quality or hife will sutsstaxtially dextine

The southern mat of the city continues to build out at a stay gering pace. The timely imple meneation oflight rail ofters the city so much in tims of a loneform retsan on inexsi ment and in termis of a better conumenity in which to live. Given that the hull rasid-traxsit expansion plun will take a decade to roll ous, Ihome that regardless of clection testits, isc sommitment to implement the plan will cont true to be his noured by all leyels of govern- mest.

The O-Train regresents a shift in philosophy that will only serve to improse living and working in this ciry. The im pasts will be far reaching: it will make it asier for com maters to reach their places of work, reduce the meed for road witenings, redisce smog, and offer opportunities for the type of development that has never tecersecn in our sulsurbs. The O-rrain is expected to be a key factor in the city's quest to achieve a target of $30 \%$ permcent puthe * ransit ridership during resh hour.

The alaestion is: Will it work? The fact remains that while each of us can decide to eitixer hor in wur cars or take a bus to get places in this city the signif knat majority opts for the siress of rush-hour traftic. With a hus system that is recogmized as one of the best in North Anerica, how could this be so? A number of factors go into choosing, one mode aver the other. For most of us, we evalu. ate which alternative is more comfortable, takes less time, is more reliable and is more flex: ble. Based orn the decisions we make, it is clear that buses simply do not fit the bill.

By this mationale, the O-Trais exparsion would excel as at transit solution. The ortawa Rapid Transit Exporsion Man

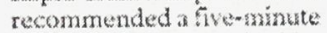
sorvice interval on a doublew tracked rail corrictor with elec trified trains. Some may call this a luxury; I call this a necessity for convincing yeaple to get out of their cars and onto public transit.

Some critics have angumd that the cify does not have the pepulation derasiry to suppor: such a system just about wery resident would have te hup on a bus in order to get to the lighterail system. While this may be true mos, this project is all about the future. Publi: transit and developmen are intricatenly linked and the prosence of a rapidtransit link. along with development guice.

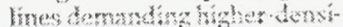
ty construction for new stiodivisions, will help this ciry grow in a way that is more responsible to the envitonment and more enozyablex for its residents.

Very few peryyle secun to know of the community of Riverside South. This is no different than 20 years ago when few recognized what larrhaven would lecoms, as years aggo when Kanata was at a sinn lat kevel at development, and 30 years ago when it was ox first that was embarking on its ferst of many growth spourts.

The community of Riverside

South is groswing out of corn.

fields, After seven years of de-

veloptucat we have a population of $6,0(00)$, no schools, and a lone Iy yas station with a corrace stor. and a swall chain restanurat. Lea lithe owe $x$ a decate, we will have a parpulation of $60,600,12$ or muse elementary solusols, three or more high setuous, and plenty of commercial services, in addir ifon to emplovment for hun

dreds in a basiness park. This is a scale of deyelopment that cannot he igroored.

If community as it is developed, yots will see a development un like any of the other major urban centres outside the Gireenbelt there is a narow window of opportunity to build a signif icani community around rapia transise. This communty would

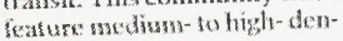

sity develognent around the Oul raxin corridor, it could fea ftre a genuine "main street" or "downtown" that people coteld shop at as they get off the train, and, for the majority of transit users, a short walk home. A few hus routes would service the community to feed the O-liain ixsteat of adding to the clogged roads heading downtown l'ossibly the bighest benefit, we would not need at efit, we would not need at
Qteensway constructed linat would tear another strip out of the Greenbelt and dow Bron son Avenue. Our residents would tend toward public transit due to its access, its rehabiliiy and is quaick service.

for the sake of the future of this city, I hopes that all three levels of govermoxnt skay "on board" the aggressive expansion of the $O$-Than to preserve and enharke the quality of lift for all its residents.

\section{KETTH PARKEF is presthen!}

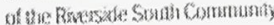

As:ckial’at. 


\section{Atransit alternative}

Re: Ottawa's light-rail fantasy, MARCH 15.

I am shocked by Councillor

opposition to Ottawa's plans to continue with light-rail transit. Of course ridership is low on the O-Train - it only goes from Greenboro to LeBreton Flats.

Not only is the O-Train more reliable than the bus system, it is actually faster than taking the bus. Unfortunately, the speed of the train is compromised by the fact that it goes nowhere. All major cities in Canada, except for the nation's capitin, have a light-rail transit system.

Do councillors such as actually think that newer buses are going to meet the transportation needs of a growing city that covers such a large geographic region? I think they should stop inhaling the fumes from the dinosaur-era buses roaming our transitways.

The current bus system is widely acclaimed only because there is no alternative for public transportation. If councillors are really serious about providing reliable and effective transportation alternatives to driving, they need to expand train service from Orléans to Kanata.

IAN MCGRATH, OttaWa 


\section{Exhibit III. Column, Ottawa Citizen, December 9, 1975}

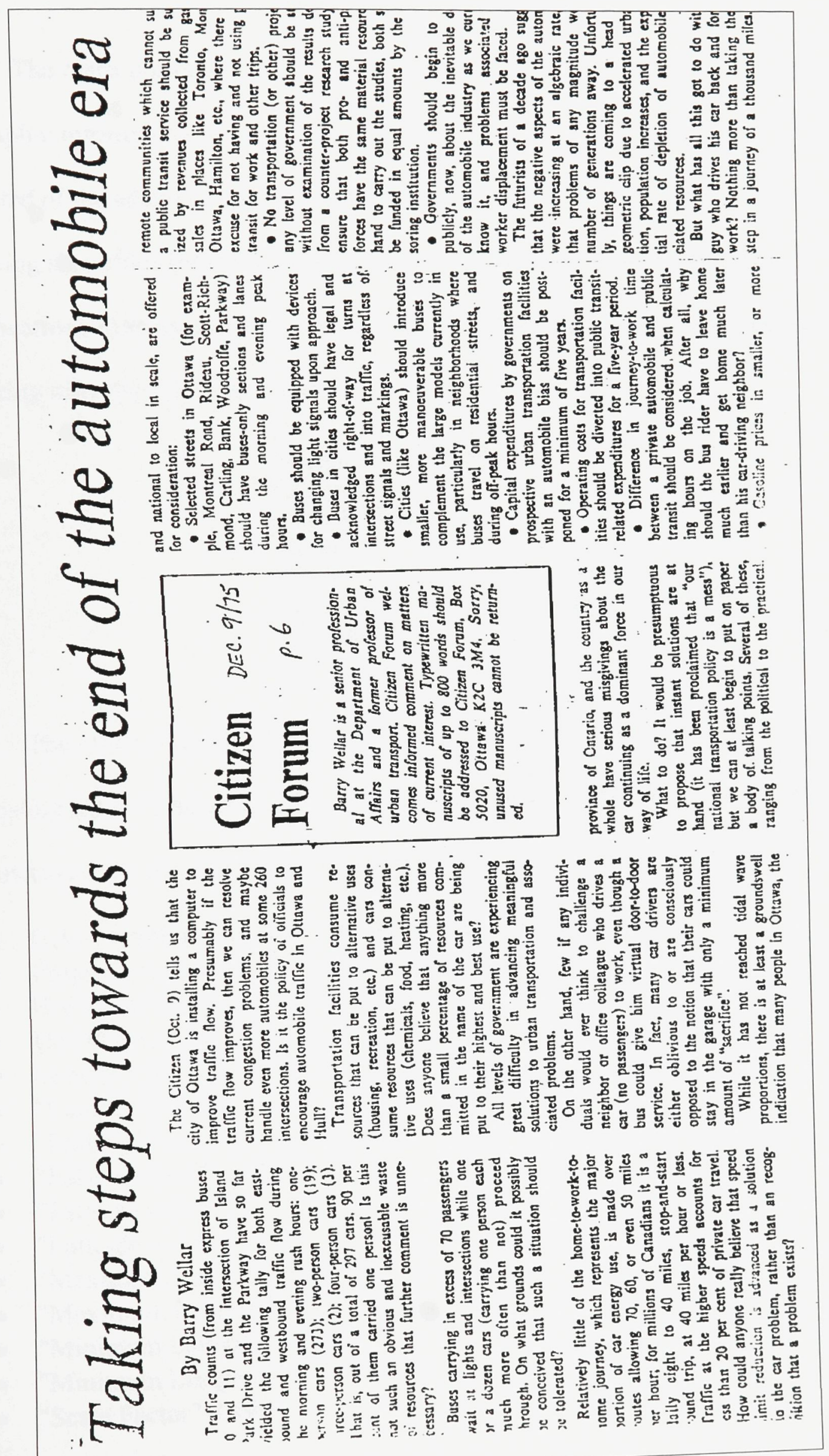




\section{APPENDIX IX}

\section{Overview of Map Design}

The maps presented in this study were designed using Arcview 3.3, a desktop geographic information system (GIS) software product produced by ESRI. The maps consisted of the adaptation of shapefiles obtained through the City of Ottawa. The following shapefiles provided the base for which to design these maps, although modifications were made on several of the shapefiles as the result of development occurring after the last date of issue.

\begin{tabular}{|l|r|}
\hline Name & Edition \\
\hline All Roads & June 2003 \\
\hline Federal Roads & 1999 \\
\hline Railways & 1998 \\
\hline Rivers & 1998 \\
\hline Land Use & 1995 \\
\hline Greenbelt & 1998 \\
\hline
\end{tabular}

The other shapefiles displayed in the maps were created through the interpretation of existing City of Ottawa maps, official planning documents, and city council records. The metadata for the maps obtained by the City of Ottawa is provided below:

- Grid Coordinate System: Universal Transverse Mercator

- Projection: Modified 3 Degree Transverse Mercator Zone 9

- Horizontal Geodetic Datum: NAD83

- Units Metres and Square Metres

- Spheriod GRS80 "6378137.0 m" "6356752.314 m"

- "Central Meridian" -76.5

- "Easting/Northing Unit" metres

- "False Easting" 304800.0

- $\quad$ "False Northing" 0

- "Latitude of Origin" 0

- "Maximum Latitude" "80 00 00"

- "Maximum Longitude" "-75 00 00"

- "Minimum Latitude" "0 0 00"

- "Minimum Longitude" "-78 00 00"

- $\quad$ "Scale Factor" 0.9999 